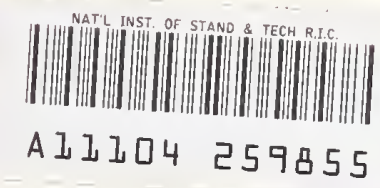

EA-77-A.01-6010-12

Distribution Category UC. 909

\title{
DEVELOPMENT, TESTING AND EVALUATION OF MHD-MATERIALS
}

\author{
Quarterly Fieport \\ for the period April - June 1978
}

W. R. Hosler, T. Negas and S. J. Schneider

\author{
Ceramics, Glass and Soliả State Science Livision \\ Center for Materials Science \\ National Bureau of Standards \\ Washirigion. D.C. 20234 \\ Date Published: June 30, 1978 \\ PREPARED FOR THE UNITED STATES \\ DEPARTMENT OF ENERGY \\ Under Contract No. EA-77.A. $01 \cdot 6010$
}

$-Q C$

100

.056

78-1506
"This report was prepared as an account of work sponsored by the United States Government. Neither the United States nor the United States Department of Energy. nor any of their employees, nor any of their contractors, subcontractors, or their employees, make any warranty. express or impled. or assumes any legal liability or responsibility for the accuracy, completeness, or usefuriess of any information. apparatus, product or process disclosed, or represents that its use would not infringe private cwred rights." 
NBS involvement in MHD related program review and coordination has continued.

Initial results on a coal slag intermediate in composition to Illinois \#6 and Montana Rosebud slags show that the log viscosity is raised about $20 \%$ by a 158 concentration of $\mathrm{K}_{2} \mathrm{O}$ seed.

Slag exposed to pressurized steam undergoes a change that increases the $\log$ viscosity by about $5 \%$

The pre-test electrical conductivity of the U-02 Phase III materials has been completed. Electrical conductivity of a possible lead out material for a slagging generator is given.

The $\mathrm{K}$ pressure over $\mathrm{KFeO} \mathrm{O}_{2}-\mathrm{K}_{2} \mathrm{O} \cdot 7 \mathrm{Fe}_{2} \mathrm{O}_{3}$ is about an order of magnitude greater than the $\mathrm{K}$ pressure over $\mathrm{KAlO} \mathrm{O}_{2}-\mathrm{K}_{2}^{3} \mathrm{O} \cdot 7 \mathrm{Al}_{2} \mathrm{O}_{3}$ showing that $\mathrm{K}_{2} \mathrm{O}$ interacts more strongly with $\mathrm{Al}_{2} \mathrm{O}_{3}$ than with $\mathrm{Fe}_{2}^{2} \mathrm{O}_{3}$. Preliminary measurements show preferential loss of Fe from a MAFF-3l composition.

Analysis of diffusion between MAFF $31 \quad\left(3 \mathrm{MgAl}_{2} \mathrm{O}_{4} \cdot \mathrm{Fe}_{3} \mathrm{O}_{4}\right)$ electrode material and $\mathrm{MgAl}_{2} \mathrm{O}_{4}$ insulator material showed that the diffusion coesficients at $1600^{\circ} \mathrm{C}$ for $\mathrm{Mg}^{2}$ were at least twice as large as those for $\mathrm{Al}$, although $\mathrm{Fe}$ diffusion was still the dominant metal diffusion process.

The electrochemical effects in a simulated slag flow using platinum electroces indicate substantial attack on the cathode electrode and minimal effect on the iron depleted layer on the ancde.

A thermodynamic analysis of the seed/slag system using the most-recently available data has been completed.

Approximately 50 materials from external sources have been analyzed structurally by $\mathrm{X}$-ray diffraction methods.

NBS/AVCO slagging test 2 electrodes will be constructed by the end of June and testing should proceed when accommodations in the AvCO chanrel can be obtained.

The electrode modules from the Phase III U-02 test carried out in Moscow May 13-19, 1978 have been sectioned. Post test analysis will be made at Battelle NW Laboratories and NBS.

The post test analysis of the electrodes tested at MIT Feb. 28, 1978 (MIT 228-NBS $F$ ) has been completed. An analysis is given concerning tive $K$ penetration into the electrode body as well as the effectiveness of the various electrode grades and bond lines with respect to the channel conditions.

A brief summary of the pre and post test analysis of the USSR materials tested at UTSI in October 1976 and February 1977 is given.

Stainless steel 304 was tested in the hot corrosion apparatus for 4 hours at $550{ }^{\circ} \mathrm{C}$ using $\mathrm{K}_{2} \mathrm{SO}_{4}$. Extensive corrosion was not detected although discontinuous ard localized oxidation/sulfidation was noted. 
Physical property data and prices are given on two new alloys that may prove to be more cost effective than 310 SS where sulfidizing is a problem such as the seed recovery system. Also property data and prices are given on new composite materials for extreme abrasion and wear. 
The overall objective of this program is to obtain chemical and physical definjtion of high temperature materials which have shown promise for use in coal-fired open-cycle MHD power systems. Major problem areas in which investigations will be concentrated are:

1. Characterization of coal slag and its effects on system components and performance at prototype temperatures.

2. Development of electrode materials wich provide adequate performance over extended periods of time.

3. Insulating materials which limit thermal losses and are resistant to prolonged thermal and erosion effects.

4. Preheater materials which can withstand the operating modes of separately and directly fired operation.

5. Seed recovery methods from slag which are technically and economically feasible.

6. Phase equilibria and diffusion rates of seed in slag and corrosive action of combination on system components and materials.

7. Durability of prototype MLiD sub-systems.

The program is designed to contribute to the solution of these problems by providing much needed data on candidate materials and by evaluating test samples and structure that have been subjected to real or simulated MHD conditions. The activities are grouped under six tasks:

G. Progran Management Coordination (Assisting DoE in coordination, planning and review of the various MHD-Materials Development Programs).

I. Operational Design Properties (viscosity, electrical conductivity, vaporization).

J. Corrosion by seed and Slag (phase equilibria, diffusion).

K. Materials Testing and Characterization (test coorcination, pre- and post-test analysis).

L. Assessment of Steam Plant Components (corrosion resistance of metals and alloys).

M. Information and Data on Materials for MHD Power Systems. 


\section{SUMMARY OF ACHIEVEMENTS (April-June 1978) \\ (Completed or Continuing Milestones-See Work Plan FY 1978)}

TASK G.

1. Plan, prepare, guide and conduct negotiations of US-USSR Working Group on Testing of MHD Materials, Phase III (completed May 30, 1978).

2. Participate in reviews, planning sessions, preparation of working documents in the area of MHD development (continuing).

TASK I.

6. Measure the viscosities of coal slags made synthetically or furnished by other MHD contractors (continuing).

9. Measure the electrical conductivity of established as well as promising (new) electrode materials (continuing).

11. Measure $\mathrm{K}$ pressure over selected $\mathrm{K}_{2} \mathrm{O}-\mathrm{FeO}$ compounds to ascertain stability of $\mathrm{Fe}_{3} \mathrm{O}_{4}$ containing electrode materials (completed May 30, 1978).

14. Determine FeO losses over several spinel compositions which are promising electrode materials (continuing).

17. Determine thermochemistry in a number of critical multicomponent systems to assess slag/seed interaction, provide potassium activity data (in conjunction with vapor pressure measurements) and to define reactions leading to corrosion of construction materials.

a. Determine invariant solid-liquid reactions and potassium activities in the $\mathrm{SiO}_{2} / \mathrm{Al}_{2} \mathrm{O}_{3}$ - rich portion of the $\mathrm{CaO}-\mathrm{K}_{2} \mathrm{O}-\mathrm{Al}_{2} \mathrm{O}_{3}-\mathrm{SiO}_{2}$ system.

b. Same as (a) but the $\mathrm{MgO}-\mathrm{K}_{2} \mathrm{O}-\mathrm{AI}_{2} \mathrm{O}_{3}-\mathrm{SiO}_{2}$ system.

c. Perform exploratory studies in the $\mathrm{K}_{2} \mathrm{O}$-rich part of the $\mathrm{K}_{2} \mathrm{O}-\mathrm{Al}_{2} \mathrm{O}_{3}-\mathrm{SiO}_{2}$ system.

d. Investigate the effect of divalent iron on solid-liquid reactions and on potassium activity in the $\mathrm{FeO}_{\mathrm{x}}-\mathrm{K}_{2} \mathrm{O}-\mathrm{Al}_{2} \mathrm{O}_{3}-\mathrm{SiO}_{2}$ system.

e. Determine melting relations for the $\mathrm{CaSiO}_{3}-\mathrm{KAISi}_{2} \mathrm{O}_{6}-\mathrm{CaAI}_{2} \mathrm{Si}_{2} \mathrm{O}_{8}$ system (pertinent to western coal ashes). (continuing)

TASK J.

18. Determine chemical reaction processes of constuction material (e.g., $\mathrm{LaCrO}_{3}$ zirconia-based, etc.) with seed/slag (continuing).

22. Conduct diffusion studies in spinel electrode (MAFF 31) spinel insulator $\left(\mathrm{MgAl}_{2} \mathrm{O}_{4}\right.$ ) sandwiches without electrj.c field to determine the degree of degradation of both materials ana diffusion constant for $\mathrm{Fe}$ into $\mathrm{MgAl}_{2} \mathrm{O}_{4}$. (completed March 1978 ). 
TASK $K$.

26. Coordinate testing and pre- and post-test analysis of specimens exposed to simulated or real MHD conditions in a variety of test rigs, arc heaters, small- and large-scale MHD-generators, etc. Stimulate, expedite and organize materials procurement, electrode design and preparation, test scheduling, materials evaluation, etc. Encourage and promote collaborative efforts aimed at gathering maximum information on MHD-materials and components in the minimum amount of time. Several tests are anticipated:

U-02 Phase III proof test 1, 2 and 3. (completed June 1978).

27. Use a variety of chemical and physical techniques to assess the stability (or degradation) of materials and structures tested for specific time periods of real or simulated MHD-facilities. Pre- and post-characterization of tested samples from experiments. performed in the MIT test rig, AVCO and U-02 generators, etc. (Continuing).

28. A system of efficient communication between MHD-workers at various institutions concerning MHD-materials and testing will be extended and formalized. This includes also the establishment of a data base management system which will be available to designers, facility operators and materials experts in the field of MHD power development (continuing).

TASK L.

29. Assess potentially promising materials for other critical components in addition to the steam heat exchanger tubes, such as (1) valve surfaces subject to a combination of abrasion and hot corrosion, and (2) seed recovery system component subject to chemical attack. Service requirement will be based on the "Baseline Plant Design Description", in terms of the chemical, physical and mechanical property requirement involved. Updates will be taken into account where feasible. (continuing).

30. Update assessment of materials for the steam heat exchanger tubes to include new promising alloys (metal alloys that are just entering the commercial market). (Continuing).

31. Design and construct apparatus to provide screening of metals for corrosion-resistance to potassium and/or slag attack for MHD boiler tube applications. (continuing). 
The U-25B Facility for Studies in Strong Magnetohydrodynamic Interaction, V. A. Kirillin, A. E. Scheindlin, A. V. Karpvthin, V. I. Maksimenko, S. A. Pashtov, D. S. Pinkhasik, N. P. Privalov, V. D. Semenov, V. S. Sidorov, Yu. D. Sokirko, Yu. N. Sokolov, E. M. Shelkov, Institute of High Temperatures, USSR Academy of Sciences; R. V. Shanklin, A. I. Liccardi, G. Rudins, W. D. Jackson, E. Levi, U. S. Department of Energy; M. Petrick, R. Neimann, B. Wang, R. P. Smith, Argonne National Laboratory; S. Schneider, National Bureau of Standards; J. Isuis, D. Teare, Massachusetts Institute of Technology; 17th Symposium on Engineering Aspects of MHD, Stanford University, Stanford, CA, March 27-29, 1978.

Invariant Melting in the System CaO- $\mathrm{K}_{2} \mathrm{O}-\mathrm{Al}_{2} \mathrm{O}_{3}-\mathrm{SiO}$, L. P. Cook, American Ceramic Society, Annual Meeting, May 8, 1978, Detroit, Michigan.

Phase Equilibria and Crystal Chemistry Related to Seed-Slag Reactions under MHD Conditions. The System $\mathrm{K}_{2} \mathrm{O}-\mathrm{MgO}-\mathrm{Al}_{2} \mathrm{O}_{3}-\mathrm{Fe}_{2} \mathrm{O}_{3}-\mathrm{SiO}, \mathrm{R}$. S. Roth, H. S. Parker, T. Negas, et.al, American Ceramic Society Annual Meeting, May 8, 1978, Detroit, Michigan. 
TASK G. PROGRAM MANAGEMENT AND COORDINATION (S.'J. Schneider)

S. J. Schneider and other NBS staff participated in assorted DoE arranged or sanctioned program review/coordination meetings, briefings and technical conferences: These included:

1. Fluidyne Corporation program review April 25, 1978 (in Minneapolis)

2. Fluidyne consultation (slag simulation and behavior) (at NBS, May 23 \& 24)

3. U.S.-U.S.S.R., U-02, Phase III post-test activities, NBS hosted three U.S.S.R. representatives May 25 - June 1 to participate in general discussion, report preparation and module characterization

4. U.S. Policy Group - U.S.-U.S.S.R. Cooperative Program on MHD

The conclusion and recomendations resulting from these meetings and other DOE assigned activities are reflected in reports to DoE, through direct corsultation with DoE staff or through documents published elsewhere. 
Task I. OPERATIONAL DESIGN PROPERTIES

1. Viscosity of Coal Slags (W. Capps and D. A. Kauffman)

\subsection{Introduction}

Previous reports have contained extensive viscosity data as functions of temperature and slag composition. Most of this work has been on systematic variations to a synthetic "base" slag. This base composition is a compromise between the high-iron Illinois \#6 slags and the high-calcium Montana Rosebud slags. The first two figures in the quarterly report for the period ending in December 1977, gave a sumary of the effects of varying the constituent oxides one at a time at 1600 and at $1300 \mathrm{C}$. These slags contained no $\mathrm{K}_{2} \mathrm{O}$ to represent seed material. As an extension of this whole series $\mathrm{K}_{2} 0$ is being added to this same base slag to determine the effect of seeding material on the viscosity.

These synthetic or artificial slags under study are somewhat simplified compared with natural slags. The unseeded slags contain five oxides, the seeded slags contain six oxides, whereas the usual coal ash analyses report about nine oxides. The minor constituents, such as $\mathrm{K}_{2} \mathrm{O}, \mathrm{Na} \mathrm{O}_{2}, \mathrm{TiO}_{2}, \mathrm{P}_{2} \mathrm{O}_{5}$ ' and $\mathrm{SO}_{2}$ were onitted from the "base" and other compositions in the series. The only exception is the current "seeded" series being reported on here in which $\mathrm{K}_{2} \mathrm{O}$ is the sixth oxide.

Although it has been of interest no previous attempt has been made to determine the effect of water vapor on coal slag viscosity. This is now being explored.

\subsection{Slag Preparation and Measurement}

a. Seeded Series:

During this quarter three out of a series of six slags were prepared by adding $\mathrm{K}_{2} \mathrm{O}$ to the base composition $(\mathrm{K}-884)$ in 58 increments. The compositions are shown in Table $I$ and the viscosity vs. temperature relationships are shown in Fig. 1 .

Some previous data on seeded slags were reported in the last three quarterly reports for 1975 , but the base to which the $\mathrm{K}_{2} \mathrm{O}$ was added (K-488) was different from the base presently under study $(K-884)$.

Because these two base slags are quite different from each other the quantitative effects of the $\mathrm{k}_{2} \mathrm{O}$ might be different. It is desirable to compare the effects of a given amount of seed in different bases. From the previous work one would conclude that first additions of seed will raise the viscosity which will reach a maximum at about 15 weight $8 \mathrm{~K}_{2} \mathrm{O}$ 
and further additions will cause a lowering. At about $303 \mathrm{k}_{2} 0$ the viscosity will return to the unseeded level. Figure 1 bears-out this expectation for the first additions of $K_{2} O$. There is an increase in viscosity with increasing $\mathrm{K}_{2} \mathrm{O}$. The next report will have the completed series for comparison.

b. In the atmosphere of a real MHD channel water vapor will be present and this is expected to affect the flow properties of molten slags. As was promised in the early stages of this viscosity program, an effort is being made to measure and understand the influence that water might exert. A steam viscometer is under development that will permit molten slags to be exposed to steam under pressure. This is expected to cause water to penetrate the slags and change the viscosity.

In the report for the period ending in March 1978, page 8, the viscosity of $\mathrm{K}-1090$, a synthetic slag, measured in air at ambient pressure was shown. This slag was then placed in the steam viscometer, viscosity measurements were made under pressure and then rerun in the ambient pressure viscometer. Figure 2 shows both the pre-steam data and the post-stean data, the latter collected to see if there is a residual effect of the steam treatment. The viscosity increased slightly as a result of the "pressurecooker" treatment. The high-pressure, high-temperature data is not presented hare because the data is tentative. The temperature measuring system in the steam viscometer is being improved and new data will be reported later. The experiment was successful in showing two things. The viscosity increased with steam pressure and there was a permanent increase shown after remelting. More detailed study is being undertaken. The slag used in this preliminary experiment was not a typical coal slag composition. It contained $15 \% \mathrm{Na}_{2} \mathrm{O}$ in order to produce a sufficiently low viscosity to obtain measurements with the new viscometer. This instrument is a new concept and its temperature and pressure limits were being explored for the first time, but results show that furtiner study is warranted. It also furnished needed information to assist in further improvement in the apparatus. More realistic coal slag compositions will be used as the improvements are made in the design.

Future Plans

1. The slag-seed-viscosity study will be completed.

2. The study of the influence of water vapor on slag viscosity will be continued. 
Table 1. Composition of slags in Seeded Series

wt 8

Melt No.

$\mathrm{R}-884$

$K-I 190$

$\mathrm{K}-1196$

$\mathrm{k}-1205$

$\mathrm{SiO}_{2}$

47.77

45.62

42.99

40.60

$\mathrm{Al}_{2} \mathrm{O}_{3}$

21.76

20.78

19.58

18.50

$\mathrm{Fe}_{2} \mathrm{O}_{3}$

16.58

15.31

14.92

14.09

$\mathrm{CaO}$

10.57

10.09

9.51

8.98

MgO

3.32

3.17

2.99

2.82

$\mathrm{K}_{2} \mathrm{O}$

$-$

5.03

10.00

15.00 


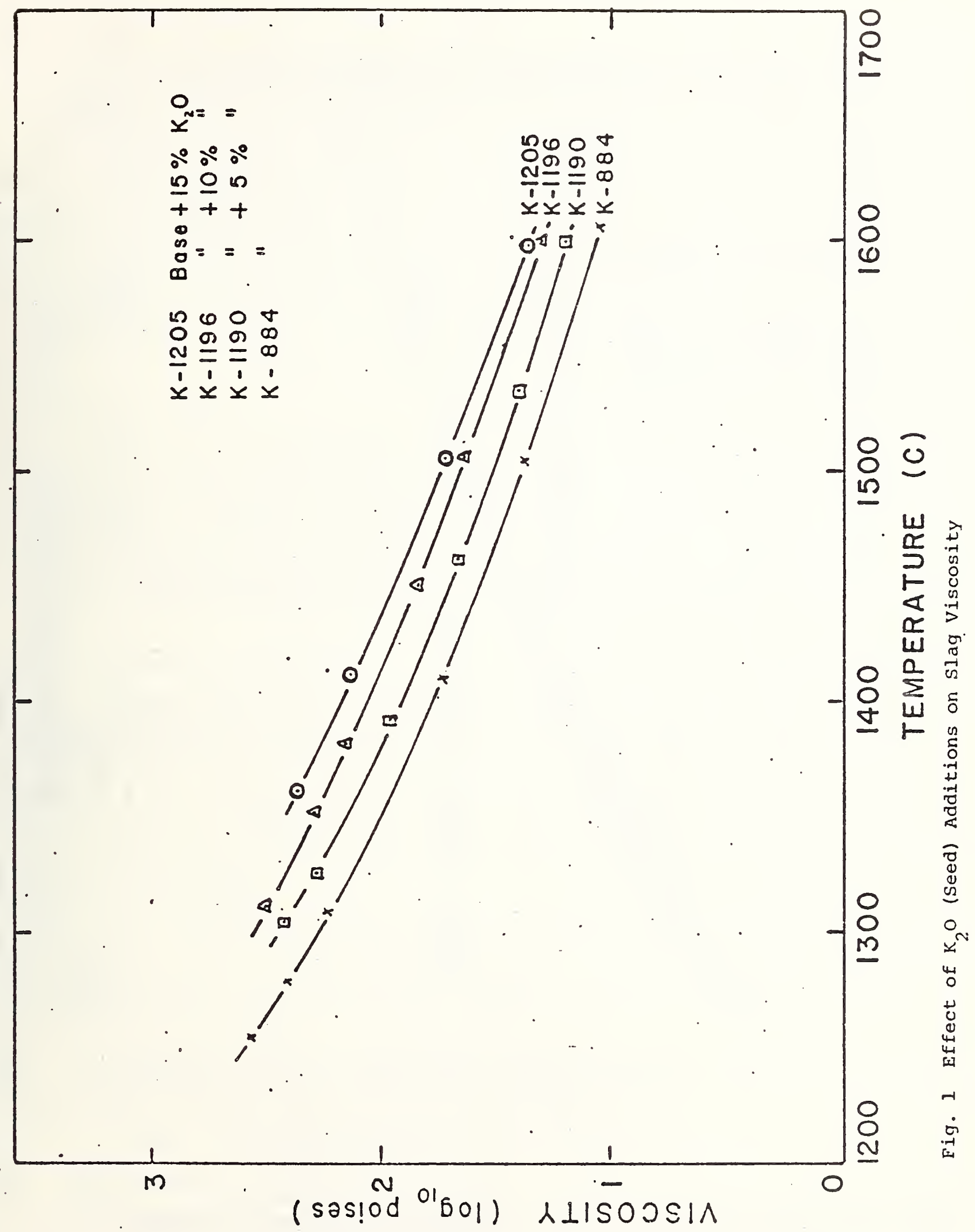




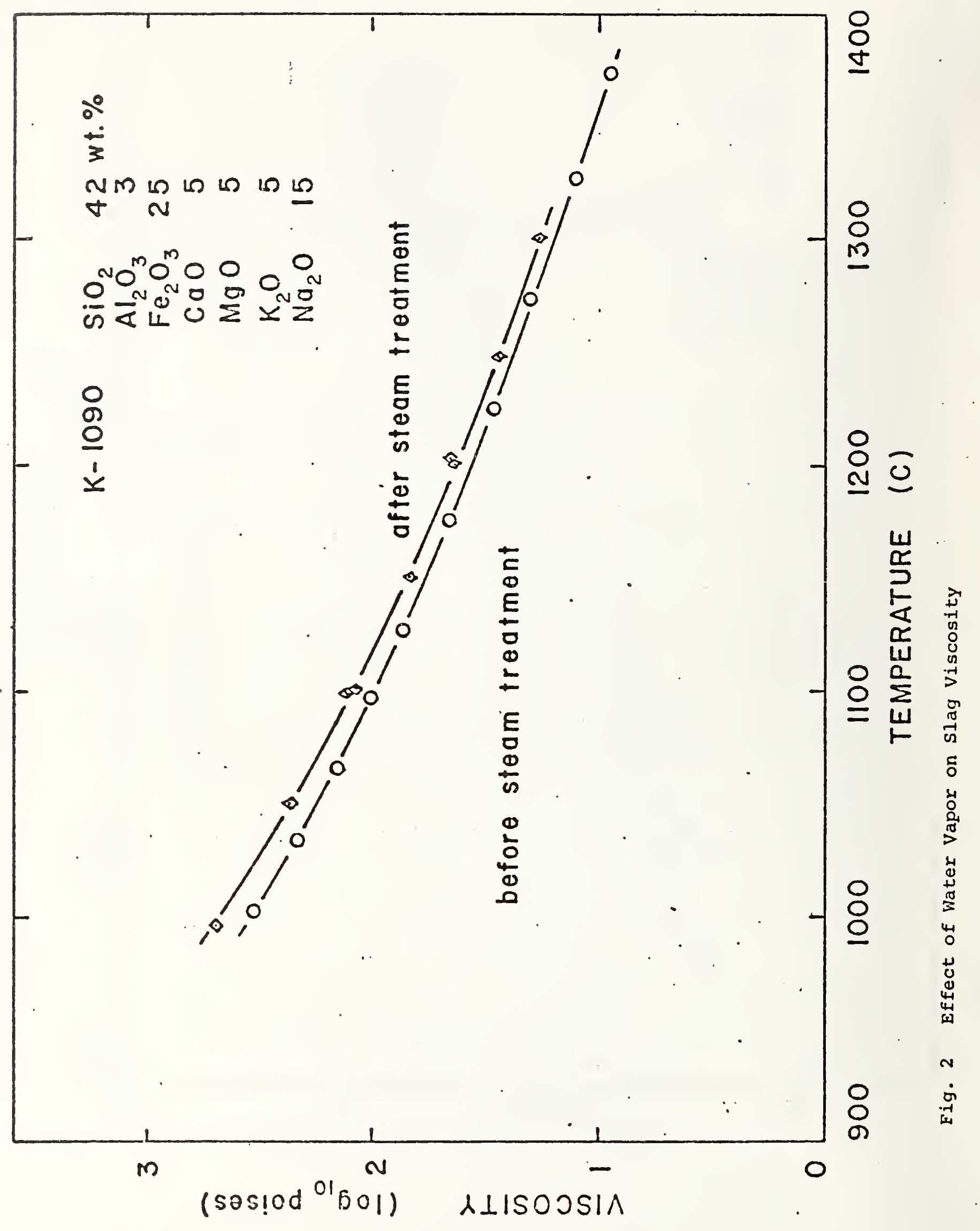




\section{Electrical Conductivity (W. R. Hosler)}

During this reporting period work has continued on measurement of the electrical conductivity of promising electrode materials developed at NBS or sent to us by other MHD contractors. The electrical measurements reported in this section are all made using the well known DC four probe technique thus basically eliminating difficulties due to contact emf's or resistances. The current is supplied by a constant current supply of variable voltage and the potential drop is measured across the conductivity probes by a $D C$ electrometer with a high input impedance $\left(>10^{14} \Omega\right)$ compared to the sample resistance. In order to increase the efficiency of the measurement process a sample holder was fabricated which will accommodate two samples for measurement at the same time. Since certain samples take long periods of time (several hours) to equilibrate at each temperature point and at the several $O_{2}$ partial pressures used this double sample holder has proven extremely useful.

$2.1 \mathrm{~K}_{2} \mathrm{O}-7 \mathrm{Fe}_{2} \mathrm{O}_{3}$

A sample of potassium ferrite $\left(\mathrm{K}_{2} \mathrm{O}-7 \mathrm{Fe}_{2} \mathrm{O}_{3}\right)$ was fabricated and the electrical properties are shown in Figure 3. The data shows the conductivity values for both increasing and decreasing temperatures in an atmosphere of $10^{-3}$ oxygen in nitrogen. These measurements are preliminary but the data does show that the electrical conductivity of the material is well suited for possible use as an MHD electrode material particularly in the area of current lead-out to room temperature. More details concerning the preparation and phase composition will be given at a later date.

\subsection{U 02 Phase III Materials}

The electrical concuctivity of the materials used in Phase III - U-02 has been completed. The data on several compositions has been reported previously and are listed below.

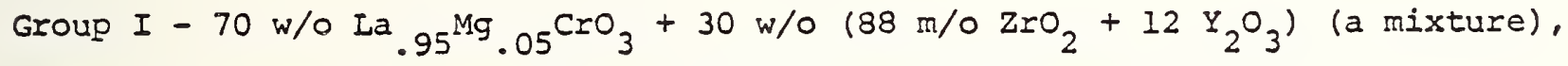

Quarterly Report, January - March 1978, page 12, Figure 3.

Group II - see below.

Group III - see below..

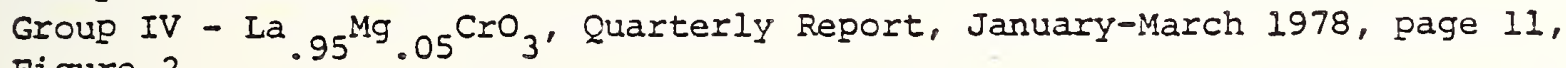

Figure 2 .

Group V - La $1.00^{\mathrm{Mg}} .02^{\mathrm{Cr}} .98^{\mathrm{O}} 3^{\prime}$ Quarterly Report, January - March 1978, page 13, Figure 4.

Group VI - same as Group I.

The material in group II was $\mathrm{LaCrO}_{3}$ graded with various amounts of $\mathrm{IaAlO}_{3}$ in layers of equal thickness. The layers consisted of:

top

$$
\mathrm{La} .95^{\mathrm{Mg}} \cdot 05^{\mathrm{Al}} \cdot 32^{\mathrm{Cr}} \cdot 68^{\mathrm{O}} 3
$$

middle

$\mathrm{La} .95^{\mathrm{Mg}} .05^{\mathrm{Al}} \cdot 24^{\mathrm{Cr}} \cdot 76^{\mathrm{O}} 3$

bottom $\mathrm{Ia} .95^{\mathrm{Mg}} \cdot 05^{\mathrm{AI}} \cdot 15^{\mathrm{Cr}} .85^{\mathrm{O}} 3$ 
and each section was sliced in such a manner to obtain a sample of single composition material for electrical measurements. The data is shown in Figure 4. The conductivity decreases as the $\mathrm{LaAlO}_{3}$ content increases as expected but the material containing the smaller amount still has an adequate conductivity for use as a lead-out with a minimum amount of Joule heating.

Group III materials were composed of $\mathrm{LaCrO}_{3}$ with four different mixtures of yttria stabilized $\mathrm{ZrO}_{2}$ in four layers of equal thickness. The $\mathrm{Y}_{2} \mathrm{O}_{3}$ content was 98 of the $\mathrm{ZrO}_{2}$. The layers consisted of

$\begin{array}{ll}\text { top } & 30 \% \mathrm{ZrO}_{2} \\ \text { second } & 20 \% \mathrm{ZrO}_{2} \\ \text { third } & 10 \% \mathrm{ZrO}_{2} \\ \text { bottom } & 0 \% \mathrm{ZrO}_{2}\end{array}$

These electrode sections were sawed again in such a manner to obtain samples for electrical conductivity and the data is shown in Figure 5 . Here again the conductivity of the $\mathrm{LaCrO}_{3}$ decreases as the $\mathrm{ZrO}_{2}$ content increases, as expected, but the material containing only $10 \% \mathrm{ZrO}_{2}^{2}$ has an adequate conductivity to be used at several degrees centigrade without appreciably joule heating for current densities of the order of $1.5 \mathrm{a} / \mathrm{cm}^{2}$.

A brief description of the Phase III - U-02 experiment is presented in Task $\mathrm{K}$, section 2 of this report. 


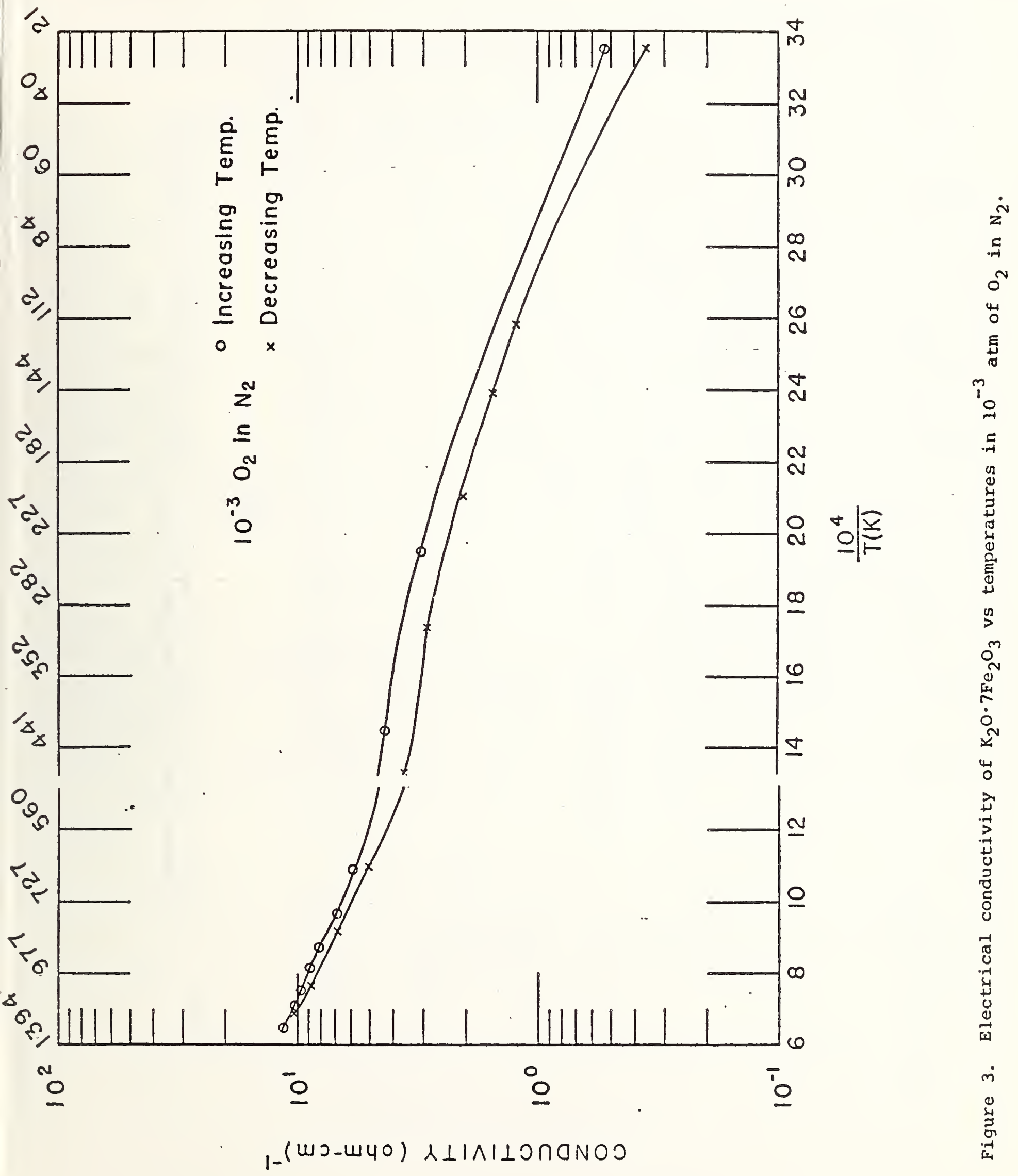




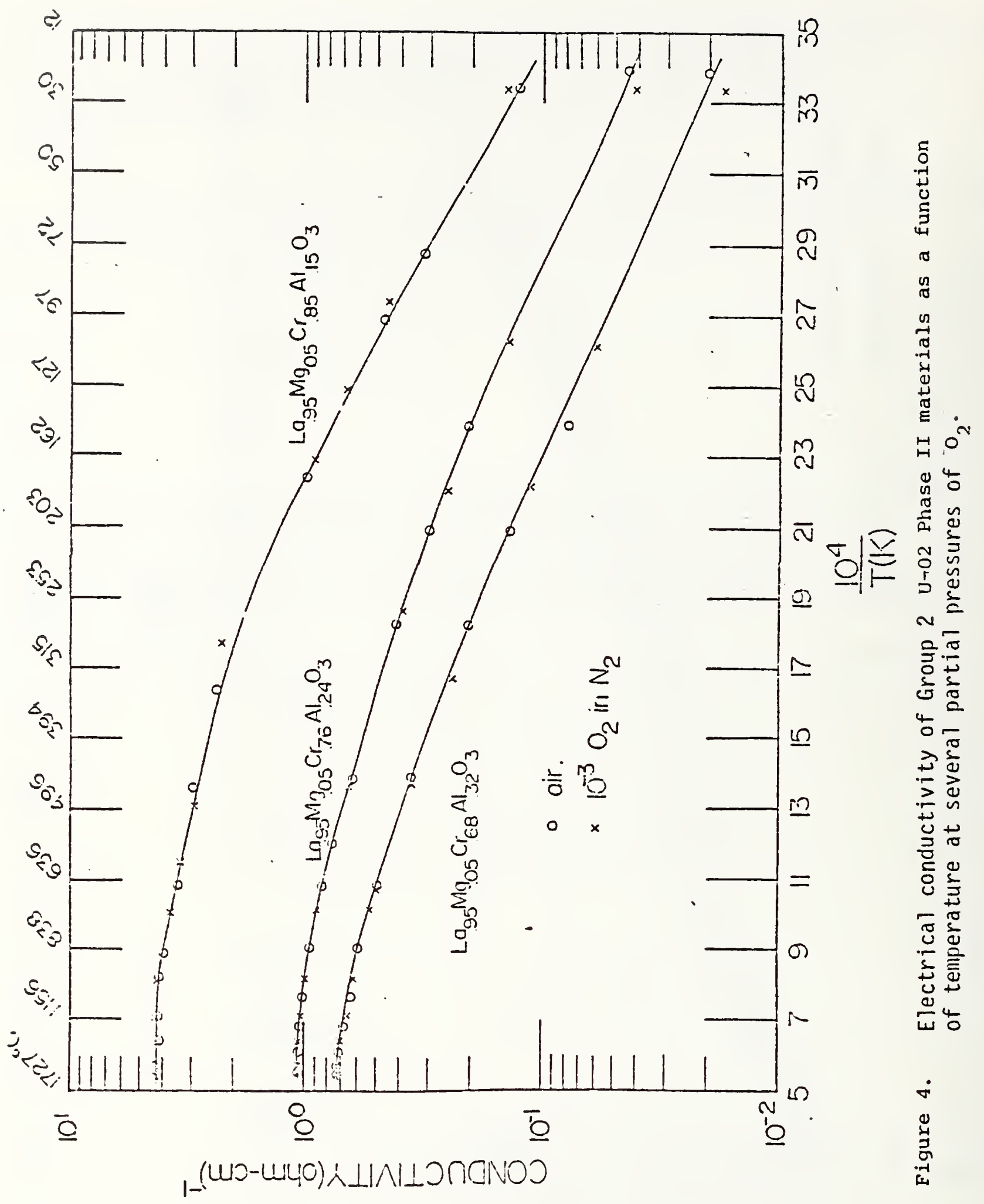




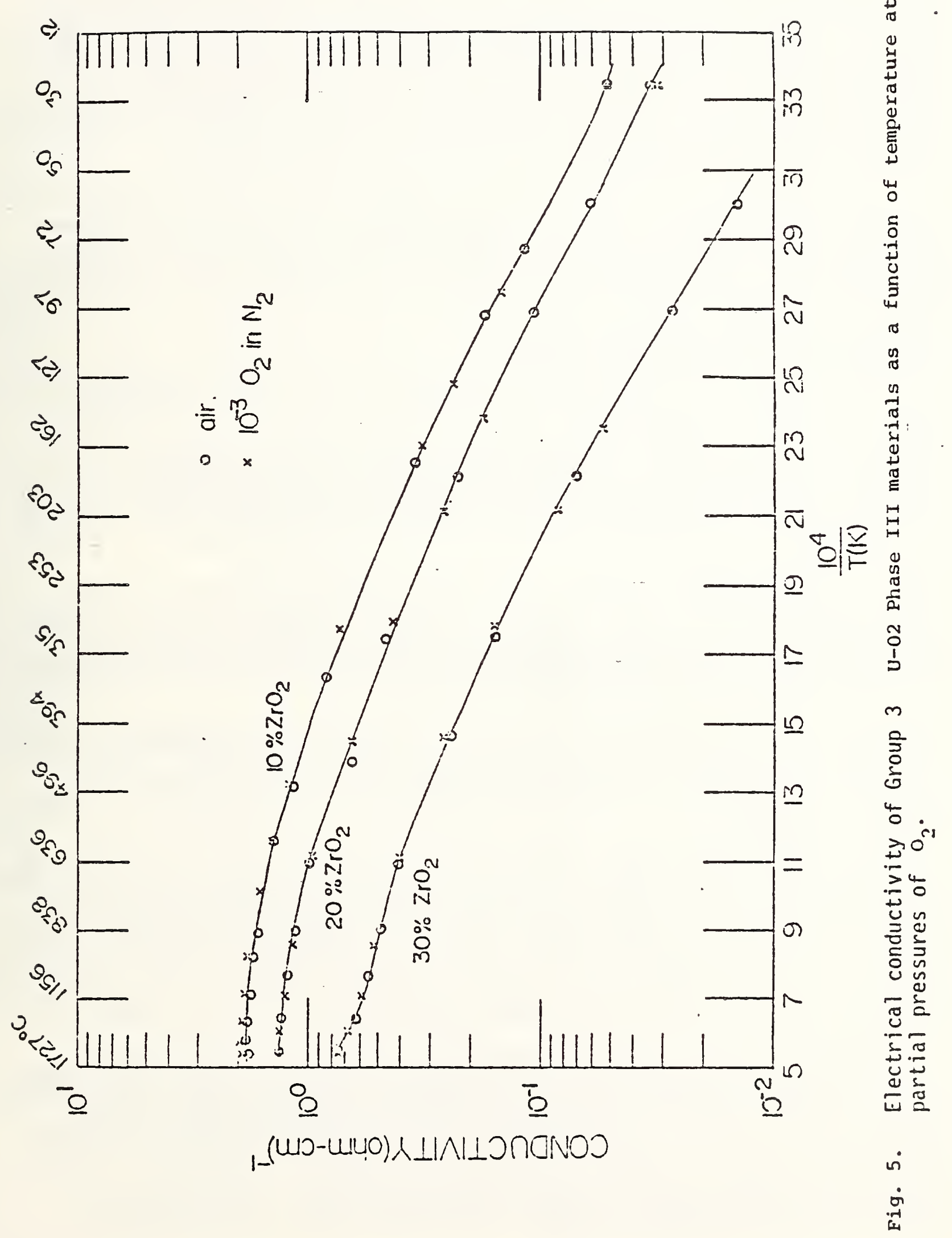


3. Vaporization Studies

(E. R. Plante)

This section describes measurements of the potassium gas pressure over $\mathrm{K}_{2} \mathrm{O}$-containing compounds or phases. These data are necessary for prediction and correlation of the interaction of a seeded MHD plasma with construction materials or coal ash using equilibrium thermodynamics. For example, Spencer noted the severe lack of thermodynamic or vapor pressure data needed to model seed-slag interaction parameters in ternary or higher order systens. The vaporization studies at NBS have been planned to provide some of the required data as well as to measure $\mathrm{K}_{2} \mathrm{O}$ activities in solutions having up to 6 components which will be more representative of slags in real MHD systems.

Because of the importance of ferrites as electrode materials measurements of the $\mathrm{K}$ and $\mathrm{O}_{2}$ pressure over $\mathrm{KFeO}_{2}$ were carried out. In acdition, observations of the pressures of several vapor species over MAFF-3I were initiated. This report will discuss the data on $\mathrm{KFeO}_{2}$ in some detail and will sumarize the preliminary work on MAFF-3l.

\section{I Vapor Pressure Measurements on "KFeO}

Results of mass spectrometric measurements of the vapor pressure of $\mathrm{KFeO}_{2}$ (series 1 ) were summarized in a previous report (2). In the series 1 data an abnomally high $I_{3}^{+} / I_{3 g}^{+}\left(\mathrm{O}_{2}^{+} / \mathrm{K}^{+}\right)$ratio was observed which was thought to indicate that significant reduction of the $\mathrm{KFeO}_{2}$ took place during the vaporization experiments. However, this observation was contrary to zesults obtained by x-ray diffraction studies of the residual sample which indicated that the evaporation process was consistent with the reaction,

$$
7 / 6\left(\mathrm{~K}_{2} \mathrm{O} \cdot \mathrm{Fe}_{2} \mathrm{O}_{3}\right)=2 \mathrm{~K}(g)+1 / 2 \mathrm{O}_{2}(g)+1 / 6\left(\mathrm{~K}_{2} \mathrm{O} \cdot 7 \mathrm{Fe}_{2} \mathrm{O}_{3}\right)
$$

The possibility that a high $\mathrm{O}_{2}$ pressure was due to reaction of $\mathrm{FeO}_{\mathrm{x}}$ with $\mathrm{Pt}$ allowing release of $\mathrm{O}_{2}$ was considered but SEM examination of the $\mathrm{Pt}$ Knudsen cell indicated only minor interaction.

Because of these conflicting observations the mass spectrometer constant could only be determined within a factor of 3 . If it was assumed that the $x$-ray diffraction data were correct the mass spectrometer calibration factor for $\mathrm{K}$ would be a factor of 3 greater than that obtained assuming the It $2 / I^{\frac{1}{3}}$ g ratio was correct.

More recent observations (3) on unrelated $\mathrm{K}_{2} \mathrm{O}$-containing slag samples have shown that the $\mathrm{I}_{32 / I_{3}^{+}}^{+}$data were probably incorrect because of misaligrment of the molecular beam with the ion source. These observations showed that the $I_{32}^{+} / I_{3}^{+}$gatio could be varied over a factor of 3 depending on the ion optics adjustments of the source. This effect is possible because $\mathrm{O}_{2}$ is non-condensible and can bounce off surfaces into the active volume of the ion source while $k$ is condensible and will be effectively removed from the molecular beam.

New measurements on the vaporization of $\mathrm{KFeO}$ were therefore undertaken. The measurements were made in our modulated bean, quadrupole mass spectrometer using a platinum effusion cell having a $0.343 \mathrm{~mm}$ diameter orifice. The experimental arrangement was essentially the same as previously used except that the thernocouple used previously had been replaced. As before, measurements of both the $\mathrm{K}^{+}$and ot ion currents were made as a check on the vaporization stoichiometry. Within experimental error, the vaporization reaction is that previously noted. 
Certain non-equilibrium effects were observed during the experiments. Measurements of the ion currents are made at constant temperature but the initial ratio of $\mathrm{I}_{32}^{+} / \mathrm{I}_{3}^{+}$depended on whether the temperature was increased or decreased in going from one constant temperature to another. When the temperature was increased, after the initial increase in the $\mathrm{K}^{+}$intensity, there was a tendency for the $\mathrm{K}^{+}$ion current to decrease with time and the $\mathrm{O}_{2}^{+}$ion intensity to increase with time until a steady state was reached. The opposite effects were noted when the temperature was decreased but the same steady state was eventually achieved. It appeared, however, that a shorter period of time was required to achieve steady state pressures if the temperature was increased from point to point and the data presented was taken in that direction. Above $1300 \mathrm{~K}$, equilibration rates were quite rapid and steady state pressures were observed within 10-15 minutes while at the lower temperatures, periods of about an hour were required.

These effects could be due to a phase boundary dependence on temperature. For example, the " $\mathrm{K}_{2} \mathrm{O} \cdot 7 \mathrm{Fe}_{2} \mathrm{O}_{3}$ " composition might become $\mathrm{O}_{2}$ deficient at higher temperatures. Other possibilities include instrumental problems with the mass spectrometer or kinetic factors in the diffusion of $\mathrm{k}$ and $\mathrm{O}_{2}$ from the evaporating phase (insufficient equilibration time). At steady state conditicns, the $\mathrm{I}_{32}^{+} / \mathrm{I}_{39}^{+}$ratio indicated a deficiency of $\mathrm{O}_{2}$ at low temperatures but at higher temperatures the $O_{2} / K$ pressure ratio appeared consistent with the proposed decomposition reaction.

Some representative data obtained during the measurements is shown in Figure 6. The upper curve is the $\mathrm{K}$ pressure and the iower curve is the $\mathrm{O}_{2}$ pressure. The ratio of the $\mathrm{K}$ pressure to the $\mathrm{O}_{2}$ pressure is based on previous experience which indicates that the mass spectrometer sensitivity constant is about 5.6 times that for $\mathrm{O}_{2}$.

The $\mathrm{K}$ pressure over $\left.\mathrm{KFeO}_{2}\right\lrcorner \mathrm{K}_{2} \mathrm{O} \cdot 7 \mathrm{Fe}_{2} \mathrm{O}_{3}{ }^{\prime \prime}$ is about an order of magnitude greater than the $\mathrm{K}$ pressure over $\mathrm{KAlO}_{2}-\mathrm{K}_{2} \mathrm{O} \cdot 7 \mathrm{Al}_{2} \mathrm{O}_{3}$ and roughly a factor of 5 greater than the $\mathrm{K}$ pressure over $\mathrm{K}_{2} \mathrm{SO}_{4}$. This confirms the general notion that $\mathrm{K}_{2} \mathrm{O}$ interacts more strongly with $\mathrm{Al}_{2} \mathrm{O}_{3}$ than with $\mathrm{Fe}_{2} \mathrm{O}_{3}$. It also shows that $\mathrm{K}_{2} \mathrm{O} \cdot 7 \mathrm{Fe}_{2} \mathrm{O}_{3}$ " will not react with $\mathrm{K}_{2} \mathrm{SO}_{4}$ to form $\mathrm{KFeO}_{2}$.

\subsection{MAFF-31 Vaporization Measurements}

These measurements are in a preliminary stage and will be summarized. MAFF-31 is a spinel structure in which $\mathrm{Fe}^{+2}$ and $\mathrm{Fe}^{+3}$ ions replace $\mathrm{Mg}^{+2}$ and $\mathrm{Al}^{+3}$ ions in the spinel. It has the nominal composition $3 \mathrm{MgAl}_{2} \mathrm{O}_{4} \cdot \mathrm{Fe}_{3} \mathrm{O}_{4}$. Observations of ion currents due to $\mathrm{Fe}(\mathrm{g}), \mathrm{O}_{2}(g), \mathrm{Mg}(\mathrm{g})$ and $\mathrm{FeO}(\mathrm{g})$ have been made. At $1700^{\circ} \mathrm{C}$ the pressure of $\mathrm{Fe}$ is about $10^{-5}$ atm which is about 10 times as high as $\mathrm{Mg}$ pressure. These preliminary measurements indicate that the upper temperature limit of MAFF-31 under clean electrode conditions should be limited to about $1600^{\circ} \mathrm{C}$.

\section{Conclusions}

The $\mathrm{K}$ pressure over $\mathrm{KFeO}_{2}+\mathrm{K}_{2} \mathrm{O} \cdot 7 \mathrm{Fe}_{2} \mathrm{O}_{3}$ " is about an order of magnitude greater than the $\mathrm{K}$ pressure over $\mathrm{KAlO}_{2}-\mathrm{K}_{2} \mathrm{O} \cdot 7 \mathrm{Al}_{2} \mathrm{O}_{3}$ showing that $\mathrm{K}_{2} \mathrm{O}$ interacts more strongly with $\mathrm{Al}_{2} \mathrm{O}_{3}$ than with $\mathrm{Ee}_{2} \mathrm{O}_{3}$. Preliminary measurements show preferential loss of Fe from a MAFF-3I composition. 
References

1. F. E. Spencer, Jr., J. C. Hendrie, Jr., and D. Bienstock, VIth International Conference on MHD Power Generation, Washington, D.C. (1975)

2. Development, Testing and Evaluation of MFD Materials, H.P.R. Frederikse, T. Negas and S.J. Schneider, (Sept. 1977)

3. E.R. Plante and L.P. Cook, 17th MHD Symposium on Engineering Aspects of MHD, Stanford, CA (1978) 


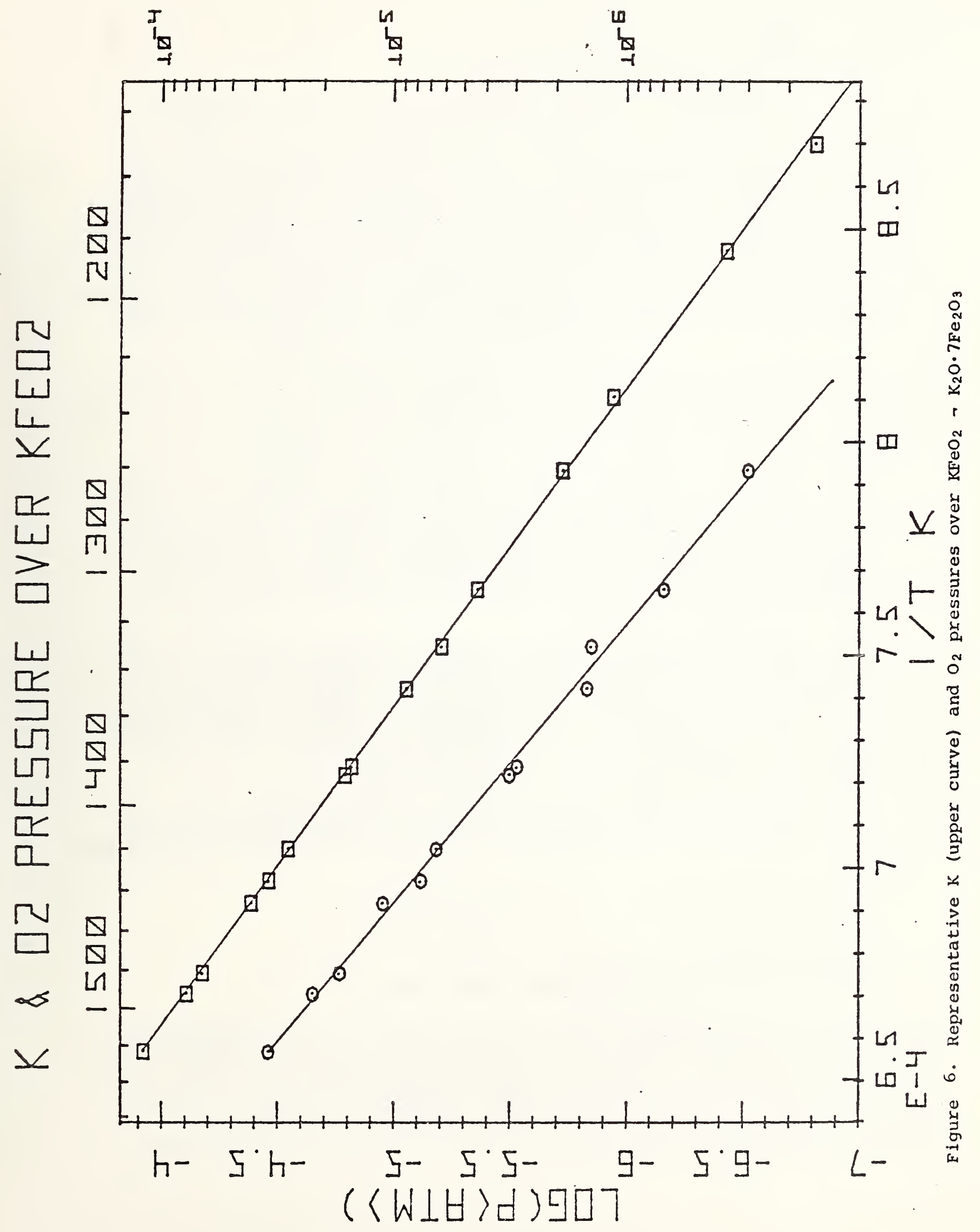




\section{Diffusion in Insulator-Electrode Couples}

(E. N. Farabaugh and J. R. Manning)

Concentration profiles for $\mathrm{Fe}, \mathrm{Mg}$ and $\mathrm{Al}$ have been obtained from MAFF31-MgO diffusion couples tested at $1400^{\circ} \mathrm{C}$ for 1 and 10 hours. Here MAFF 31 has the nominal composition $3 \mathrm{MgAl}_{2} \mathrm{O}_{4} \cdot \mathrm{IFe}_{3} \mathrm{O}_{4}$. These profiles show a marked decrease of $\mathrm{Fe}$ penetration into the $\mathrm{MgO}$ insulator when compared to equal testing times at $1600^{\circ} \mathrm{C}$. The $1 \mathrm{hr}$. test at $1600^{\circ} \mathrm{C}$ yields a Fe concentration profile similar to the $10 \mathrm{hr}$. test at $1400^{\circ} \mathrm{C}$. These tests all showed significant discontinuities in the $\mathrm{Fe}$ concentrations at the couple interface. The $100 \mathrm{hr}$. test at $1400^{\circ} \mathrm{C}$ has yet to be examined. The rate of $\mathrm{Fe}$ diffusion into $\mathrm{MgO}$ or $\mathrm{MgAl}_{2} \mathrm{O}_{4}$ insulators determines the rate at which the insulating properties will degrade if used in MED channels. This rate is smaller in $\mathrm{MgAl}_{2} \mathrm{O}_{4}$ than in $\mathrm{MgO}$.

The AI and $\mathrm{Mg}$ concentration profiles in MAFF31-S71 couples diffused at $1600^{\circ} \mathrm{C}$ for 10 hrs. and 100 hrs. have been analyzed. Here $S 71$ has the composition $\mathrm{MgAl}_{2} \mathrm{O}_{4}$. The $\mathrm{Fe}$ profiles in these couples were analyzed and reported previously (Quarterly Report 3-78). The data were plotted on probability paper and normalized for diffusion time assuming a $\sqrt{t}$ dependence. Smooth curves then were drawn through these points, which fell in a single composition-distance band as expected for a simple diffusion process, with the scatter covering about $10 \%$ of the total concentration variation. The Matano interface, which is the plane across which equal amounts of material flowed in both directions, was located 20 to $25 \mu \mathrm{m}$ into the 571 specimen after 10 hours. Calculations for all three metal concentration profiles ( $\mathrm{Mg}, \mathrm{Al}$ and $\mathrm{Fe}$ ) agreed on the location of this Matano interface.

From the composition-distance profiles, the total amount of $\mathrm{Mg}$ and $\mathrm{Al}$ that had passed from the 571 specimen into the MAFF31 specimens was calculated. This was found to be very nearly equal for $\mathrm{Mg}$ and $\mathrm{Al}$; also the amount of $\mathrm{Fe}$ that had passed from the MAFF3I specimens to the 571 specimens was determined. From these values, intrinsic diffusion coefficients for $\mathrm{Mg}$, $\mathrm{Al}$ and $\mathrm{Fe}$ were

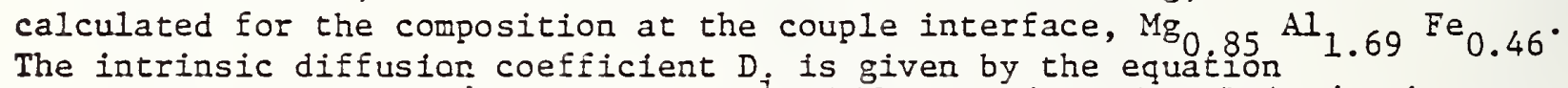
$D_{j}=-A_{i}\left[2 t\left(\partial c_{i} / \partial x\right)_{t}\right]^{-1}$ where $t$ is the diffusion time, $\left(\partial c_{i} / \partial x\right)_{t}$ is the concentration gradient of element $i$ at the interface at time $t$ and $A_{i}$ is the net amount of $i$ which has flowed across the interface. At $1600^{\circ} \mathrm{C}$ the $\frac{i}{s e}$ measurements yielded

$$
\begin{aligned}
D_{M g} & =4 \times 10^{-10} \mathrm{~cm}^{2} / \mathrm{sec} \\
D_{A 1} & =1 \frac{1}{2} \times 10^{-10} \mathrm{~cm}^{2} / \mathrm{sec} \\
D_{F e} & =7 \times 10^{-10} \mathrm{~cm}^{2} / \mathrm{sec}
\end{aligned}
$$

It may be noted that $\mathrm{D}_{\mathrm{Mg}}$ is appreciably larger than $\mathrm{D}_{\mathrm{Al}}$.

Calculations by a Matano analysis from the fndividual $\mathrm{Mg}$ and $\mathrm{Al}$ profiles also showed that the interdiffusion coefficient $\mathrm{D}_{\text {. }}$ (which is related to the total penetration and mixing of species) is significantly larger for Mg than for AI in these materials. D ranged from $6 \times 10^{-10} \mathrm{~cm}^{2} / \mathrm{sec}^{\text {in }}$ the MAFF31 side of the couple to $14 \times 10^{-10} \mathrm{~cm}^{2} / \mathrm{Sg}$ on the 571 side, whereas $\mathrm{D}$ ranged from $2 \times 10^{-10}$ $\mathrm{cm}^{2} / \mathrm{sec}$ to $6 \times 10^{-10} \mathrm{~cm}^{2} / \mathrm{sec}$ with again the larger diffution coefficients and penetrations being in the 571 specimen. 
2. High Temperature Charge Transport in Coal Slags (K. Young, A. Franklin, N. Adams, L. Hsu)

The current problem under this subtask is to measure, separately, the low-current electronic and various ionic conductivities of coal slags. Initial work will be done using a synthetic slag ( $\mathrm{K}$ 302), selected because although relatively simple in composition it is expected to exhibit the major characteristics of charge transport in real slags, and because the viscosity has already been measured over the temperature range of interest (data reported on fig. 36, p. 105 of Interim Report for period July 1, 1972 to June 30, 1974, labeled NBSIR 74-543, OCR-14-32-001-1230, High Temperature MHD Materials, S. J. Schneider, et al., August 1974). This slag composition is:

\begin{tabular}{llr} 
& Wt. \% & $\frac{\text { Mol. \% }}{\mathrm{SiO}_{2}}$ \\
\cline { 2 - 2 } & 50.79 & 60.00 \\
$\mathrm{Al}_{2} \mathrm{O}_{3}$ & 21.55 & 15.00 \\
$\mathrm{Fe}_{3} \mathrm{O}_{4}$ & 16.31 & 5.00 \\
$\mathrm{MgO}$ & 11.36 & 20.00
\end{tabular}

The experiment to be performed to measure the electronic conductivity is to measure the change in current with change in applied potential in a simple conductivity cell containing the slag as electrolyte and with the cathode reversible with respect to both electrons and $F e$ ions (an Fe alloy, e.g., with Pt, chosen to be stable in the presence of the test atmosphere, e.g., $10^{-3}$ or $10^{-4}$ atm of $\mathrm{O}_{2}$ ) and the anode reversible only to electrons (e.g., Pt). Following the discussion given by F. A. Rröger in "The Chemistry of Imperfect Crystals", (North-Holland, Amsterdam, 1964), Chapter 22, the expected behavior of the slag may be analyzed as follows. The mobile species capable of changing their average concentrations are expected to be:

$$
\mathrm{Fe}^{2+}, \mathrm{Fe}^{3+}, \mathrm{O}^{2-}, \mathrm{e}
$$

where e represents an electron. $\mathrm{Mg}^{2+}$ is expected to be mobile but fixed in average composition. The following equilibria should hold everywhere:

$$
\begin{gathered}
2 \mathrm{e}+\frac{\mathrm{l}}{2} \mathrm{O}_{2} \rightarrow \mathrm{O}^{2-} \\
\mathrm{Fe}^{2+} \rightleftarrows \mathrm{Fe}^{3+}+\mathrm{e} \\
\mathrm{Fe} \rightleftarrows \mathrm{Fe}^{2+}+\mathrm{Fe} \text { (virtual iron activity) }
\end{gathered}
$$

The only external current that can flow is that carried by electrons and oxygen ions:

$$
J=-\left(\frac{\sigma e}{F} \nabla n(e)+\frac{\sigma_{0} 2-}{2 F} \nabla n\left(0^{2-}\right)\right)
$$


where $\sigma e$ and $\sigma_{\mathrm{O}_{2}}$ - are the (position-dependent) conductivities due to electrons and $\mathrm{O}_{2}$ - ions, $\mathrm{F}$ is the Faraday, $\eta$ denotes the electrochemical. potential, and $\nabla$ signifies the gradient. Using eq. ( 1 ),

$$
\nabla \eta\left(0^{2-}\right)=2 \nabla \eta(e)+\nabla \eta\left(\frac{1}{2} \mathrm{O}_{2}\right)
$$

Since all of the specimen is exposed to the same oxygen partial pressure, the last term is zero. For a simple cell with parallel electrodes $\mathrm{L} \mathrm{cm}$ apart, eq. (4) becomes

$$
J=-\frac{1}{\text { FL }} \int_{\text {Cathode }}^{\text {Anode }}\left(\sigma e+\sigma_{02-}\right) \operatorname{dn}(e)
$$

Since $\sigma e$ and $\sigma_{02}$ - are unknown functions of position at this stage, the integral cannot be evaluated. However, the derivative with respect to the potential across the electrodes is

$$
\frac{\mathrm{dJ}}{\mathrm{dV}}=-\frac{1}{\mathrm{FL}}\left(\sigma_{\mathrm{e}}+\sigma_{\dot{\theta}^{2-}}\right) \text { Anode }
$$

where the zero of potential has been taken at the cathode. Thus the slope of a plot of current vs voltage gives the sum of the electronic and oxygen conductivities at the anode.

In order for this information to be useful, it is necessary to know also the activities of the iron and oxygen ions at the anode. These are found by noting that the total Fe flux is zero, or

$$
0=\frac{\sigma_{\mathrm{Fe}} \mathrm{e}^{2+}}{(2 \mathrm{~F})^{2}} \frac{\mathrm{dn}\left(\mathrm{Fe}^{2+}\right)}{\mathrm{dx}}+\frac{\sigma_{\mathrm{Fe}^{3+}}}{(3 \mathrm{~F})^{2}} \frac{\mathrm{dn}\left(\mathrm{Fe}^{3+}\right)}{\mathrm{dx}}
$$

Then using the equality of electrochemical potentials implied in the equilibria expressed by eqs. (2) and (3), and integrating from the cathode to the anode,

$$
\mu(\mathrm{Fe})_{\text {Anode }}=\mu(\mathrm{Fe}){ }_{\text {Cathode }}+6 \int_{\text {Cathode }}^{\text {Anode }}\left\{\frac{2 \sigma_{\mathrm{Fe}^{3+}}+3 \sigma_{\mathrm{Fe}^{2+}}}{4 \sigma_{\mathrm{Fe}} 3++9 \sigma_{\mathrm{Fe}}{ }^{2+}}\right\} \mathrm{d}(\mathrm{e})
$$

For the special case in which $\sigma_{\mathrm{Fe}}{ }^{3+}>\sigma_{\mathrm{Fe}}{ }^{2+}$ the integration can be done, yielding

$$
\mu(\mathrm{Fe})_{\text {Anode }}=\mu(\mathrm{Fe})_{\text {Cathode }}+3 \mathrm{~V}
$$

or for $\sigma_{\mathrm{Fe}^{3+}} \ll \sigma_{\mathrm{Fe}}{ }^{2+}$

$$
\mu(\mathrm{Fe})_{\text {Anode }}=\mu(\mathrm{Fe}) \text { Cathode }+2 \mathrm{~V}
$$

The chemical potential of $\mathrm{Fe}$ is fixed by the iron-reversibie electroce at the cathode, and by eq. (10) or (11) at the anode. The oxycen chemical potential is fixed by the atmosphere. Therefore, the controlling 
activities at the anode are known, and eq. (7) can be used to obtain $\left(\sigma e+\sigma_{02}\right)$ as a function of these activities. Under conditions such that $\sigma_{\mathrm{Fe}} 3+\sim \sigma_{\mathrm{Fe}} 2+$, eq. (9) cannot be simplified, and it will be necessary to resort to models.

It should be noted that the presence of the Fe-reversible electrode is essential since the concentrations of the various mobile $F e$ ions and of mobile electrons, and therefore the corresponding conductivities, vary with potential across the specimen. Only by fixing the $\mathrm{Fe}$ activity somewhere in the specimen can meaningful measurements be made.

To obtain ionic conductivities both electrodes will be reversible to $\mathrm{Fe}$, and variation of the oxygen partial pressure will be used to vary the $\mathrm{Fe}^{2+} / \mathrm{Fe}^{3+}$ ratio. Conductivity by $\mathrm{Mg}^{2+}$ ions will be blocked, but should be obtainable using ac techniques, as described in the last report.

The specimen holder and furnace to be used in making these measurements have been constructed and are illustrated in figs. 1 through 6 . The furnace is shown in fig. 1. It is a resistance tube furnace with two 80 Pt 20 Rh windings. Figure 2 shows the power supply and control set-up for the windings. They are controlled simultaneously, with the relative currents set by feeding the outer winding through a variac. The inner tube is a gas-tight alumina tube fitted with brass end-plates (fig. 3) with fittings to allow a gas stream to pass in one end and out the other, and to support the central alumina rod of the specimen holder (fig. 4). This control rod is a 6-hole thermocouple tube that acts also as the feed-through and support for the electrical leads and thermocouple brought in to the specimen boat. The alumina disks of the specimen holder provide radiation shields, mechanical support inside the furnace tube, and act as baffles for gas mixing and thermalization.

The specimen boat (fig. 5) is an alumina boat into which blocks of cold slag will be placed, fitted around the electrodes and then melted in place. The oxygen partial pressure of the flowing gas atmosphere will be controlled by mixing $\mathrm{O}_{2}$ into a dried Ar stream using a variable leak. The oxygen partial pressure will be monitored using a stabilized zirconia Nernst cell. This system (fig.6) has been tested and found to produce a gas stream of very stable and zeproducible composition. 


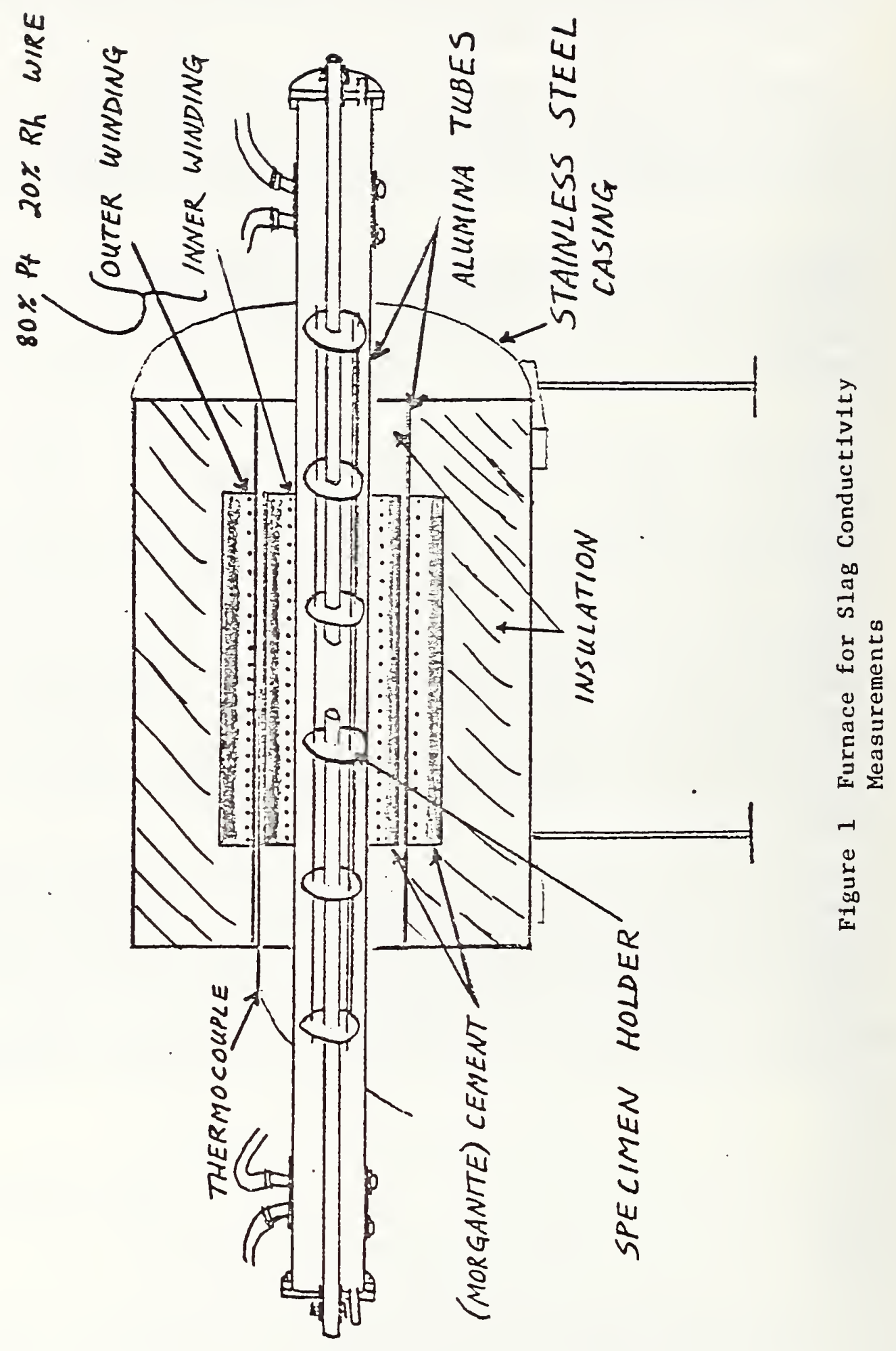




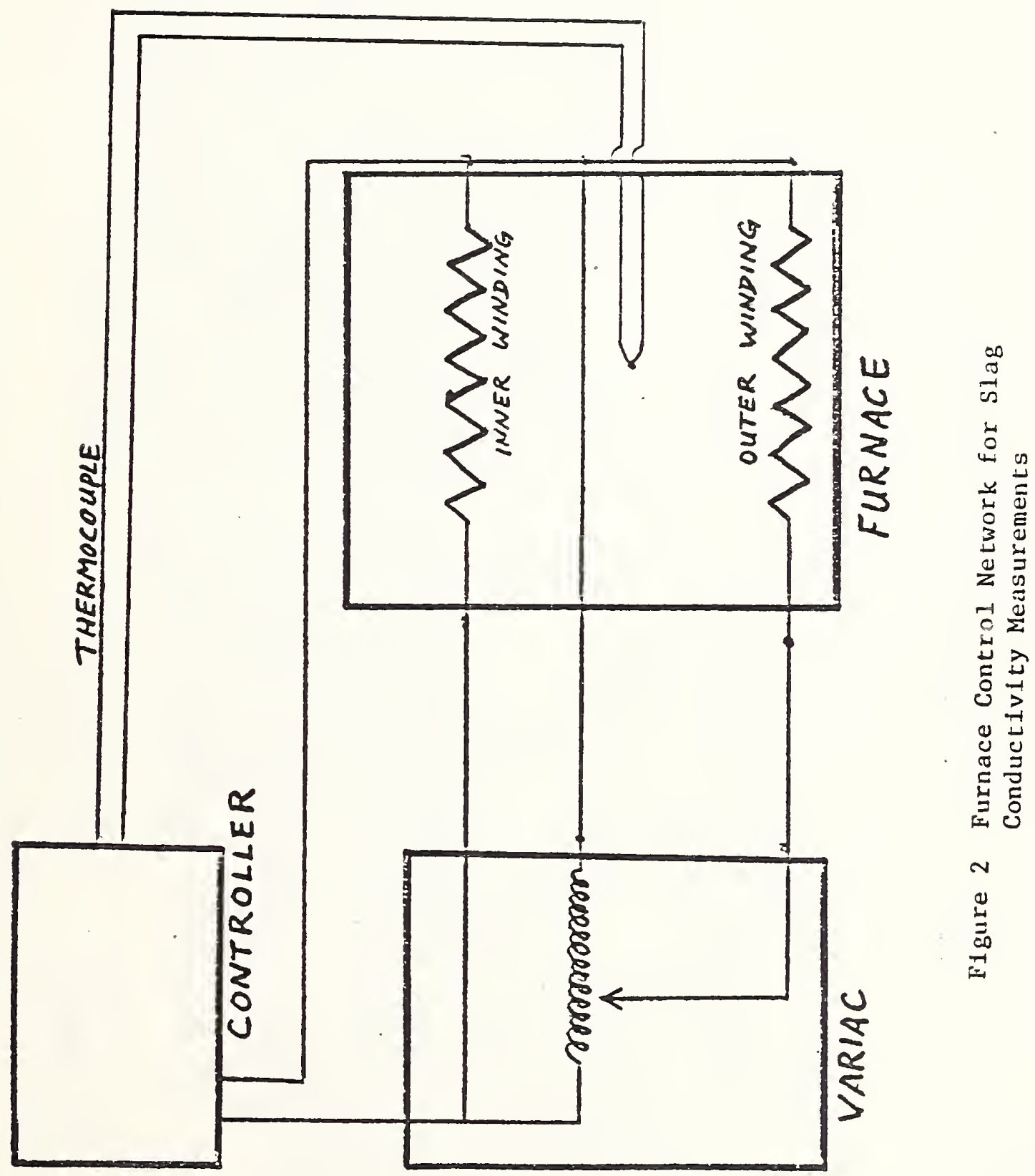




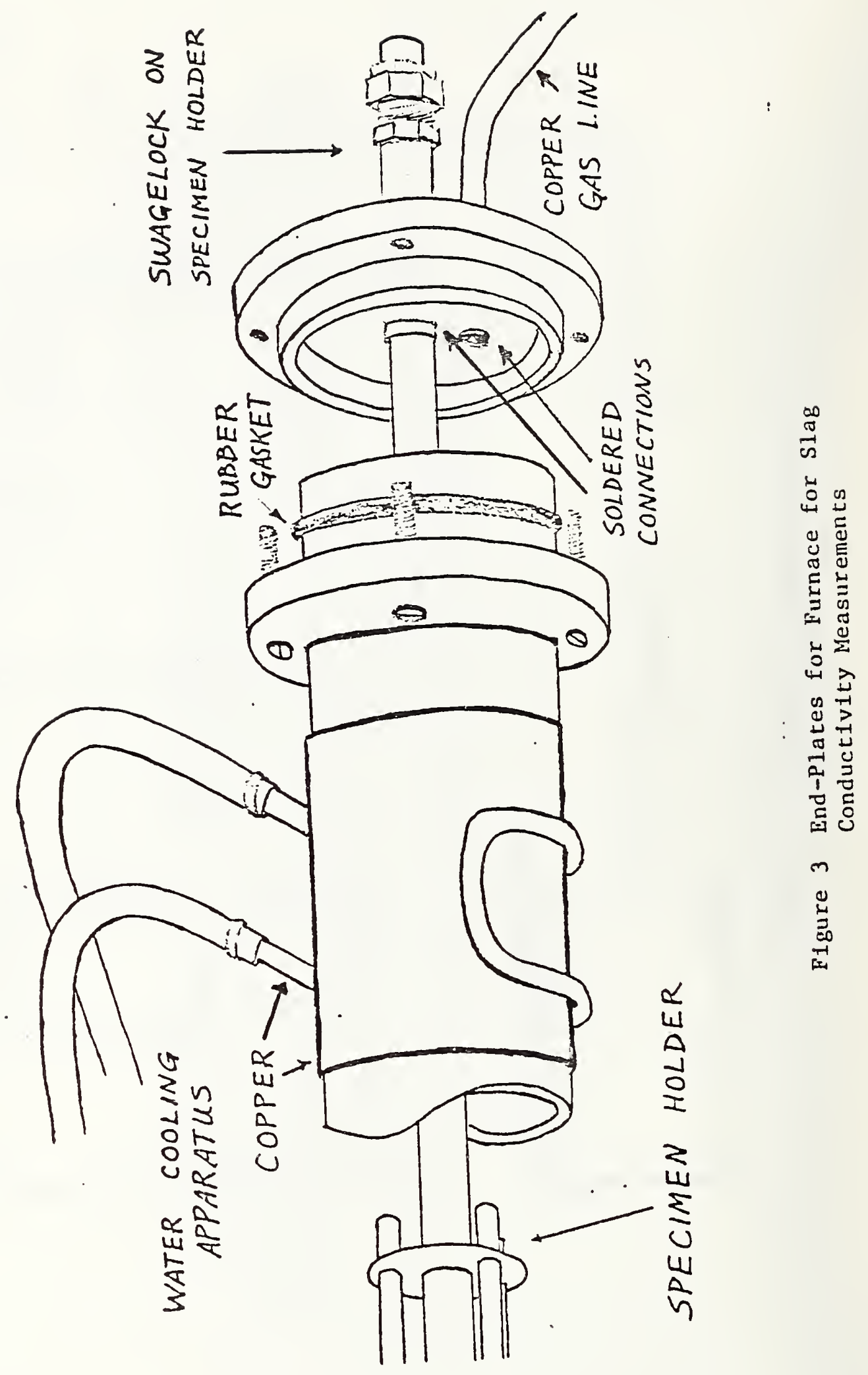




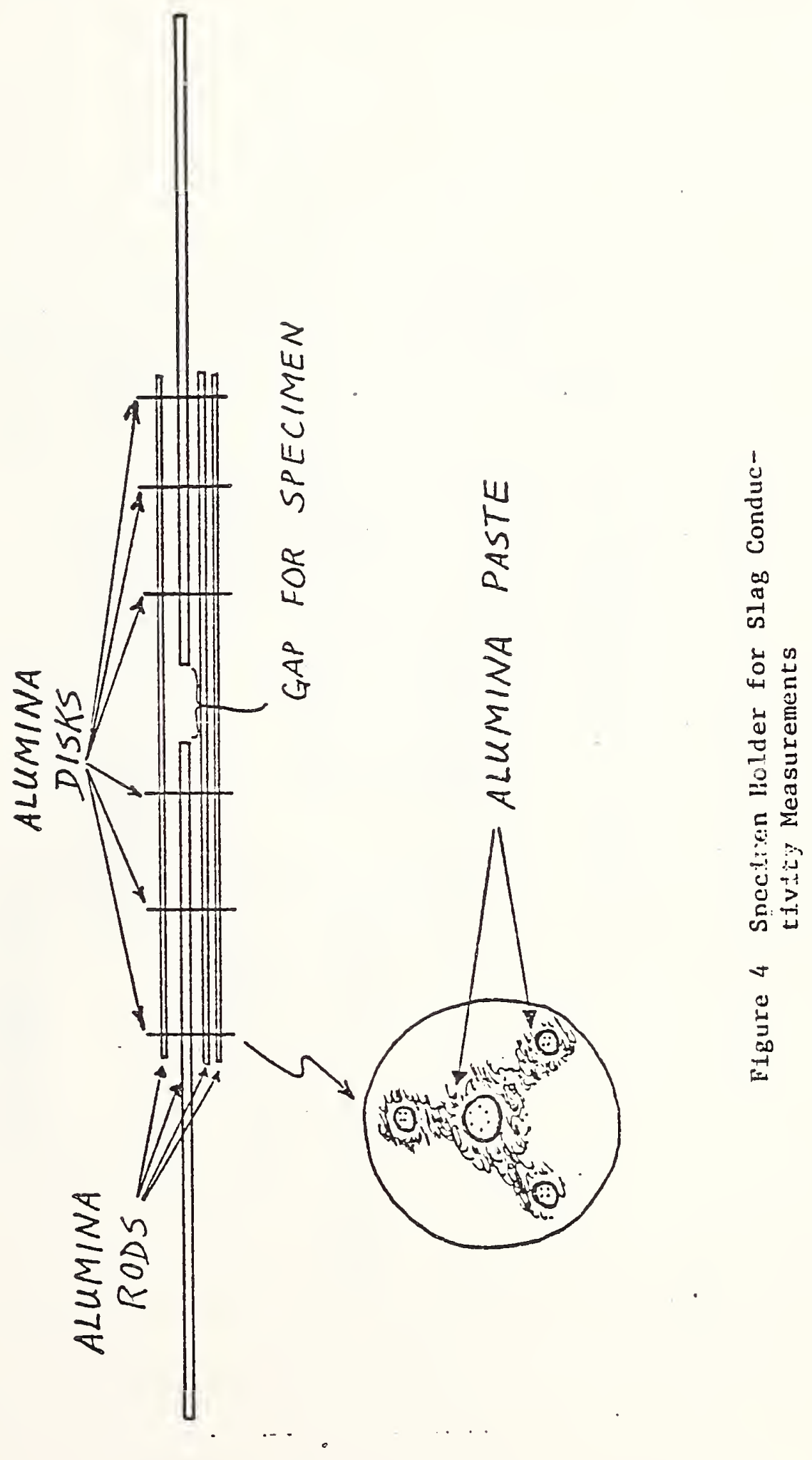




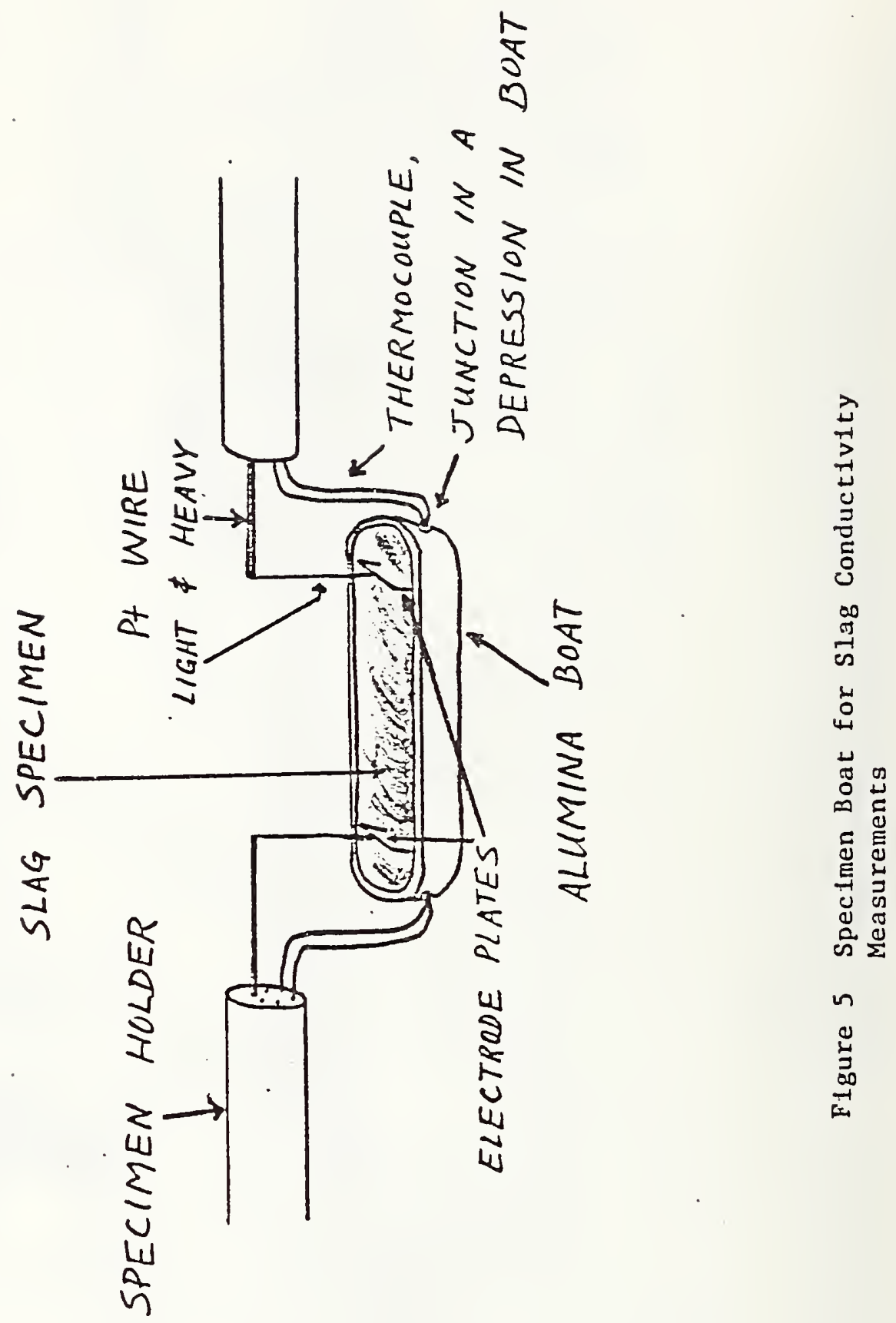



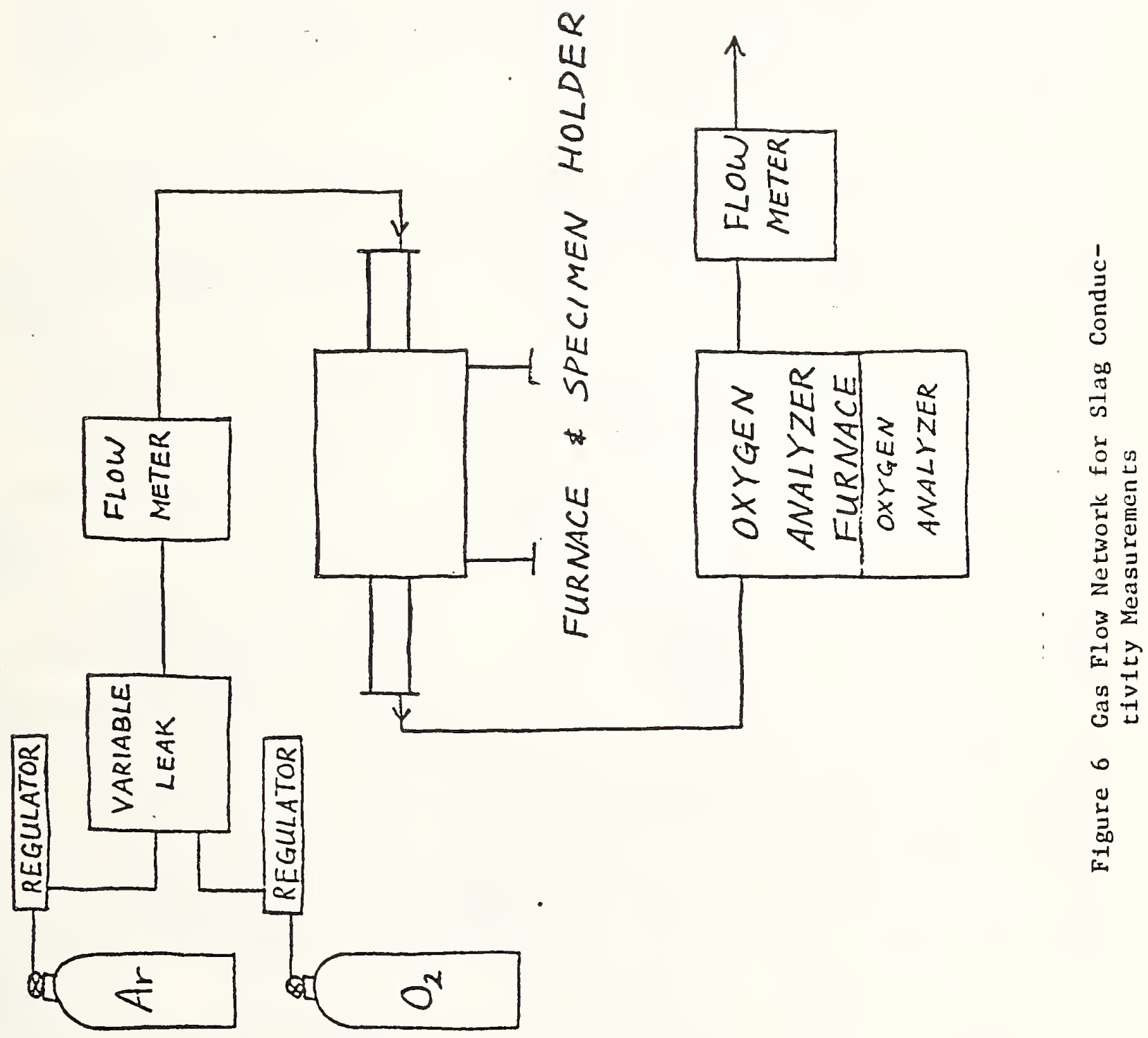
3. Electrochemical Effects in Simulated Slag Flow (W. Capps, D. A. Kauffman, and W. R. Hosler)

In the last quarterly Report (January-March 1978) (page 30) some preliminary measurements were reported using an apparatus to simulate the slag flow on "hot" electrodes in a slagging generator. The problem of slag flow and its relation to the electrochemical effects on the junction of slag and the electrode material below is extremely important. At the same time effective ion transport, particularly iron in coal slag alone can be dependent on the slag flow velocity. Experiments to address these and related problems are continuing.

During this reporting period at least four runs have been made using the apparatus mentioned above and described in the previous report on page 30 . Each of these 20 hour runs were made using fly ash from the Bow New Hampshire Power Plant. The first two (E5 and E6) runs were made with this flyash as received and contained no added seed material and were made at a temperature of $1400{ }^{\circ} \mathrm{C}$.

The second two runs (E7 and E8) were made with the slag containing $20 \%$ by weight of $\mathrm{K}_{2} \mathrm{O}$ added in the form of $\mathrm{K}_{2} \mathrm{CO}_{3}$ and made at a temperature of $1500{ }^{\circ} \mathrm{C}$. The reason for the different temperatures is due to the increased viscosity of the slag containing seed material. Both temperatures were chosen such that the slag would wipe or flow over the electrode surface during rotation. After each run transverse sections were sawed off the rotor (platinum tube approximately $8 \mathrm{~mm}$ diameter and $0.5 \mathrm{~mm}$ wall) and off the stator (platinum sheet approximately $8 \mathrm{~mm}$ wide and $0.5 \mathrm{~mm}$ thick). The removed circular cross section of the rotor in each case then was cut transverse to the cross section plane and all pieces were potted for examination. Figure 7 is a scirematic diagram of the sections sawed and potted.

Figure $8 \mathrm{a}$ is a photograph of the section from run $\mathrm{ES}$ in which the rotor was negative (cathode) and the stator was positive while figure $8 \mathrm{~b}$ shows the time dependence of the current as the run continued. Figures $9 a$ and $9 b$ is the same information for run $6 \mathrm{E}$ but with the rotor as anode and stator as cathode. One conclusive result from this set of runs is that the platinum electrode used as a cathode is attacked by the coal slag (iron) and that the rotational effect or slag flow does not inhibit the attack. At the same time the rotational effect did not prevent an apparent iron depleted layer from forming on the rotating anode as can be noted by the decay in current with time in figure $9 b$ (run $6 E$ ).

Figures $10 \mathrm{a}$ and $10 \mathrm{~b}$ show the potted cross sections of $E 7$ and time dependence of $E 7$ respectively, while figures $11 \mathrm{a}$ and $1 \mathrm{lb}$ give the same information for run E8. In E7 the rotor was positive (anode) while in E8 it was negative (cathode). Here again it is quite obvious that the platinum cathode is badly attacked by the molten slag either rotor or stator. There appears, however, to be an effect on the time dependence of the iron depletion layer on the rotating anode. The depletion layer has less tendency to form with a rotating anode as seen from comparison of figures $10 \mathrm{~b}$ and $11 \mathrm{~b}$.

The results of these experiments are generally inconclusive and not what we had anticipated. The potted sections will be examined (using scanning electron microscope techniques) for iron depletion layers near anode-slag interfaces as well as iron (or other slag components) attack on the cathode. 

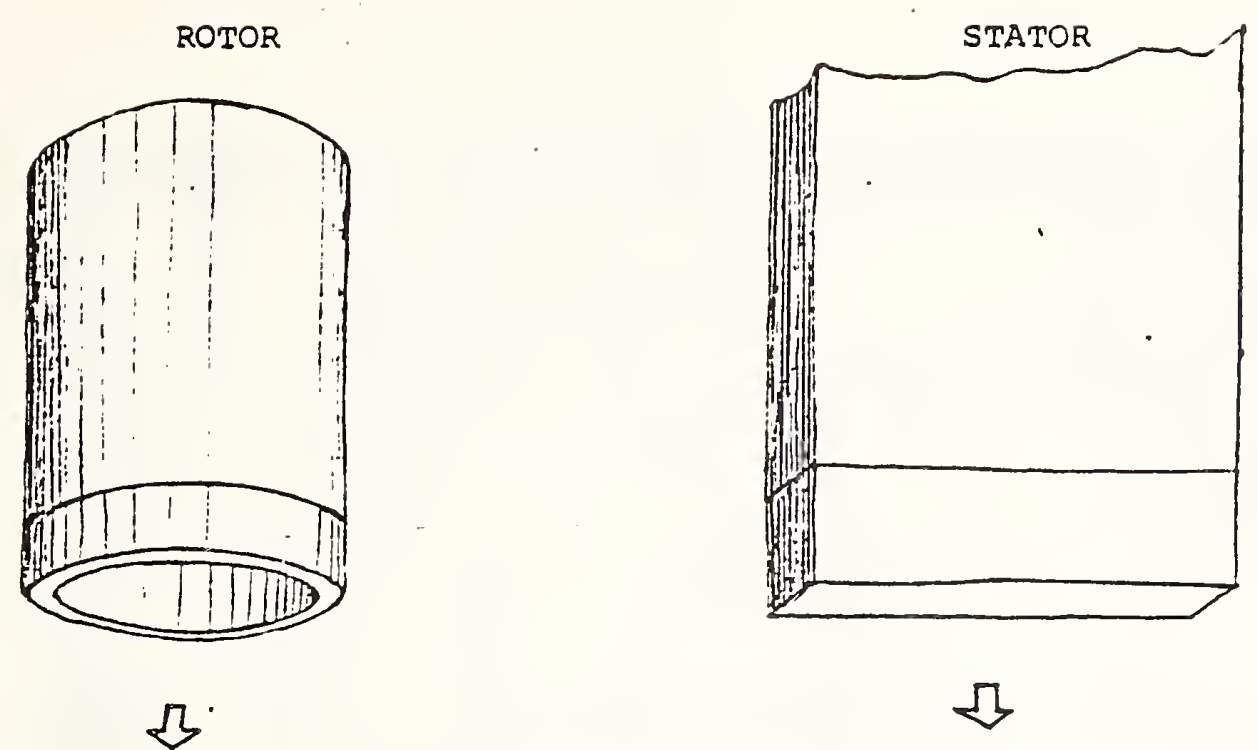

几.

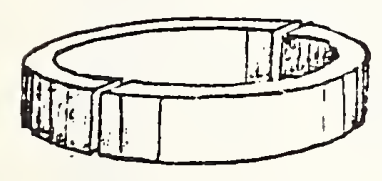

I3

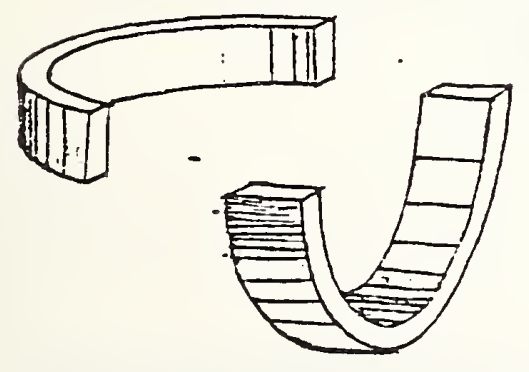

E

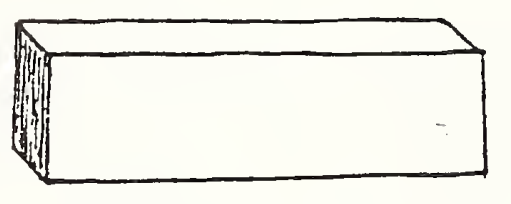

3

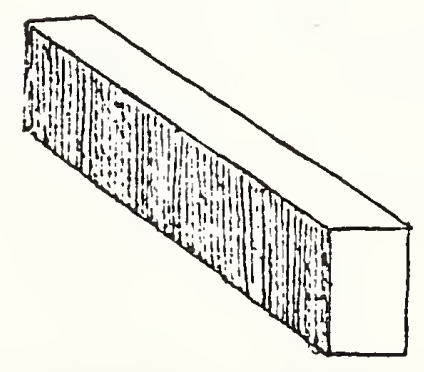

$\sqrt{3}$

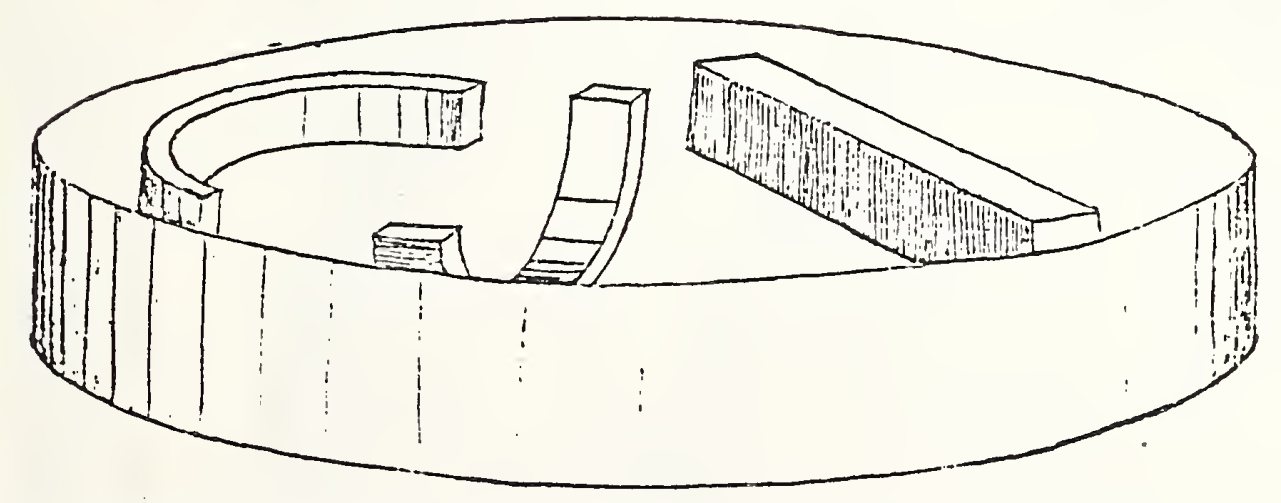

Figure 7. Schematic diagram showing form of rotor and stator, sectioning of tested electrodes and potted sections. 


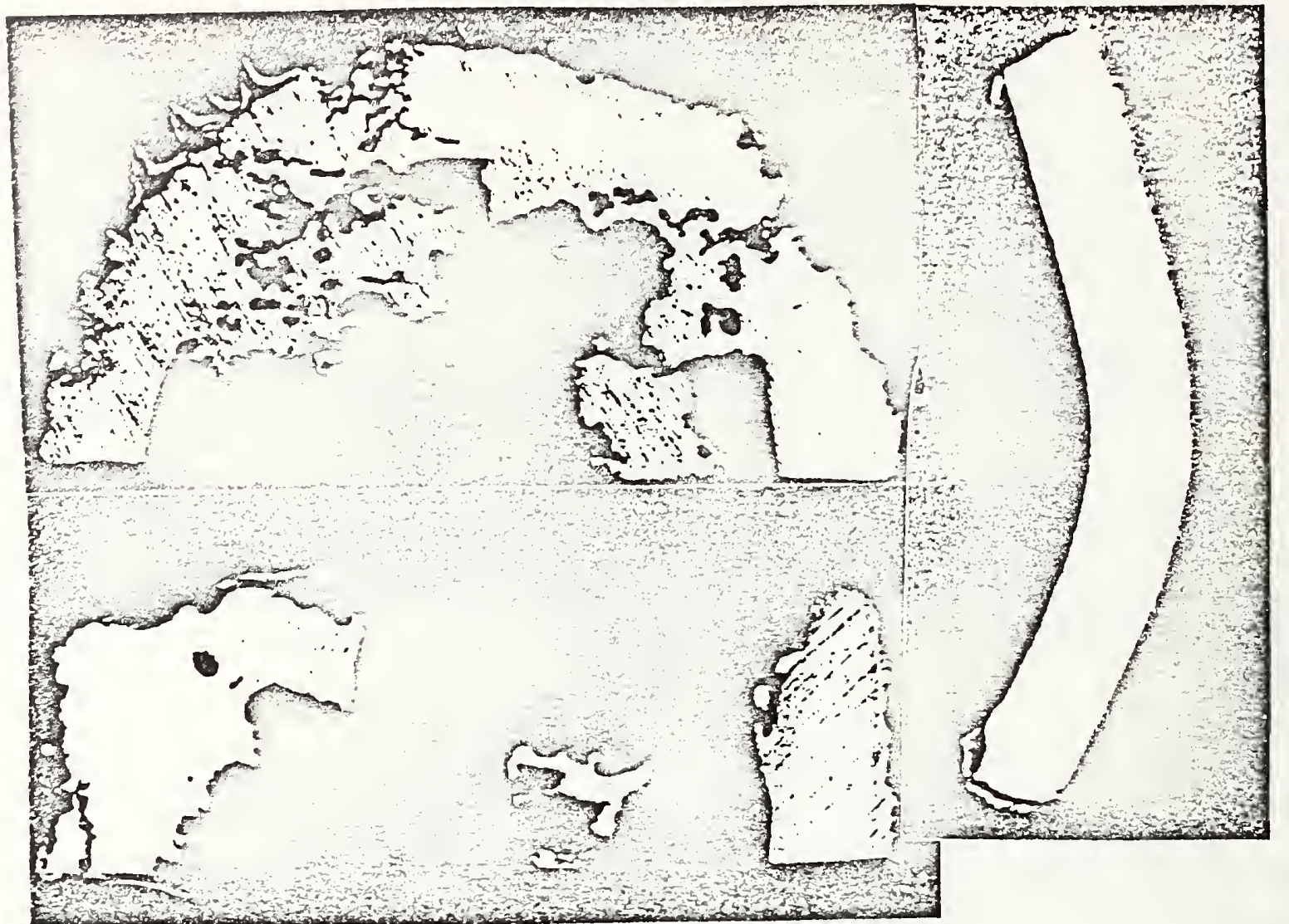

Run E5

Fig. 8a. Potted electrodes from E5 rotor cathode, stator anode $-1400^{\circ} \mathrm{C}$ and no seed.

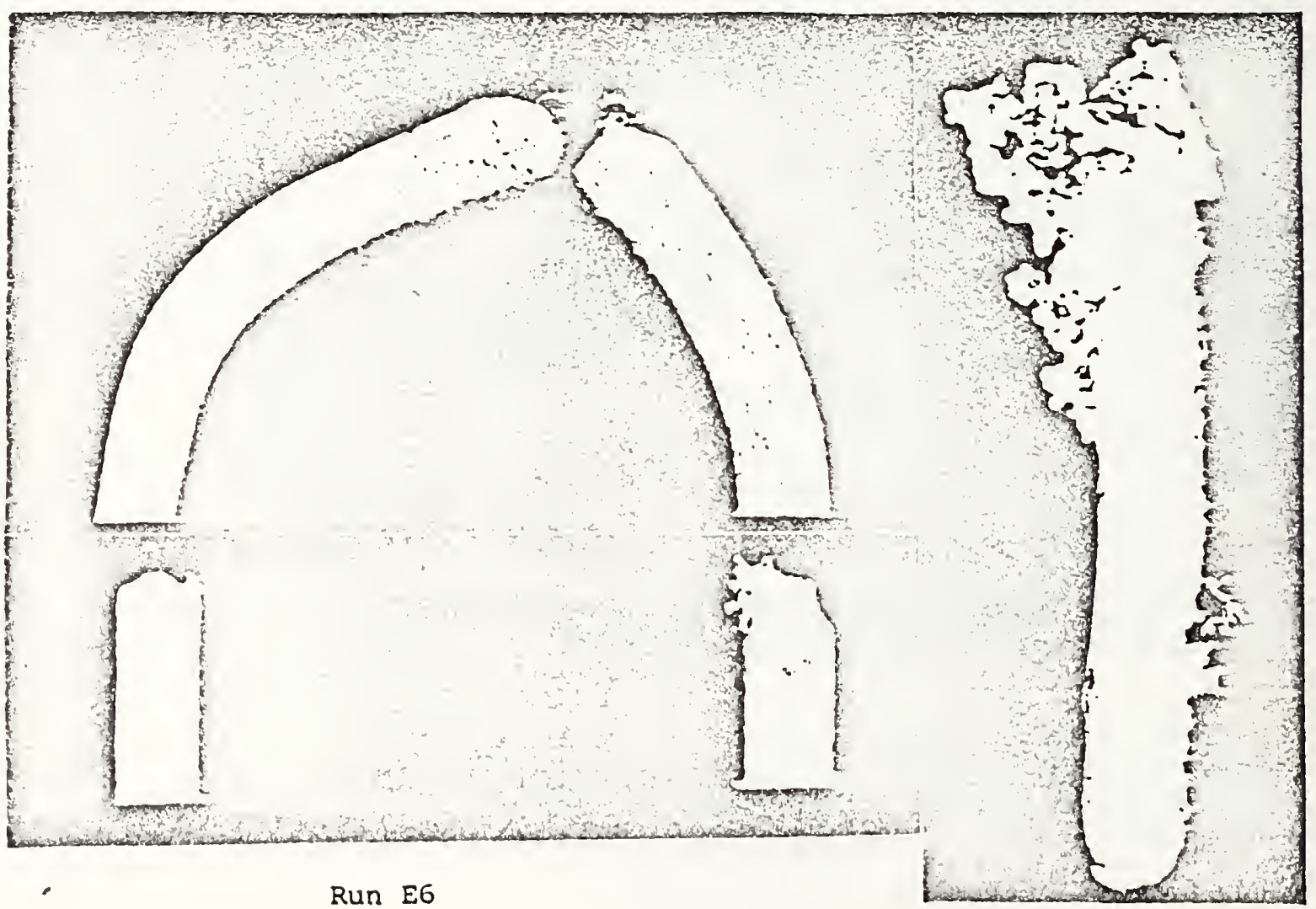

Fig. 9a. Potted electrodes from E6 - rotor anode, 


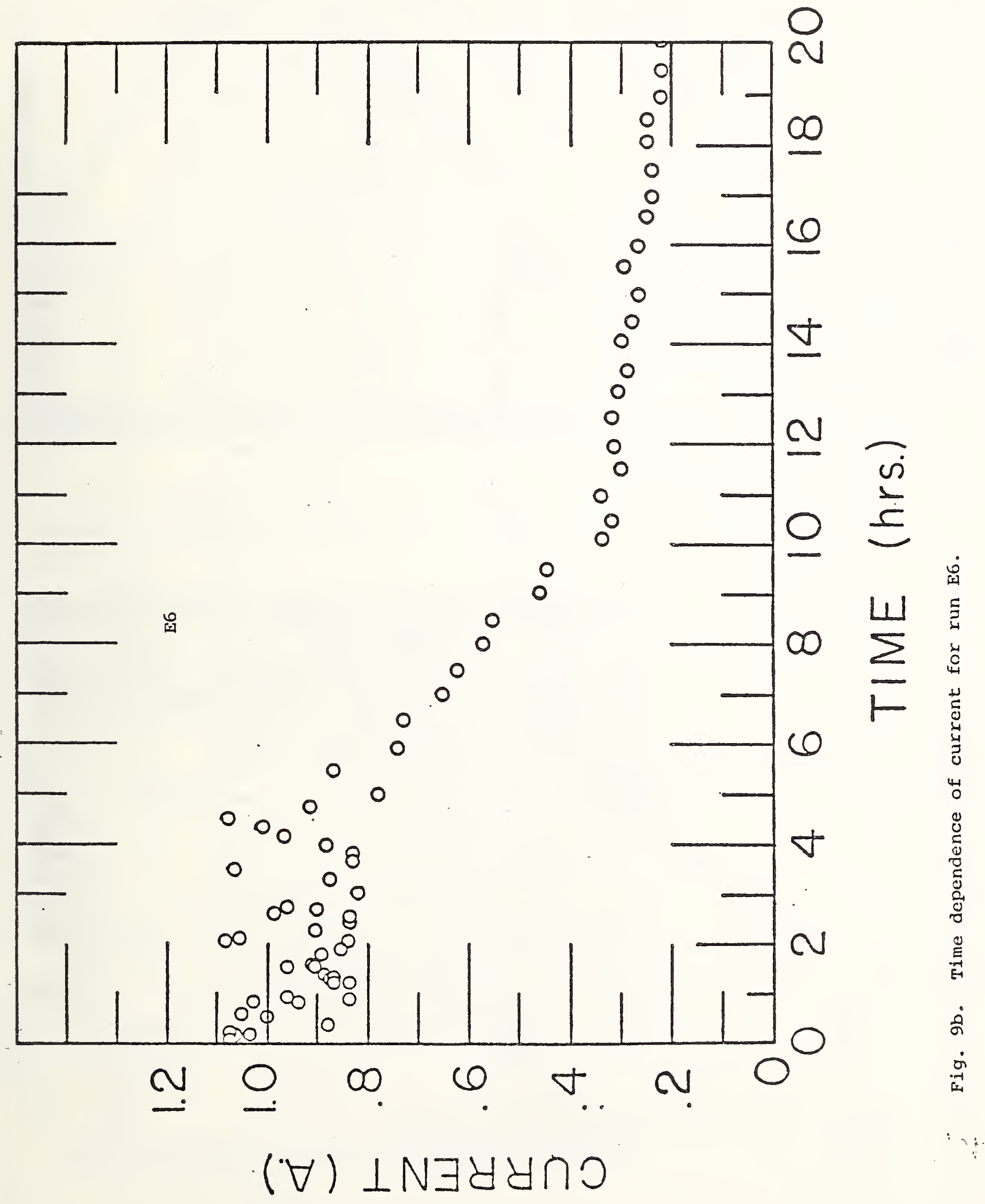




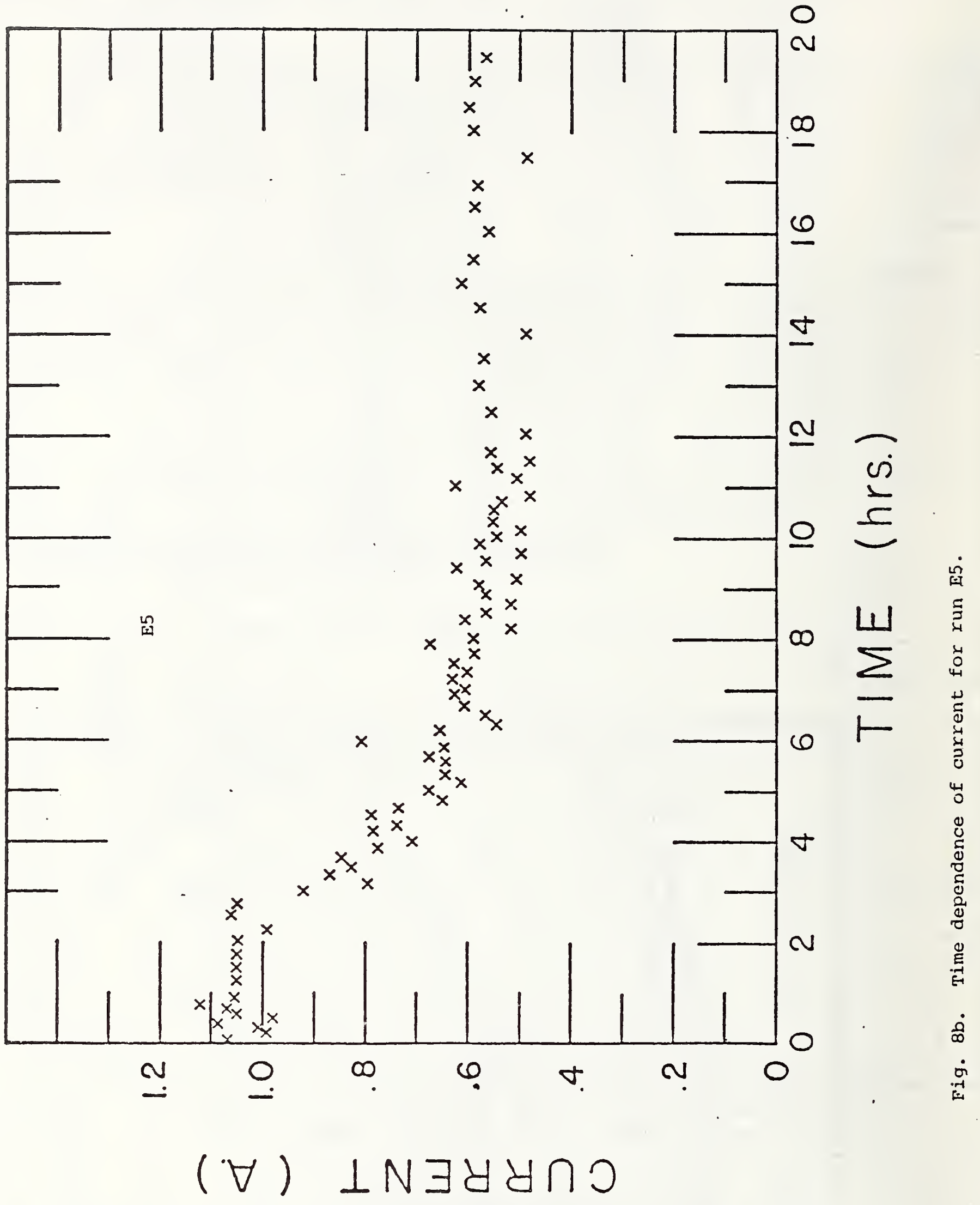



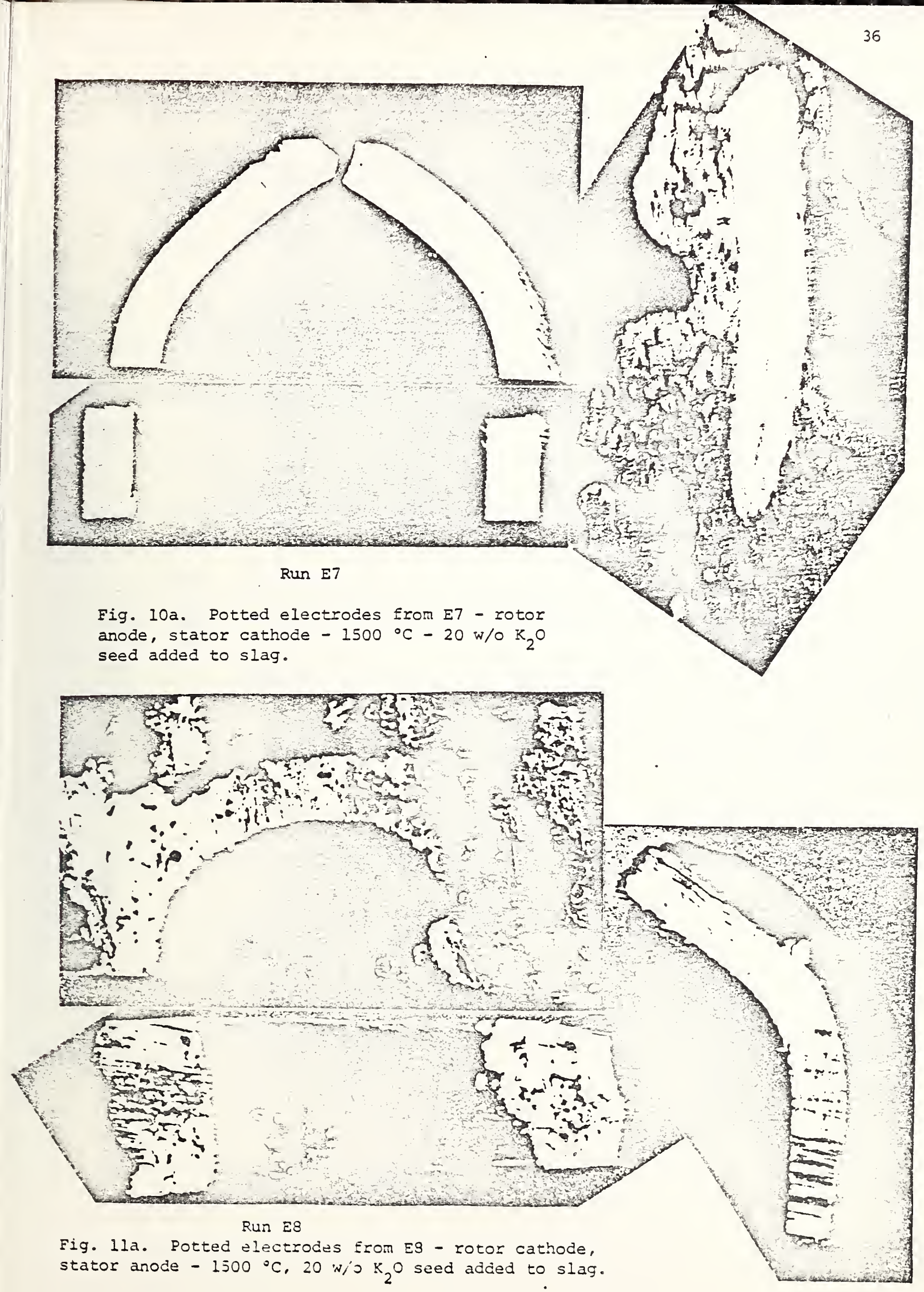


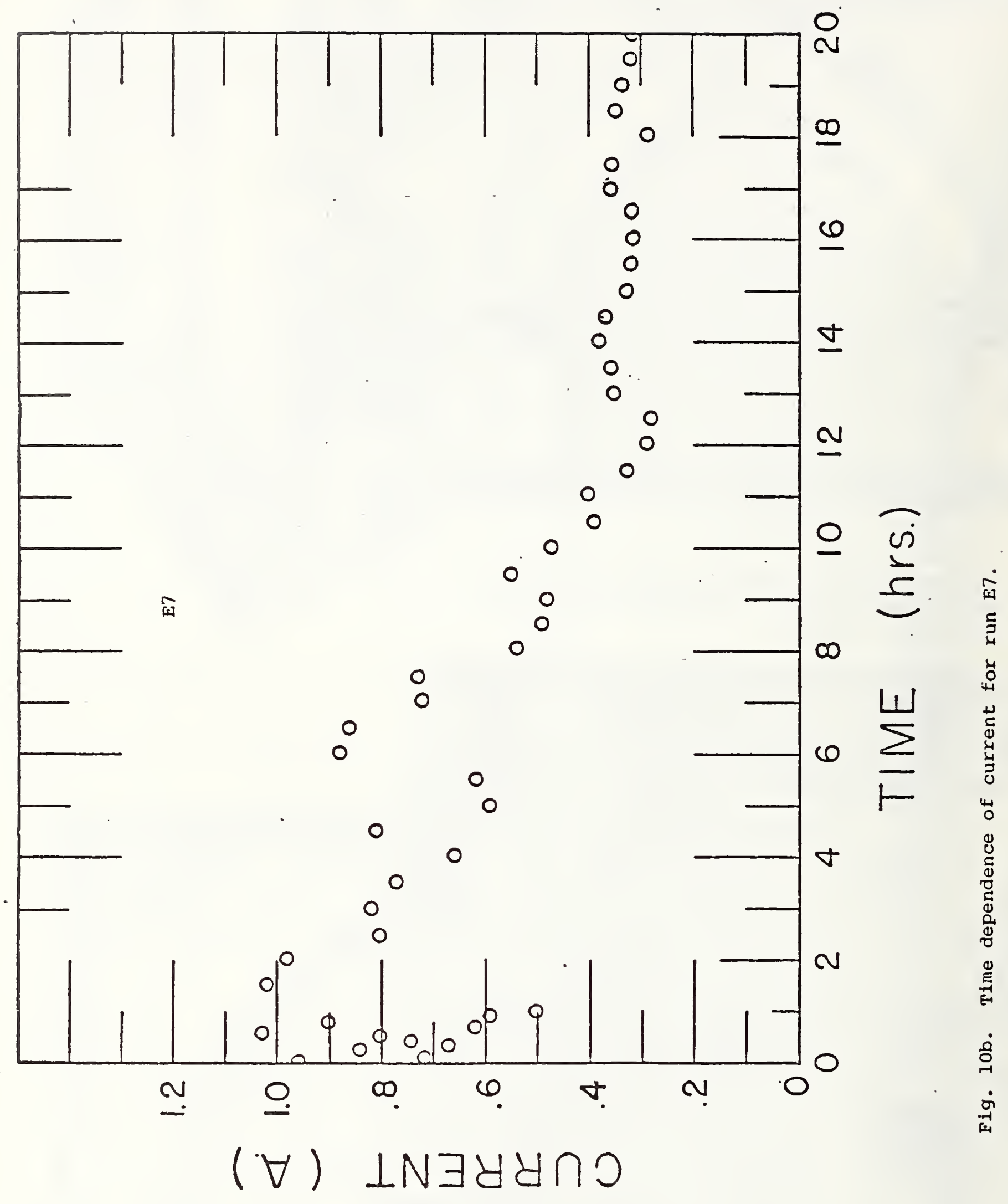




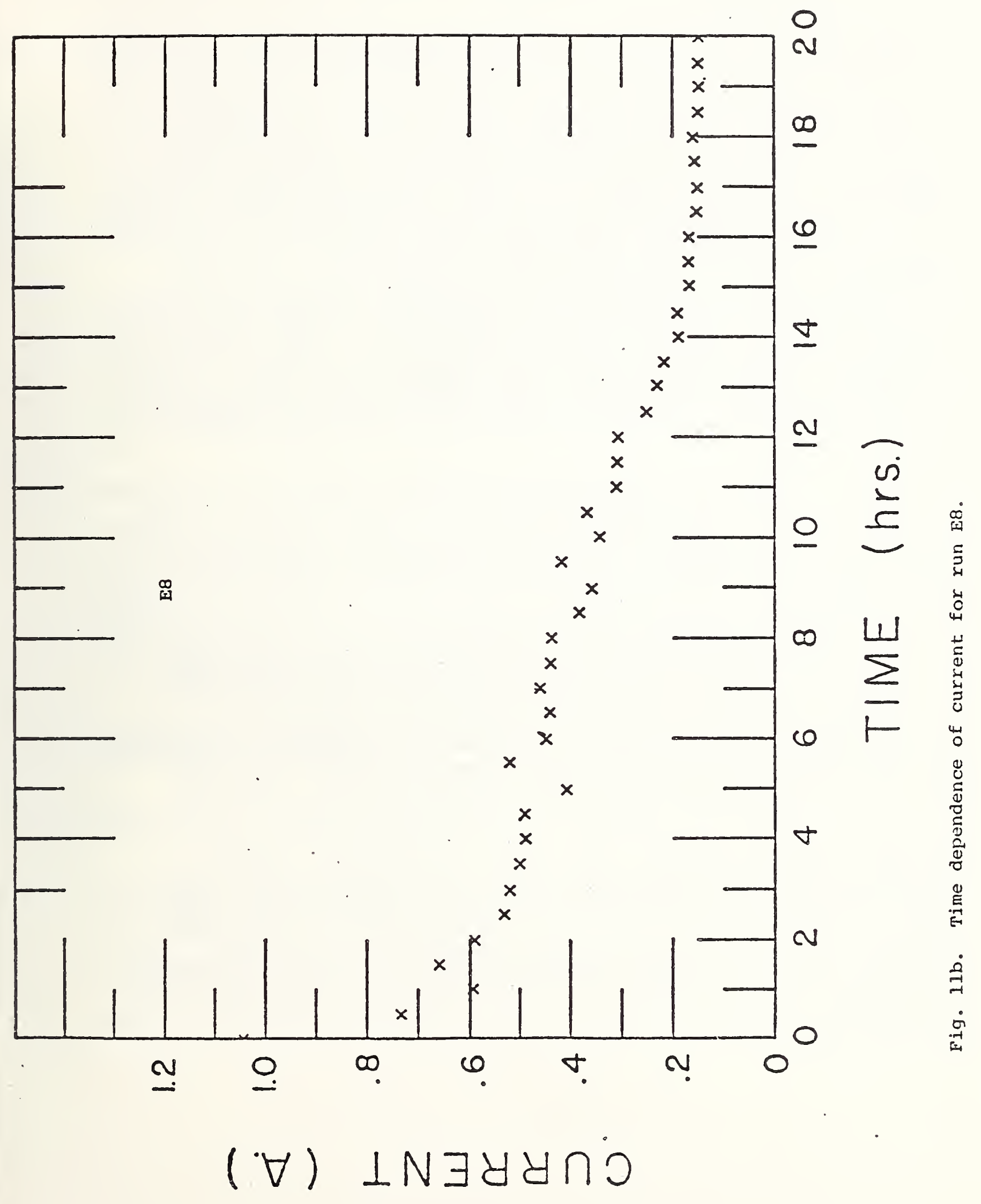


4. Seed SIag Interactions

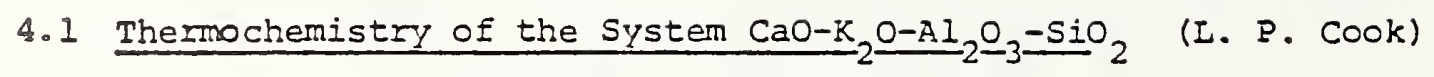

Subsolidus phase relations in the quaternary system CaO-K $\mathrm{O}-\mathrm{Al}_{2} \mathrm{O}_{3}-\mathrm{SiO}_{2}$ have been presented in earlier reports $[1,2,3]$, and for convenience are shown in Fig. 12, where tie lines involving $\mathrm{Ca}_{2} \mathrm{SiO}_{4}$ and $\mathrm{Ca}_{3} \mathrm{Si}_{2} \mathrm{O}_{7}$ have been added $[4,5]$. Abbreviations for chemical tormulae are given in Table 1. As explained previously [1], these data when combined with the composition of invariant melts, can be used to calculate potassia activity coefficients, in addition to giving more direct information on the behavior of Western MHD channel slags. Mixtures of each quaternary four phase equilibrium assemblage have been prepared and held at 10 to $50{ }^{\circ} \mathrm{C}$ or more above the temperature of minimum melting, to produce sufficient melt for microchenical analysis (this was not possible for some of the ccmpositions involving $\mathrm{KAISi}_{3} \mathrm{O}_{8}$, due to kinetic factors). Weight percentages of $\mathrm{CaO}, \mathrm{K}_{2} \mathrm{O}, \mathrm{Al}_{2} \mathrm{O}_{3}$ and $\mathrm{SiO}_{2}{ }^{8}$ in the melt phase were estimated using an $\mathrm{I} / \mathrm{I}_{0}$ approximation from comparison with a series of standard glasses. Results ${ }^{\circ}$ are giver. in Table 2. It is hoped that compositions can be refined by further experimentation and application of a Bence-Albee quantitative analysis routine.

Using more recent themochemical data [6] the calculations begun in a previous quarterly report [1] have been repeated and expanded for four-phase volumes in Fig. 12, according to reactions in Table 3. As Figure 13 shows, calculated potassia pressures are nearly in agreement with the order predicted from topology, at, least at $1200 \mathrm{~K}$ (referring to Table 3 , the precicted order of decreasing $P_{K}^{2} \cdot P_{0}^{1} /_{2}^{2}$ is $\left.13,12,4,3,2,1[5,7],[6,8], 9,11,10\right)$. This is in marked contrast to calculations performed in a previous quarterly report [1], made using earlier thermochemical data [7], which, though of high precision, have recently been shown to possess a systematic error [8]. However in view of the revised calculations graphed in Figure 13,it is no longer necessary to postulate entry of $\mathrm{K}$ in the gehlenite structure [1], in agreement witin the failure of all efforts to synthesize K-containing gehlenites experimentally. The phase diagram presented by Nurse and Midgley [9] must therefore be regarded as open to question (Yoder [10] has disproved the diagran proposed for the sodium analogue).

The dashed curves in Fig. 13 (with labels in parentheses) indicate equilibria which do not fall in the correct order with respect to the others, and have higher values of $\mathrm{P}_{\mathrm{K}}^{2} \cdot \mathrm{P}^{1} /{ }^{2}$ than allowed by the topology, suggesting metastability. It is significant that two of these involve tridymite, and the other two involve $\mathrm{CA}_{6}$. Solution of $\mathrm{KAIO}_{2}$ in the tridymite structure, expected on crystal-chemical grounds, is thus also predicted. indirectly from the themodynamics. Similarly, $\mathrm{CA}_{6}$ has a structure like that of $\mathrm{B}-\mathrm{Al}_{2} \mathrm{O}_{3}$, and substantial entry of potassiun into the structure could also be expected. 
4.2 Thermochemistry of the System $\mathrm{K}_{2} \mathrm{O-MgO-AI}_{2} \mathrm{O}_{3} \frac{-S i O}{2}_{2}$ (I. P. Cook)

Subsolidus phase relations in the quaternary system $\mathrm{K}_{2} \mathrm{O}-\mathrm{MgO}-\mathrm{Al}_{2} \mathrm{O}_{3}-\mathrm{SiO}_{2}$, derived from the experimental work of Schairer [11], Euth [12] and experiments in this laboratory [2], are shown in Fig. 14 for reference; abbreviations for chemical formulae are given in Table 4. Calculations begun in a previous quarterly report [I] have been carried out in more complete form, according to the reaction schemes in Table 5 below, and using the more recent thermochemical data [6]. The assumption of no Mg solid solution in tectosilicate phases appears to be justified for these relatively MgO-poor four-phase volumes, based upon experimental data for crystal/liquid fractionation in $\mathrm{K}_{2} \mathrm{O}-\mathrm{MgO}-\mathrm{FeO}-\mathrm{CaO}-\mathrm{Al}_{2} \mathrm{O}_{3}-\mathrm{SiO}_{2}$ synthetic slags. This may not be true for melts and solids côxisting with magnesia.

Calculated reaction curves are shown in Figure 15. Agreement with the orcer predicted from topology is reasonably good (referring to Table 5, the predicted order of decreasing $\left.\mathrm{P}_{\mathrm{K}}^{2} \cdot \mathrm{P}_{2}^{1}\right)^{2}$ is $\left.1,[2,3],[4,6],[5,8],[7,10], 9\right)$. Again, dashed curves represent higher potassia pressures (metastable) than allowed by the topology. Significantly, two of the three curves involve tridymite and the third is a four-phase volume metastable with respect to the occurrence of $\mathrm{Mg}_{2} \mathrm{Al}_{4} \mathrm{SiO}_{10}$. Subsequent calculations will therefore include estimated data for $50^{\circ}$.

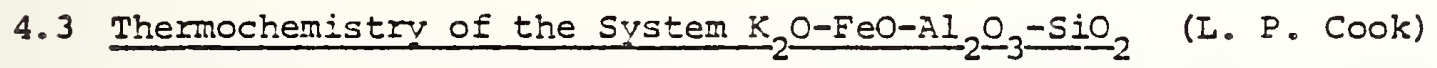

Subsolidus phase relations for a part of the quaternary system $\mathrm{K}_{2} \mathrm{O}-\mathrm{FeO}$ $\mathrm{Al}_{2} \mathrm{O}_{3}-\mathrm{SiO}_{2}$ are shown in Figure 16, based upon data of Roedder [13] and Muan and Csborn [14]. Abbreviations are given in Table 6. The iron analogue of $\mathrm{MgSiO}_{3}$ is unstable at low pressure, and an iron analogue of $\mathrm{Mg}_{2} \mathrm{Al}_{4} \mathrm{SiO}_{10}$ has not been reported in symthetic systems. Reaction schemes used to calculate curres in Eigure 17 are giver, in Table 7 . The topology of Figure 16 gives, in order of decreasing $\mathrm{P}_{\mathrm{K}}^{2} \cdot \mathrm{P}_{\mathrm{O}}^{1 / 2}$, the following sequence: $2,1,3$, which agrees well with that in Figure 17 .

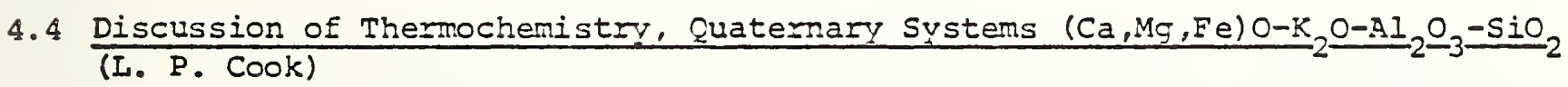

The themochemical calculative approach has important limitations which must be mentioned before ary discussion:

1. Certain thermochemical data have had to be estimated, including $C p(T)$ for $\mathrm{FeAl}_{2} \mathrm{O}_{4} ; \mathrm{S}_{298}^{\circ}$ and $\mathrm{CP}(\mathrm{T})$ for $\mathrm{Ca}_{3} \mathrm{Si}_{2} \mathrm{O}_{7} ;$ and $\Delta \mathrm{H}_{\mathrm{F}, 298^{\circ}}^{\circ} \mathrm{S}_{298}^{\circ}$ and $\mathrm{CP}(\mathrm{T})$ for orthorhombic $\mathrm{KIISiO}_{4}$ and $\mathrm{CaAl}_{12}{ }_{19^{\circ}}$

2. Unaccounted for solid solution may lead to erroneous results, esfecially when entry of $\mathrm{K}$ into a structure is involved. 
With these restrictions in mind, it may be noted that the compositional volumes involving $\mathrm{KAISiO}_{4}$ with $\mathrm{Ca}_{2} \mathrm{SiO}_{4}, \mathrm{Fe}_{2} \mathrm{SiO}_{4}$ and $\mathrm{Mg}_{2} \mathrm{SiO}_{4}$ occupy similar compositional space and thus may be compared with regard to order of magnitude potassia pressures, as has been done in Figure 18. CKAS pressures appear to fall close to the plasma equilibration curse for the volume $\mathrm{C}_{2} \mathrm{~S} / \mathrm{C}_{3} \mathrm{~S}_{2} / \mathrm{KIs} / \mathrm{Ge}$. The FKAS curve for $\mathrm{He} / \mathrm{Fa} / \mathrm{Kls} / \mathrm{Lc}$ intersects the plasma curve at the high temperature end, whereas the analogous MKAS curve doesn't intersect it at all. On this basis, and from comparison of $\mathrm{Figures}$ 13 \& 14, CaO appears on a mole basis to have a more pronounced effect on $k_{2} O$ pressures than MgO (a spread of 10 orders of magnitude at $1600 \mathrm{~K}$ as opposea. to 5). However, it may be significant that only for the more CaO-rich compositions can it be said that $k_{2} \circ$ pressures are significantly higher for CRAS than MKAS (and possibly FKAS)? Thus this effect may be important in the most calciun-rich of the Western-type channel slags [5].

\section{References}

1. H.P.R. Frederikse, T. Negas and S.J. Schneider, Development, Testing and Evaluation of MHD Marerials, NBS Quarterly Report March-June 1977, p. 25-46.

2. H.P.R. Frederikse, T. Negas and S.J. Schneider, Development, Testing and Evaluation of MHD Materials, NBS Quarterly Report July-September 1977 , p. $31-38$.

3. H.P.R. Frederikse, T. Negas and S.J. Schneider, Development, Testing and Evaluation of MDD Materials, NBS Quarterly Report October-December 1977, p. 25 .

4. E.M. Levin, C.R. Robbins and H.F. MCMurdie, 1964, Phase Diagrans for Ceramists: Columbus, An. Ceram. Soc., Fig. 630.

5. L.P. Cook, E.R. Plante, T. Negas, R.S. Roth and C.D. Olson, 1976, Crystallization and Vaporization Studies on Synthetic Coal Slag Compositions, Proc. 15th Symp. Eng. Aspects MHD, Philadelphia, P.II.4.I-II.4.6.

6. R.A. Robie, B.S. Hemingway, and J.R. Fischer, Thermodynamic Properties of Minerals and Related Substances at $298.15 \mathrm{~K}$ and 1 bar ( $10^{5}$ pascal) Pressure and at Higher Temperatures: U.S. Geol. Surv. Bull. 1452.

7. R.A. Robie and D.R. Waldbaum, 1968, Thermocynamic Properties of Minerals and Related Substances at $298.15 \mathrm{~K}\left(25.0^{\circ} \mathrm{C}\right.$ ) and one atmosphere ( 1.013 bars) Pressure and at Higher Temperatures: U.S. Geol. Surv. BuIl. 1259.

8. B.S. Hemingway and R.A. Robie, 1977, Enthalpies of Formation of Low Albite (NaAlsi $\mathrm{O}_{8}$ ), Gibbsite $\left(\mathrm{AI}(\mathrm{OH})_{3}\right.$ ) and $\mathrm{NaAlO}_{2}$; Revised Values for $\Delta \mathrm{H}_{f}^{\circ}, 298$ and $8 \mathrm{G}_{f}^{\circ}, 298$ of Some Aluminosilicate Minerals: J. Res. U.S. GesI? Surv., 者: 298 , p. 413-429. 
9. R.W. Nurse and H.G. Midgley, 1953, Studies on the Melihite Solid Solutions, J. Iron and Steel Inst., 174, 121-131.

10. M.S. Yoder, 1973, Melilite Stability and Paragenesis', Fortschm. Miner. 50, 140-173.

11. J.F. Schairer, 1954, J. Am. Ceran. Soc., V. 37, p. 526.

12. พ.C. Luth, 1967, J. Am. Ceram. Soc., v. 50, p. 174 .

13. E. Roedder, 1951, Am. Mineral., V. 36, p. 283.

14. E.M. Levin, C.R. Robbins and E.F. MCMurdie, 1964, Phase Diagrams for Ceramists: Columbus, Amer. Ceram. Soc., Fig. 696. 
Table 1. Abbreviations, $\mathrm{CaO}-\mathrm{K}_{2} \mathrm{O}-\mathrm{Al}_{2} \mathrm{O}_{3}-\mathrm{SiO}_{2}$

$$
\begin{aligned}
& \mathrm{c}_{2} \mathrm{~s}=\mathrm{Ca}_{2} \mathrm{SiO}_{4} \quad \operatorname{trd}=\mathrm{SiO}_{2} \\
& c_{3} s_{2}=\mathrm{Ca}_{3} \mathrm{Si}_{2} \mathrm{O}_{7} \quad \mathrm{ksp}=\mathrm{KAISi}_{3} \mathrm{O}_{8} \\
& \text { wo }=\mathrm{CaSiO}_{3} \quad 1 \mathrm{C}=\mathrm{KAISi}_{2} \mathrm{O}_{6} \\
& \text { ge }=\mathrm{Ca}_{2} \mathrm{Al}_{2} \mathrm{SiO}_{7} \quad \mathrm{kIs}=\mathrm{KAlSiO}_{4} \\
& \text { an }=\operatorname{CaAl}_{2} \mathrm{Si}_{2} \mathrm{O}_{8} \quad \mathrm{mu}=3 \mathrm{Al}_{2} \mathrm{O}_{3} \cdot 2 \mathrm{SiO}_{2} \\
& \mathrm{ca}_{6}=\mathrm{CaAl}_{12} \mathrm{O}_{19} \quad \text { cor }=\mathrm{Al}_{2} \mathrm{O}_{3}
\end{aligned}
$$

Table 2. Estimated Compositions of CaO- $\mathrm{K}_{2} \mathrm{O}-\mathrm{Al}_{2} \mathrm{O}_{3}-\mathrm{SiO}_{2}$ Invariant Melts.

Four Phase Volume

Approximate wt\% $\mathrm{K}_{2} O$

1. $\mathrm{kls} / \mathrm{cor} / \mathrm{ca}_{2} / \mathrm{an}$

12.5

2. $\mathrm{kls} / \mathrm{ca}_{6} / \mathrm{ge} / \mathrm{an}$

$8 . \dot{8}$

3. $\mathrm{kls} / \mathrm{lc} / \mathrm{ge} / \mathrm{an}$

12.3

5. $\mathrm{kls} / \mathrm{lc} / \mathrm{cor} / \mathrm{an}$

1.7

7. $1 c / g e / a n$ /wo

2.6 
Table 3. Equilibria in the system CaO- $\mathrm{K}_{2} \mathrm{O}-\mathrm{Al}_{2} \mathrm{O}_{3}-\mathrm{SiO}_{2}$.

$\begin{array}{ll}1 & \mathrm{kls} / \mathrm{cor}_{\mathrm{ca}} / \mathrm{an} \\ 2 & \mathrm{kls} / \mathrm{ca}_{6} / \mathrm{ge} / \mathrm{an} \\ 3 & \mathrm{kls} / \mathrm{lc} / \mathrm{ge} / \mathrm{ar} \\ 4 & \mathrm{kls} / \mathrm{lc} / \mathrm{ge} / \mathrm{wo} \\ 5 & \mathrm{kls} / \mathrm{lc} / \mathrm{cor} / \mathrm{an} \\ 6 & 1 \mathrm{c} / \mathrm{cor} / \mathrm{mu} / \mathrm{an} \\ 7 & \mathrm{lc} / \mathrm{ge} / \mathrm{an} / \mathrm{wo} \\ 8 & \mathrm{lc} / \mathrm{ksp} / \mathrm{an} / \mathrm{wo} \\ 9 & \mathrm{lc} / \mathrm{ksp} / \mathrm{mu} / \mathrm{an} \\ 10 & \mathrm{ksp} / \mathrm{mu} / \mathrm{an} / \mathrm{trd} \\ 11 & \mathrm{ksp} / \mathrm{an} / \mathrm{wo} / \mathrm{trd} \\ 12 & \mathrm{kls} / \mathrm{c}_{3} \mathrm{~s}_{2} / \mathrm{ge} / \mathrm{wo} \\ 13 & \mathrm{kls} / \mathrm{c}_{2} \mathrm{~s} / \mathrm{c}_{3} \mathrm{~s}_{2} / \mathrm{ge}\end{array}$

$$
\begin{aligned}
& 2 \mathrm{kls}+\mathrm{ca}_{6}=1 \mathrm{an}+6 \mathrm{cor}+2 \mathrm{k}+1 / 2 \mathrm{o}_{2} \\
& 34 \mathrm{kls}+12 \mathrm{ge}=1 \mathrm{ca}_{5}+23 \mathrm{an}+34 \mathrm{~K}+17 / 2 \mathrm{O}_{2} \\
& 1 \mathrm{kls}+1 \mathrm{lc}+\mathrm{Ige}=2 \mathrm{an}+2 \mathrm{~K}+1 / 2 \mathrm{O}_{2} \\
& 5 \mathrm{kls}+2 \mathrm{wo}=1 \mathrm{ge}+3 \mathrm{lc}+2 \mathrm{~K}+1 / 2 \mathrm{O}_{2} \\
& 4 \mathrm{kls}=2 \mathrm{lc}+1 \mathrm{cor}+2 \mathrm{~K}+1 / 2 \mathrm{O}_{2} \\
& 2 \mathrm{lc}+5 \operatorname{cor}=2 \mathrm{mu}+2 \mathrm{~K}+1 / 2 \mathrm{O}_{2} \\
& 3 g e+41 c^{\circ}=5 a n+1 w o+4 \mathrm{~K}+\mathrm{O}_{2} \\
& 1 w o+51 c=3 k s p+1 a n+2 \mathrm{~K}+1 / 2 \mathrm{O}_{2} \\
& 161 \mathrm{c}=1 \mathrm{mu}+10 \mathrm{ksp}+6 \mathrm{~K}+3 / 2 \mathrm{O}_{2} \\
& 6 \mathrm{ksp}=1 \mathrm{mu}+16 \mathrm{trd}+6 \mathrm{k}+3 / 2 \mathrm{O}_{2} \\
& 1 w o+2 k s p=5 \operatorname{trd}+a n+2 k+1 / 2 O_{2} \\
& 18 \mathrm{kls}+27 \mathrm{c}_{3} \mathrm{~s}_{2}=9 \mathrm{ge}+63 \mathrm{wo}+18 \mathrm{k}+9 / 2 \mathrm{o}_{2} \\
& 12 k l s+42 c_{2} s=6 g e+24 c_{3} s_{2}+12 k+3 o_{2}
\end{aligned}
$$

Table 4. Abbreviations, $\mathrm{MgO}_{2} \mathrm{~K}_{2} \mathrm{O}-\mathrm{Al}_{2} \mathrm{O}_{3}-\mathrm{SiO}_{2}$

$$
\begin{array}{ll}
\text { fo }=\mathrm{Mg}_{2} \mathrm{SiO}_{4} & \operatorname{trd}=\mathrm{SiO}_{2} \\
\mathrm{en}=\mathrm{MgSiO}_{3} & \mathrm{ksp}=\mathrm{KAIS}_{3} \mathrm{O}_{8} \\
\mathrm{~cd}=\mathrm{Mg}_{2} \mathrm{Al}_{4} \mathrm{Si}_{5} \mathrm{O}_{18} & \mathrm{lc}=\mathrm{KAIS}_{2} \mathrm{O}_{6} \\
\mathrm{sp}=\mathrm{MgAl}_{2} \mathrm{O}_{4} & \mathrm{kls}=\mathrm{KAISiO}_{4} \\
\mathrm{sa}=\mathrm{Mg}_{2} \mathrm{Al}_{4} \mathrm{SiO}_{10} & \mathrm{mu}=\mathrm{AAI}_{2} \mathrm{O}_{3} \cdot 2 \mathrm{SiO}_{2} \\
& \mathrm{cor}=\mathrm{Al}_{2} \mathrm{O}_{3}
\end{array}
$$


Table 5. Equilibria in the system $\mathrm{MgO}-\mathrm{K}_{2} \mathrm{O}-\mathrm{Al}_{2} \mathrm{O}_{3}-\mathrm{SiO}_{2}$.

$\begin{array}{cl}1 & \mathrm{sp} / \mathrm{fo} / \mathrm{kls} / \mathrm{lc} \\ 2 & \mathrm{sp} / \mathrm{fo} / \mathrm{cd} / \mathrm{lc} \\ 3 & \mathrm{sp} / \mathrm{kls} / \mathrm{lc} / \mathrm{cor} \\ 4 & \mathrm{fo} / \mathrm{lc} / \mathrm{cd} / \mathrm{en} \\ 5 & \mathrm{sp} / \mathrm{cd} / \mathrm{mu} / \mathrm{lc} \\ 6 & \mathrm{sp} / \mathrm{cor} / \mathrm{lc} / \mathrm{mu} \\ 7 & \mathrm{~cd} / \mathrm{mu} / \mathrm{lc} / \mathrm{ksp} \\ 8 & \mathrm{en} / \mathrm{cd} / \mathrm{lc} / \mathrm{ksp} \\ 9 & \mathrm{~cd} / \mathrm{trd} / \mathrm{mu} / \mathrm{ksp}\end{array}$

$$
\begin{aligned}
& \text { fo }+9 k 1 s=2 s p+5 l c+4 k+O_{2} \\
& 8 s p+201 c+5 f o=9 c d+20 \mathrm{~K}+5 \mathrm{O}_{2} \\
& 4 \mathrm{kls}=2 \mathrm{lc}+1 \mathrm{cor}+2 \mathrm{~K}+1 / 2 \mathrm{O}_{2} \\
& 5 f o+4 I c+c d+8 e n+4 K+O_{2} \\
& 6 l c+4 s p=m u+2 c d+6 \mathrm{~K}+3 / 2 \mathrm{o}_{2} \\
& 21 \mathrm{c}+5 \mathrm{cor}=2 \mathrm{mu}+2 \mathrm{~K}+1 / 2 \mathrm{O}_{2} \\
& 161 \mathrm{c}=1 \mathrm{mu}+10 \mathrm{ksp}+6 \mathrm{~K}+3 / 2 \mathrm{O}_{2} \\
& 4 e n+181 c=2 c d+10 k s p+8 \mathrm{~K}+2 \mathrm{O}_{2} \\
& 6 \mathrm{ksp}=1 \mathrm{mu}+16 \operatorname{trd}=6 \mathrm{~K}+3 / 2 \mathrm{O}_{2} \\
& 2 e n+4 k s p=c d+9 t r d+4 k+O_{2}
\end{aligned}
$$

Table 6. Abbreviations, $\mathrm{EeO}-\mathrm{K}_{2} \mathrm{O}-\mathrm{Al}_{2} \mathrm{O}_{3}-\mathrm{SiO}_{2}$

$$
\begin{array}{rl}
\mathrm{fa}=\mathrm{Fe}_{2} \mathrm{SiO}_{4} & 1 \mathrm{c}=\mathrm{KALSi}_{2} \mathrm{O}_{6} \\
\mathrm{he}=\mathrm{FeAl}_{2} \mathrm{O}_{4} & \mathrm{kls}=\mathrm{KAlSiO}_{4} \\
\mathrm{mu} & =3 \mathrm{Al}_{2} \mathrm{O}_{3} \cdot 2 \mathrm{SiO}_{2} \\
\mathrm{cor} & =\mathrm{Al}_{2} \mathrm{O}_{3}
\end{array}
$$

Table 7. Equilibria in the System EeO-K $\mathrm{O}_{2} \mathrm{O}-\mathrm{Al}_{2} \mathrm{O}_{3}-\mathrm{SiO}_{2}$.

1 cor/he/kIs/lc

$2 \mathrm{fa} / \mathrm{he} / \mathrm{kls} / \mathrm{lc}$

$3 \mathrm{he} / \mathrm{cor} / \mathrm{mu} / \mathrm{Ic}$

$$
\begin{aligned}
& 4 \mathrm{kls}=2 \mathrm{Ic}+1 \mathrm{cor}+2 \mathrm{~K}+\mathrm{I} / 2 \mathrm{O}_{2} \\
& \mathrm{fa}+9 \mathrm{kls}=2 \mathrm{he}+5 \mathrm{Ic}+4 \mathrm{~K}+\mathrm{O}_{2} \\
& 2 \mathrm{lc}+5 \mathrm{cor}=2 \mathrm{mu}+2 \mathrm{~K}+1 / 2 \mathrm{o}_{2}
\end{aligned}
$$




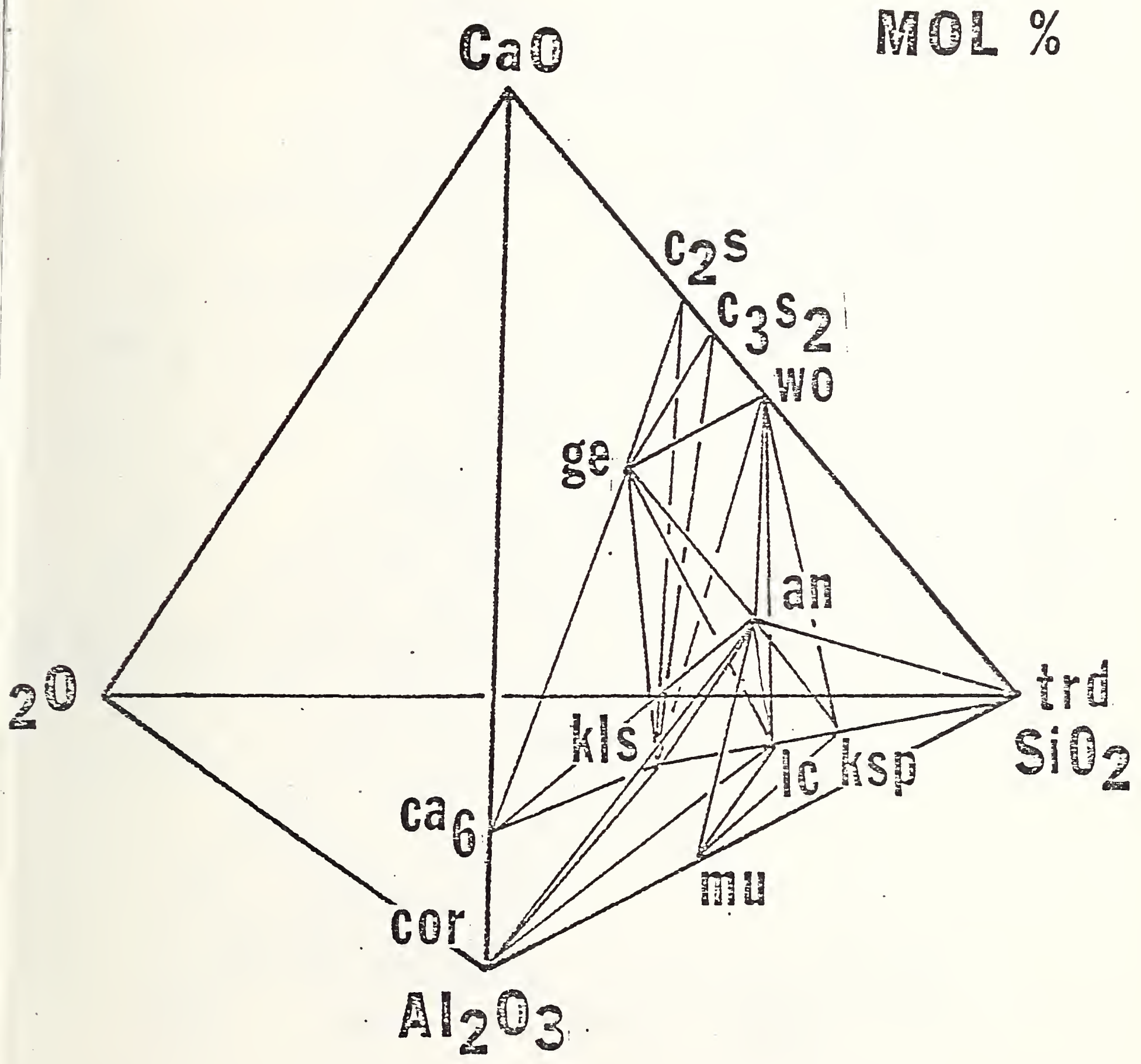

Figure 12. Subsolidus relations for synthetic CaO-K $\mathrm{K}_{2} \mathrm{O}-\mathrm{Al}_{2} \mathrm{O}_{3}-\mathrm{SiO}_{2}$ slags
(refer to Table 1 for abbreviations). 


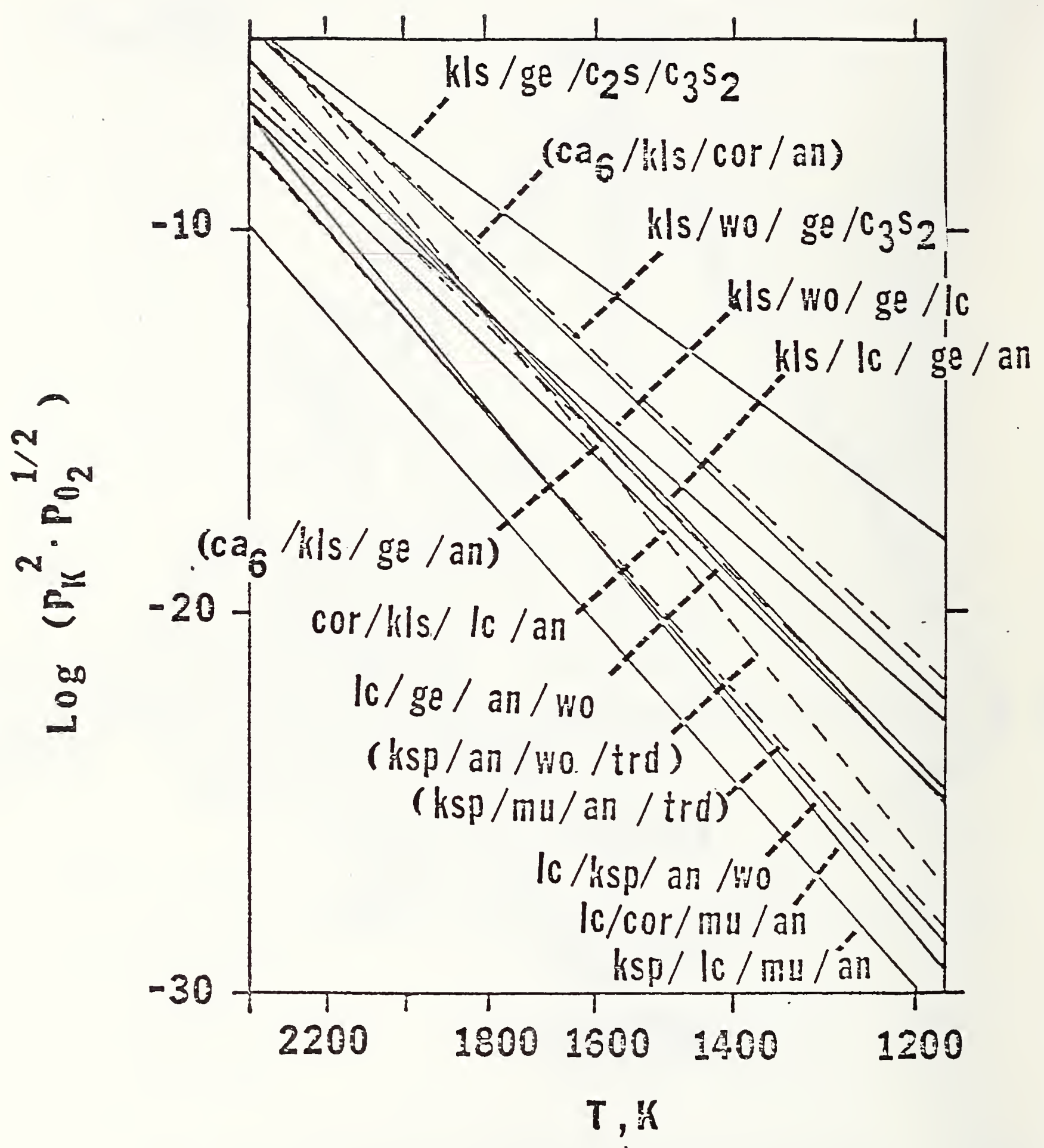

Figure 13. Calculated equilibrium potassia pressures for subsolidus assemblages in Figure 12. 


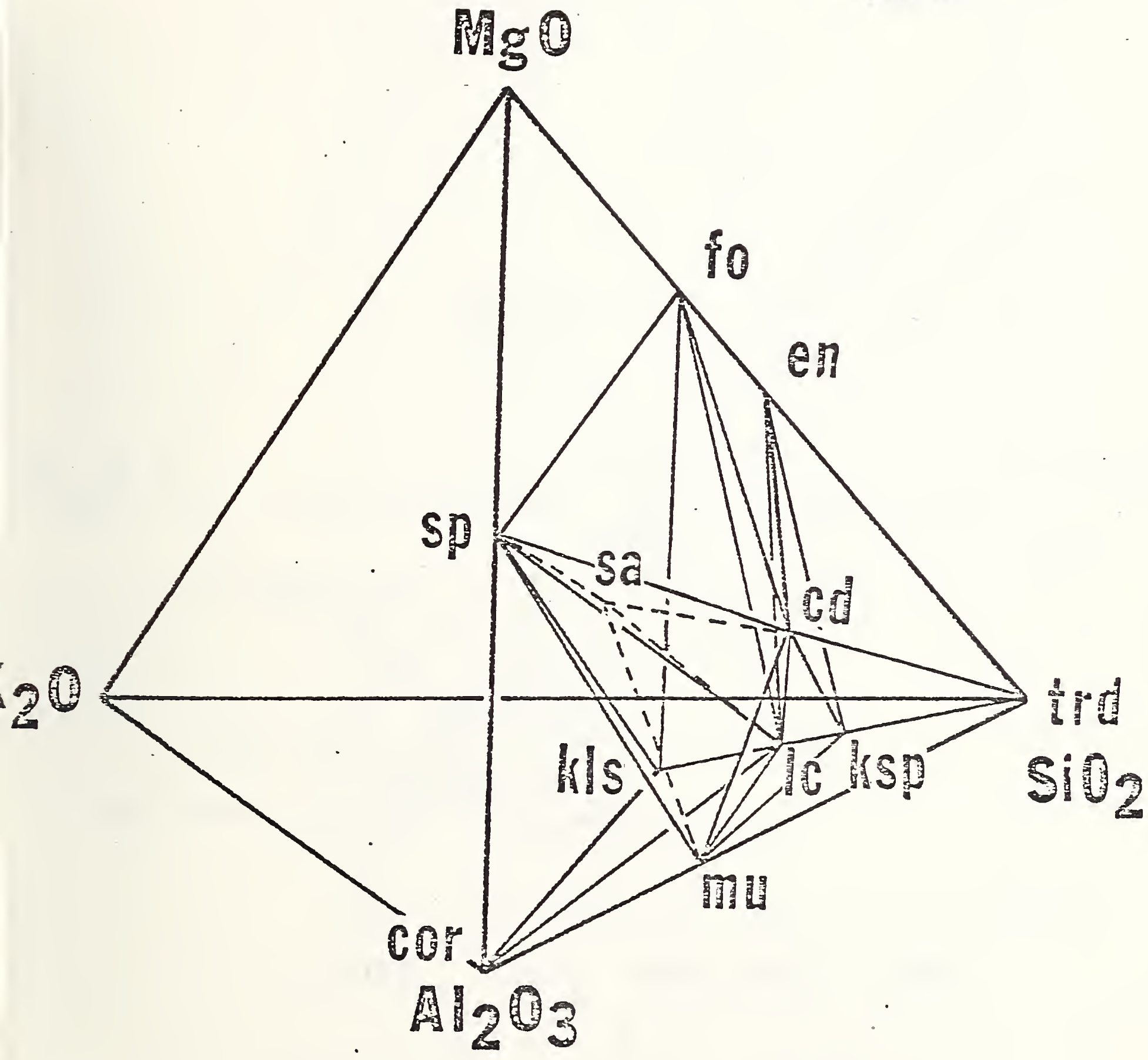

Figure 14. Subsolidus relations for synthetic MgO-K $\mathrm{O}_{2} \mathrm{-AI} \mathrm{O}_{3}-\mathrm{SiO}_{2}$ slags (refer to Table 4 for abbreviations). 


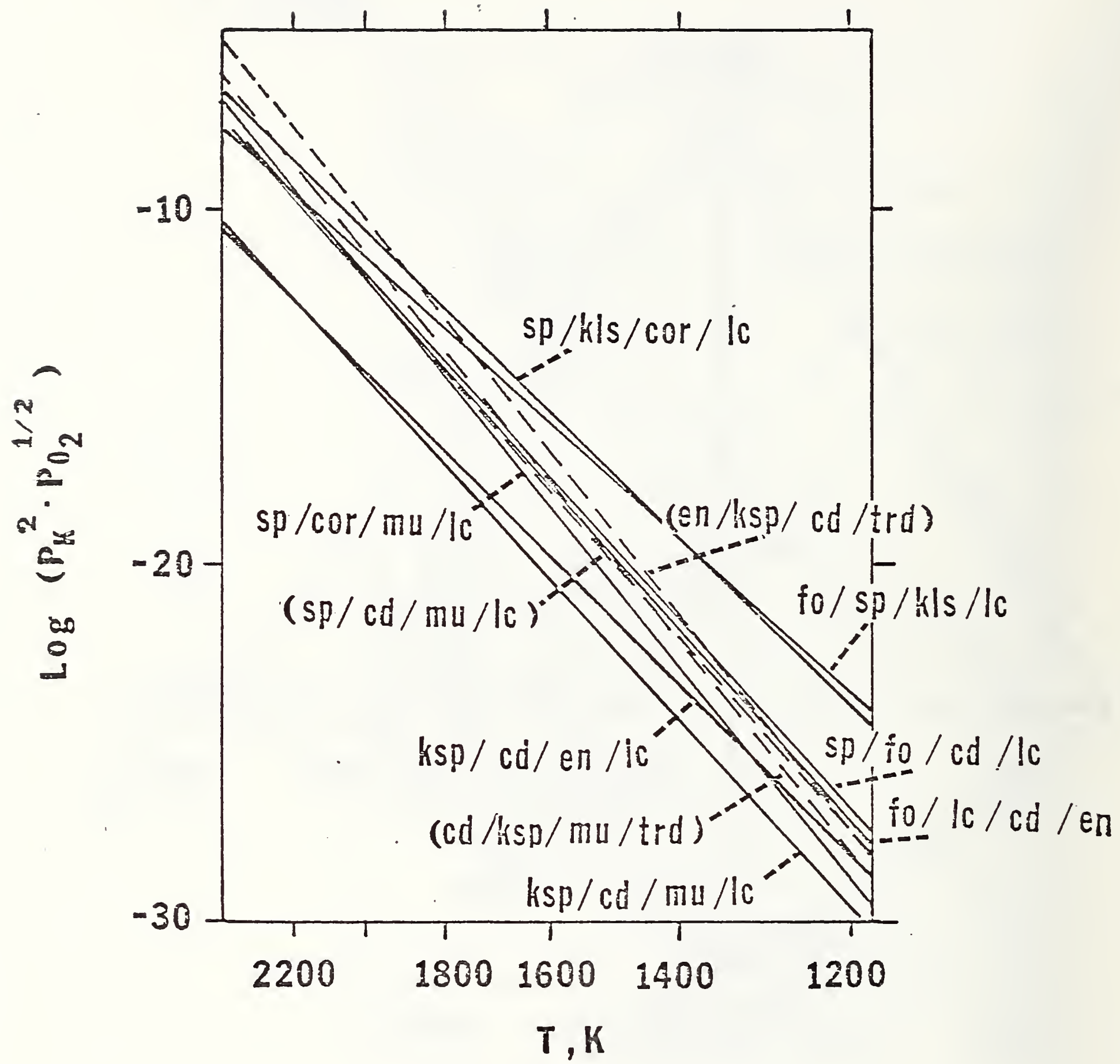

Figure 15. Calculated equilibrium potassia pressures for subsolidus assemblages in Figure 14. 


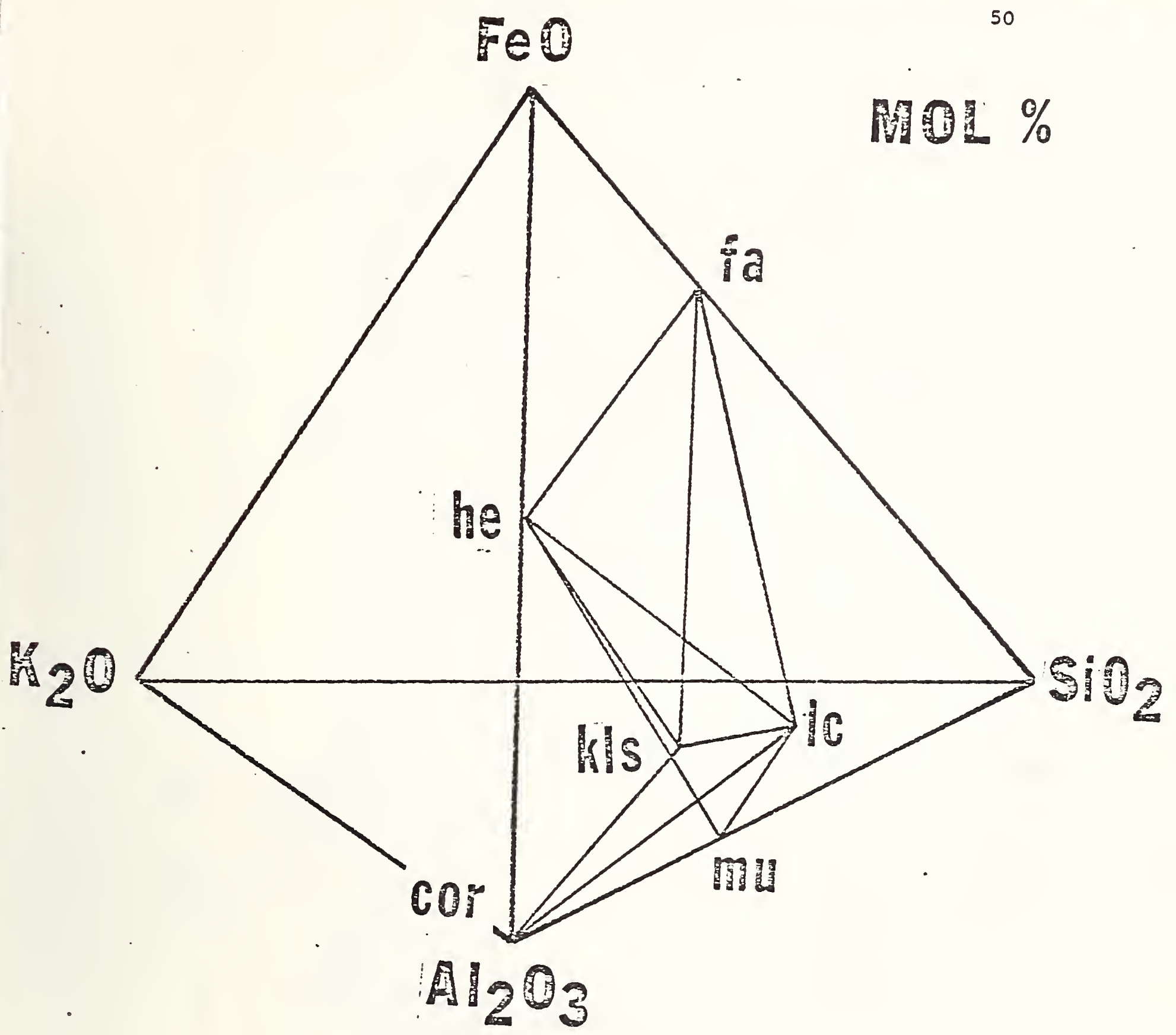

Figure 16. Subsolidus relations for synthetic FeO-K $\mathrm{K}_{2} \mathrm{O}-\mathrm{Al}_{2} \mathrm{O}_{3}-\mathrm{SiO} \mathrm{O}_{2}$ slags
(refer to Table 6 for abbreviations). 


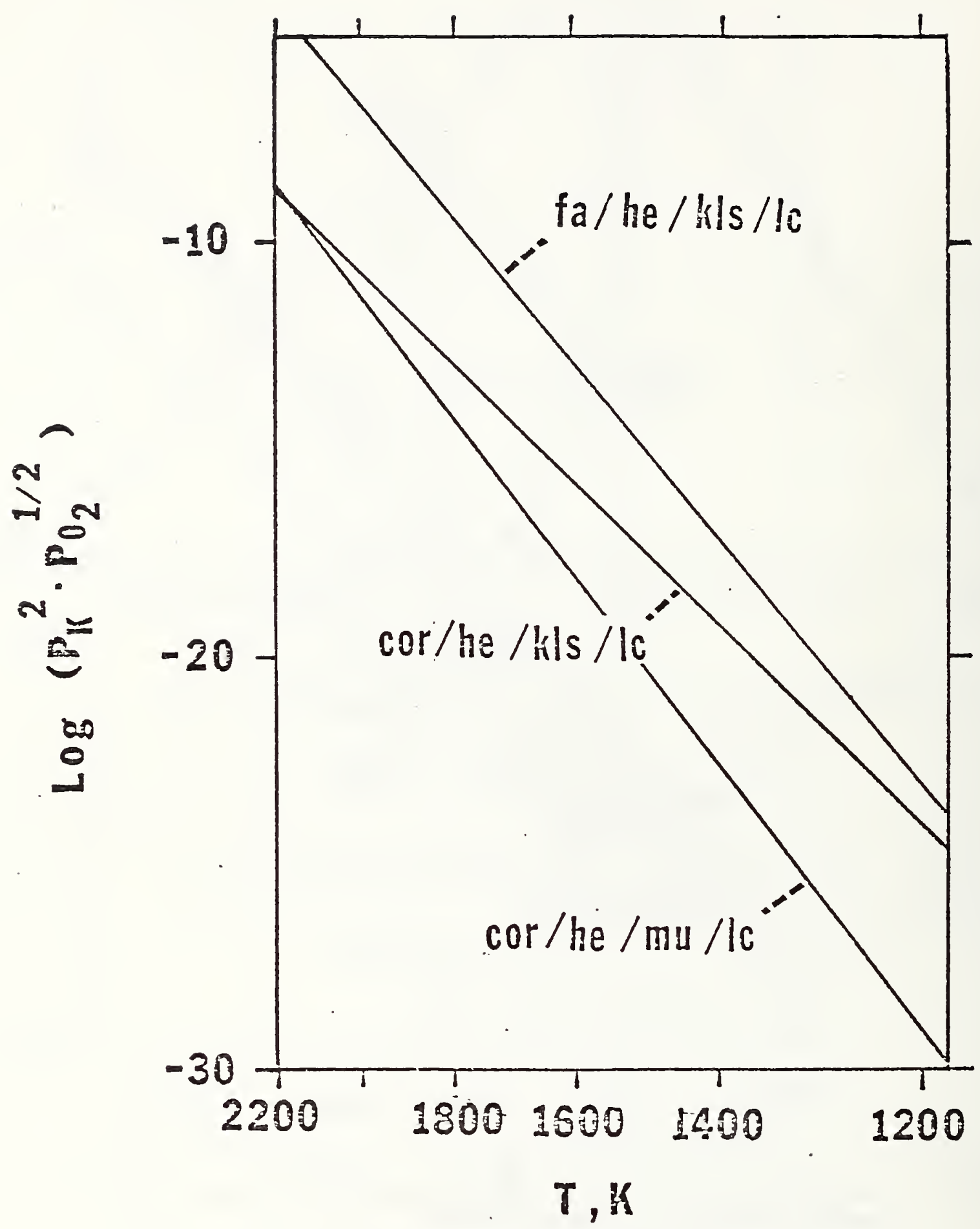

Figure 17. Calculated equilibrium potassia pressures for subsolidus assemblages in Figure 16. 


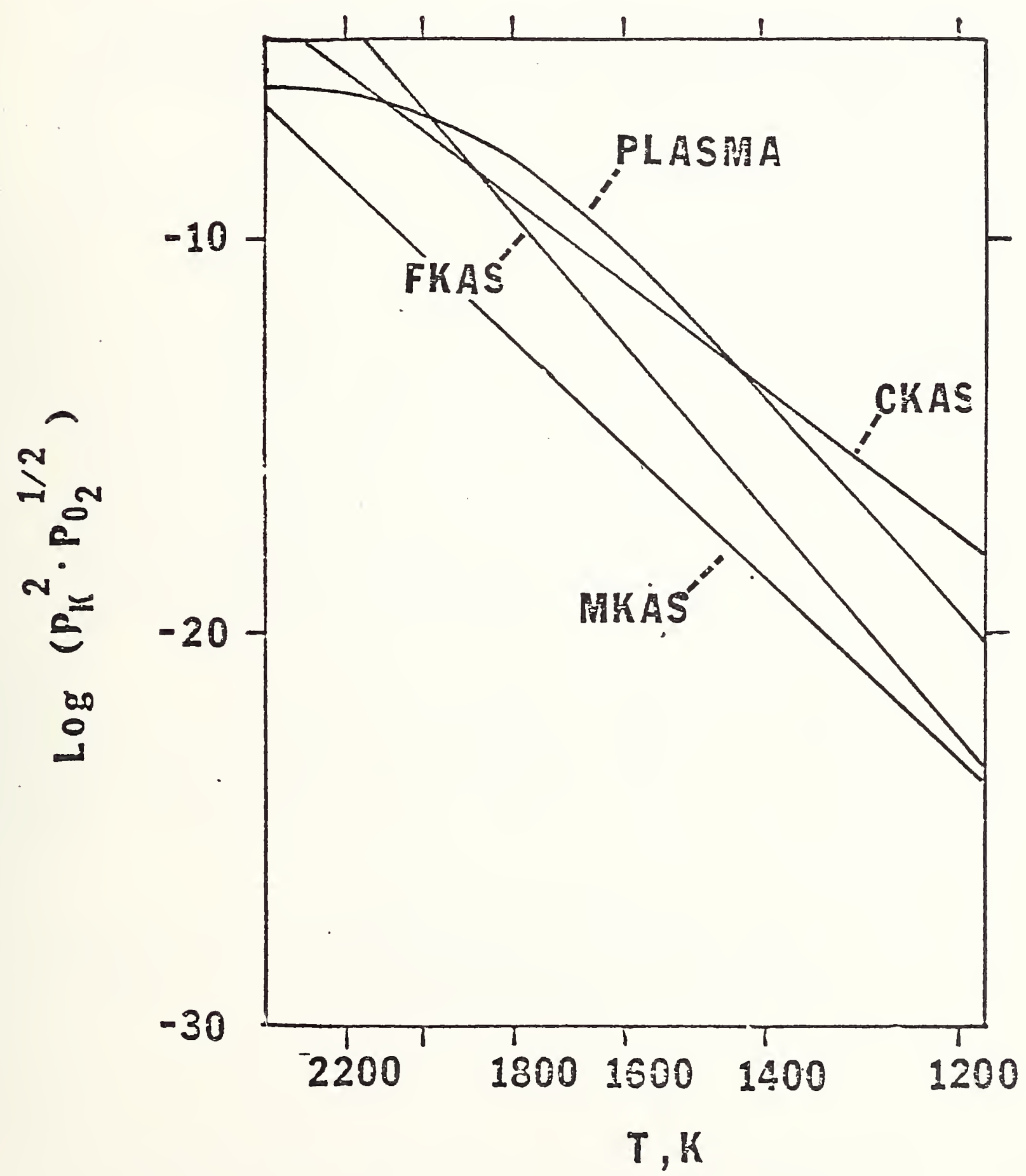

Figure 18. Comparison of calculated pressures for volumes containing $\mathrm{KAlSiO}_{4}+(\mathrm{Ca}, \mathrm{Mg}, \mathrm{Fe})_{2} \mathrm{SiO}_{4}$ with plasma. Plasma curve supplied by E. Dlante (NBS). 
TASK K. MATERIALS TESTING AND CHARACTERIZATION

1. Structural Analysis of Powdered and Solid Ceramics

a. X-ray Diffraction of MHD Materials (C. L. McDaniel)

During this quarter we received about 50 materials (powders, dense ceramics, etc.) from various external sources. These were analyzed by $x$-ray diffraction methods. Data, transmitted to the appropriate source, are shown in Table 1. 


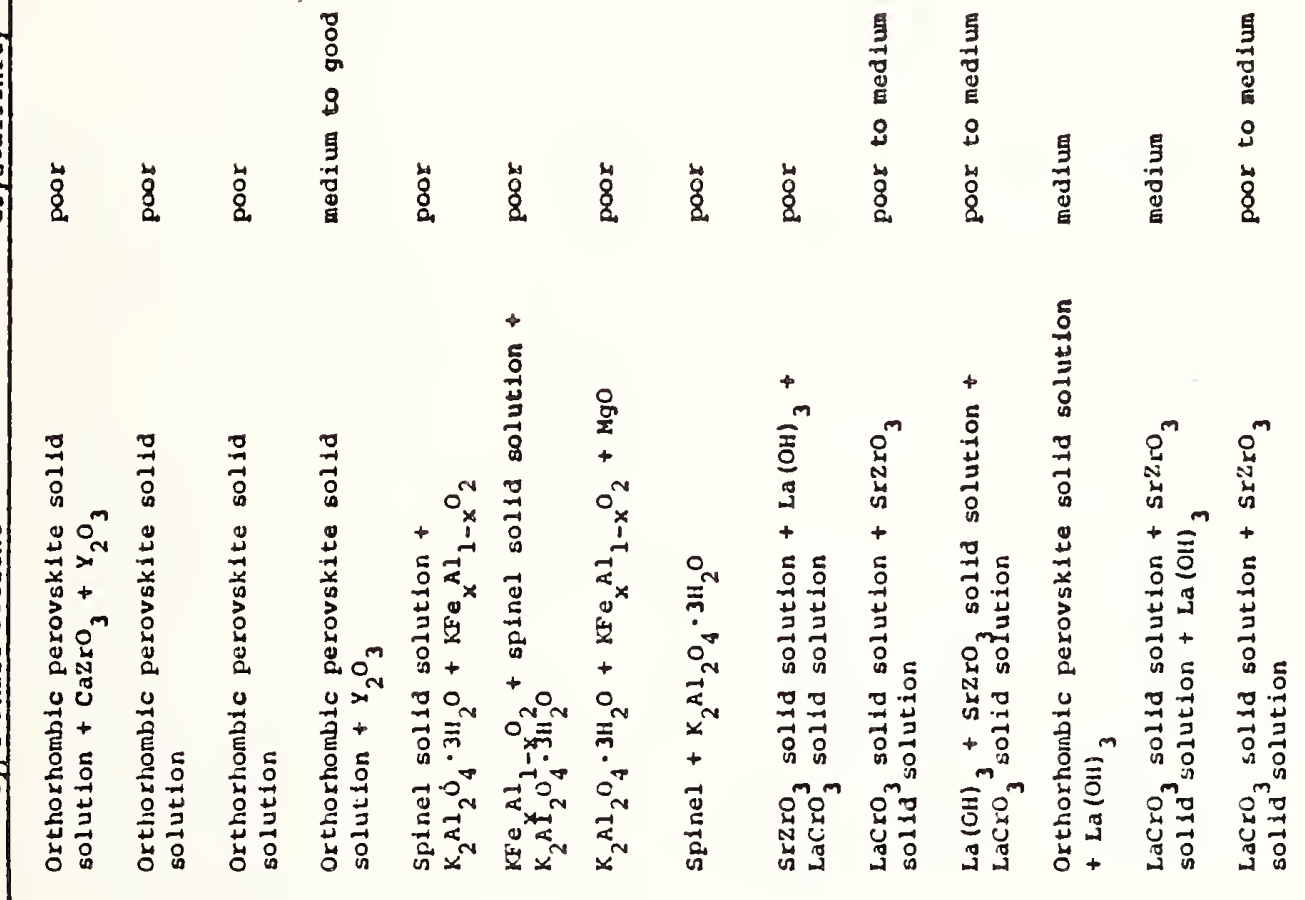

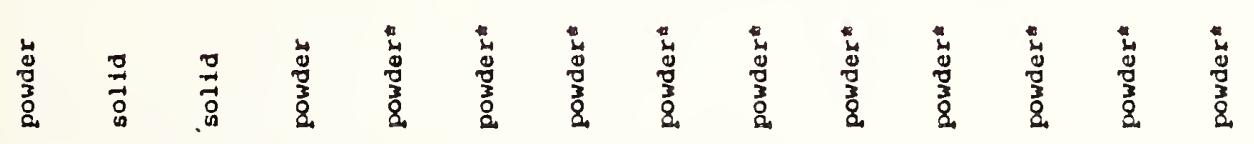

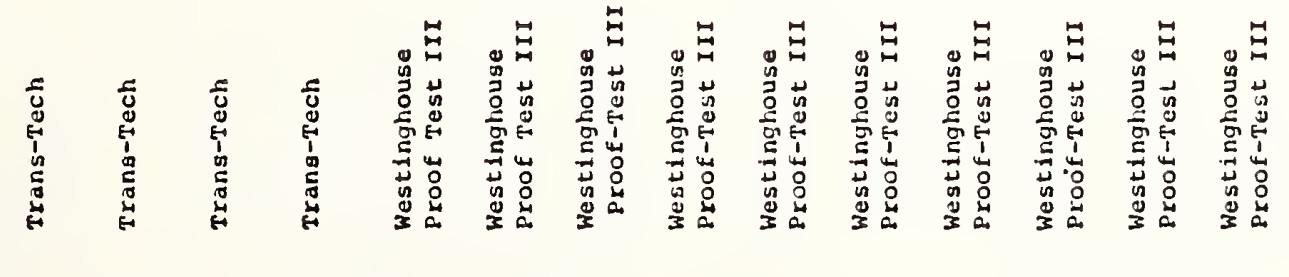




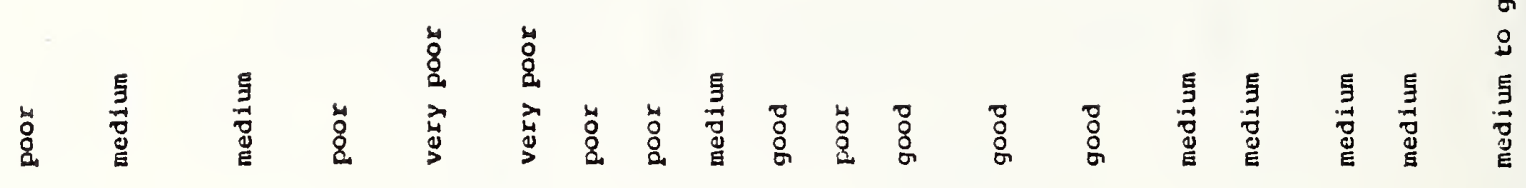

丞

过

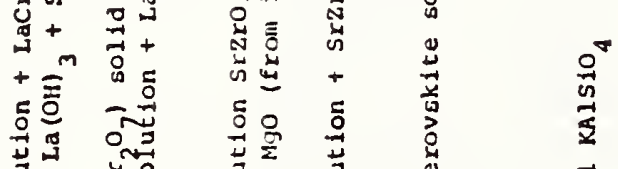

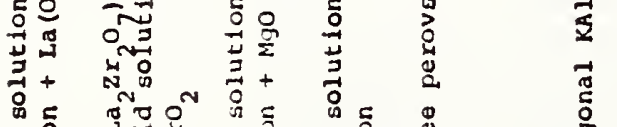

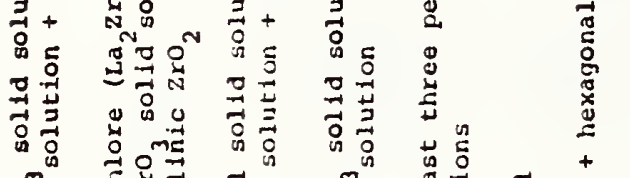

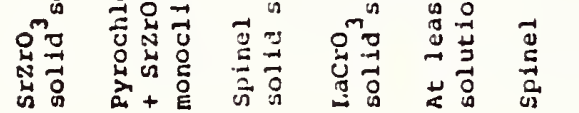

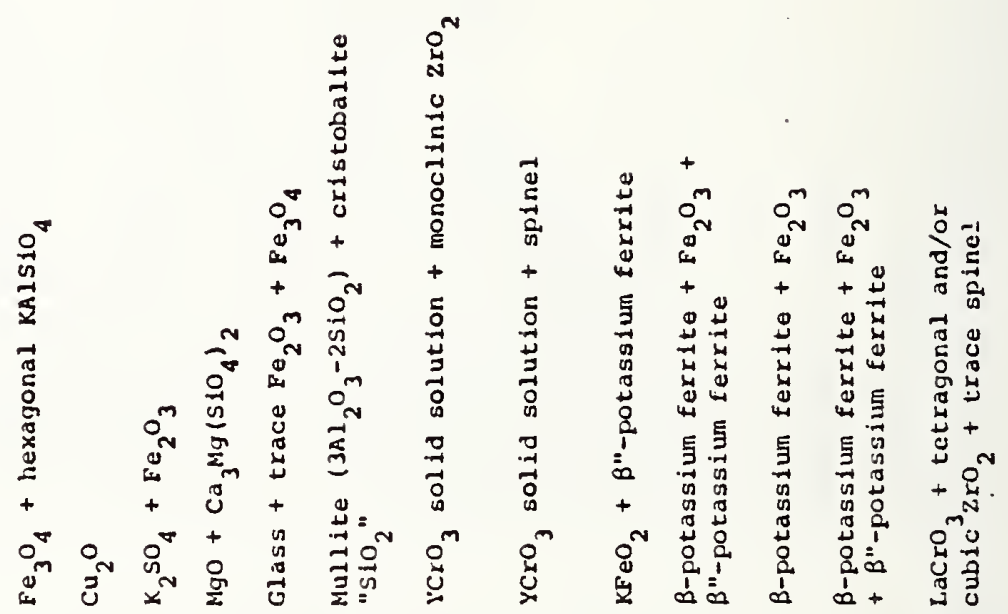

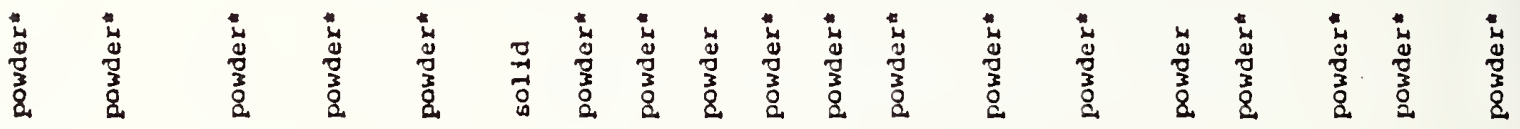

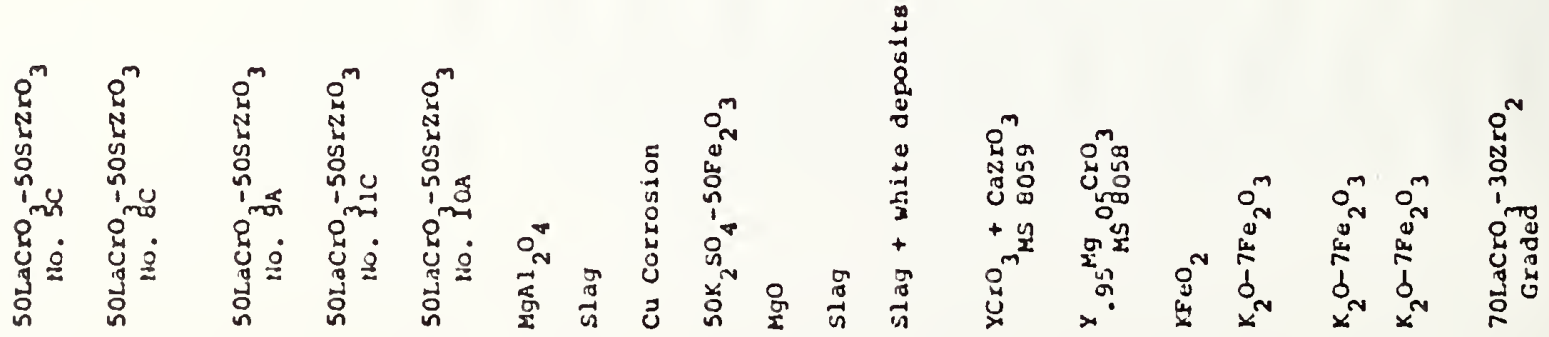




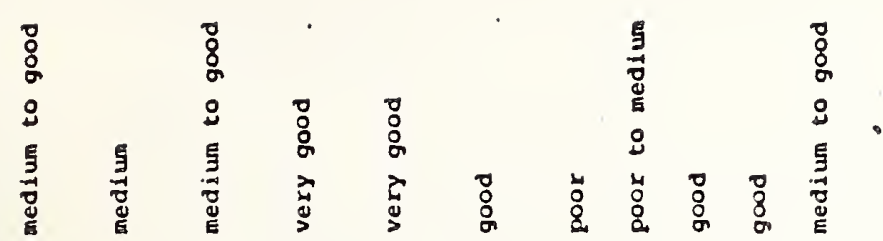

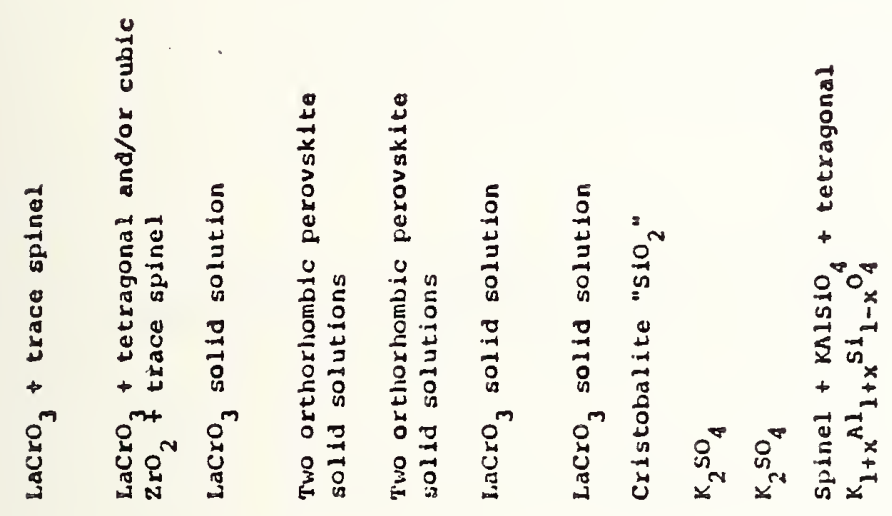

1111111

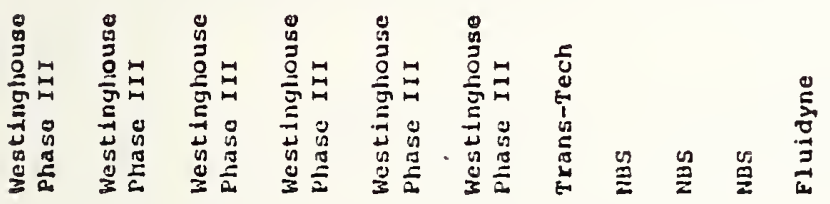

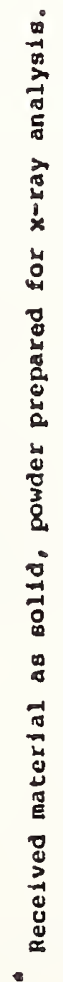


2. Electrode Systems and Materials Test (W. R. Hosler and E. N. Farabaugh)

\subsection{NBS/AVCO Slagging Test 2.}

A description in the design and materials incorporated in this test has been given in the last Quarterly Report (January-March 1978), page 38. These electrodes (six) are being fabricated in part by APS Materials, Inc., Dayton, $\mathrm{OH}$. It is expected that they will be finished by the end of June with testing to take place as soon as arrangements can be made for accomodations in the AVCO channel. A brief description of the analysis of the pretest electrode is given in the next section of Task $K$, this report.

\subsection{NBS/APS Electrode Test (MIT 228-NBS F)}

This set of six electrodes described briefly in Task $K$, page 43 of Quarterly Report (October-December 1977) was tested. at the MIT test bed on February 28, 1978. A schematic diagram of the electrode shown in figure 35, page 77 of that report. A description of the test procedure and immediate test results was given in Quarterly Report (January-March 1978).

The post test materials characterization performed on these tested electrodes is given in the next section of this report.

A complete report including details on design, pretest analysis, test procedure and post test analysis will be available.

\subsection{U-02 Phase III, US-USSR Cocperative Program}

Phase III of the US-USSR cooperative program was carried out from 13th to 19th of May, 1978 in Moscow. An NBS representative was a memioer of the test team. The test section consisted of electrode walls made by the US and of insulating walls made by the USSR.

The main purpose of the experiment was to conduct a life test of electrode and insulator materials under MHD conditions. The electrode materials were $\mathrm{LaCrO}_{3}$ based ceramics and the insulators were $\mathrm{MgO}_{2}$ or $\mathrm{MgAI}_{2} \mathrm{O}_{4}$. Thirtysix pairs of electrodes were tested operating under varied temperature and electrical conditions. The test itself was divided into four general parts.

1. Heating of the test train and selection of test parameters,

2. Electrophysical tests of the electrodes,

3. Life tests of electrodes, and

4. Cooling the train.

The total exposure time of the module to the specified thermal conditions was 107 hours including 100 hours in which the electrodes were under electrical load. After the test the electrode walls were carried to NBS where sectioning and post test analysis is in progress. Westinghouse Research and Development Center, Pittsburgh, PA, was responsible for the design, construction and execution of the test in Moscow. NBS and Battelle N.W. laboratories are primarily responsible for the post test analysis."

An Express Report stating the main details of the test was written just after the experiment and this report is available. A complete and final report including design, fabrication, testing and post test analysis will be assembled later by Westinghouse Research and Development Center, Pittsburgh, PA. 
3. Test Analysis (Pre and Post Test Materials Characterization)

3.1 Examination of Zirconia, Yttria and Ceria Capped. Lanthanum Chromite Electrodes Tested at the MIT Test Bed on February 28, 1978; MIT 非228-NBS 非F (E. N. Farabaugh)

These 6 electrodes consisted of a $85 \mathrm{ZrO}_{2}-3 \mathrm{Y}_{2} \mathrm{O}_{3}-12 \mathrm{CeO}_{2}$ cap on top of APS $\mathrm{LaCrO}_{3}$. The $\mathrm{LaCrO}_{3}$ was joined to a nickeI plated copper spacer which was, in turn, brazed to the copper cooling strip. The cap was joined to the $\mathrm{LaCrO}_{3}$ by means of grading from the cap material to $\mathrm{LaCrO}_{3}$. Similarly, the $\mathrm{LaCrO}_{3}^{3}$ was joined to the copper spacer through a cermet grade METCO 447 to $\mathrm{LaCrO}_{3}{ }^{3}$. The insulators were $\mathrm{MgAl}_{2} \mathrm{O}_{4}$ (S7I).

Anodes were numbered 2,5 and 1 with 非 containing a thermocouple. Anode \#5 was the middle anode in the anode stack. The anode closest to the

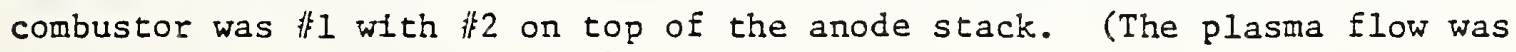
vertically upward in this rig).

Cathodes were numbered 3,6 and 4 with $\# 6$ containing the thermocouple on the cathode side. The middle cathode in the stack was \# 6 with $\# 3$ nearest the combustor and 4 on top of the stack.

All the electrodes drew current during the entire course of the test. Visual observation of the electrodes, together with monitoring of the voltage and current characteristics, indicated that the cap parted from \# 6 and 非. The cap loosened from 3 first then from 3 非 about $3 / 4$ of the way through the test. These electrodes still drew current, however.

Figures la and ib are optical micrographs of slices taken from the cathode side. The slices shown in Figure la were taken so as to show the embedded thermocouple in $k_{6} 6$. Slices displayed in Figure 1b were taken in material away from the thermocowsle and nearer the center ine. Note in Figure la the cap is raised in 1 k 6 just above the thermocouple and sheath. Most of the cap is missing from 非 6 in both slices. The cap is partially gone from \#3 in the slice shown in Figure 1b. The cap to 1 . 4 , the most downstream cathode was in the best post-test condition of the cathodes.

Figure 2 shows cathode $\# 6$ at a magnification of $19 x$. In it are identifled the copper spacer, 1; the METCO-LaCrO 3 grade, 2; the $\mathrm{LaCrO}_{3}$ body, 3; and the cap and grade to $\mathrm{LaCrO}_{3}$, 4. Very high $\mathrm{K}$ concentrations as well as $\mathrm{La}, \mathrm{Cr}$ and some $\mathrm{Mg}$ are seen in 5, near the thermocouple sheath. Close examination of these various regions suggested that there were sharp boundaries between the APS LaCrO 3 and where the cap to $\mathrm{LaCrO}_{3}$ grade ended. The METCO to copper joint was better than the $\mathrm{METCO}$ to $\mathrm{LaCrO}_{3}{ }^{3}$ bond. The poorest of bonds was the cap grade to APS $\mathrm{LaCrO}_{3}$.

The outermost plasma surface (Area 4 in Figure 2) is seen at 180X in Figure 3. The more porous appearing zone is what remains of the cap. Figure 4 displays the EDX spectra from this area. What remains of the cap is mostly single phase material. It is noted that no $K$ is present and further EDX examinations has, in fact, shown $\mathrm{K}$ concentrations vary from zero in this cap area to a maximum where the cap to $\mathrm{LaCrO}_{3}$ grade ends. 
As one moves in from the cap, Into the grade, La-Cr phases are encountered which are Cr-poor. The material in which these phases are seen is usually porous. Going further into the electrode, the density increases as does the $\mathrm{Cr}$ concentration in the $\mathrm{La}-\mathrm{Cr}$ phases. Generally, the $\mathrm{Zr}-\mathrm{Ce}-\mathrm{Y}$ concentration decreases while moving in this direction. However, there are 1solated $\mathrm{Zr}-\mathrm{rich}$, Zr-Ce-Y-La-Cr regions encountered. The difference between the denser interior areas and the more porous areas nearer the plasma surface seems to be that a $\mathrm{Zr}-\mathrm{La}-\mathrm{Cr}$ phase rich in $\mathrm{Cr}$ and $\mathrm{Zr}$, which surrounded larger grains, has been reacted away as one moves toward the plasma surface. Thus, the change in microstructure seen in Figure 3 is accounted for by the presence of intergranular $\mathrm{Cr}$, Zr-rich phases in the denser regions.

As the boundary between the grade and the $\mathrm{LaCrO}_{3}$ body is approached, $\mathrm{K}$ concentrations begin to appear. Figure 5 shows, at $180 \mathrm{x}$, a crack with different microstructures present on adjacent sides of the crack. The crack is a boundary between the grade, 2, and APS LaCrO 3,3 . In regions 1 and 2, cap constituents, mainly $\mathrm{Zr}$, are found, while in 3, no $\mathrm{Zr}, \mathrm{Y}$ or Ce was detected. In region 1 , the material is La-rich and $\mathrm{Zr-K}$-poor compared to region 2. The EDX spectra from these regions is shown in Figure 6 . In region 3, no cap materials were seen, the phases present being nearly normal La-Cr phases with appreciable $\mathrm{K}$ concentrations. In area 4 , the $\mathrm{K}$ concentration is quite high, and there are no cap constituents and the concentrations of $\mathrm{La}$ and $\mathrm{Cr}$ are somewhat lower than in 3 . EDX spectra from areas 3 and 4 are given in Figure 7. Thus, there is a sharp boundary between the cap phases and the APS $\mathrm{LaCrO}_{3}$ body. The boundary is evidenced by a crack and by a La-poor, K-rich phase on the plasma side of the crack. It can also be seen, in Figure 5, that the areas of highest $\mathrm{K}$ concentrations, 2 and 4 , show surface microstructure attributed to $\mathrm{K}$-phases forming on the specimen surface.

Figure 8 shows at $180 \mathrm{X}$ the thermocouple and sheath embedded in $\# 6$. The material between the sheath and the thermocouple wire is MgO. However, EDX analysis of this MgO insulator material showed large $\mathrm{K}$ peaks as well as some $\mathrm{La}$ and $\mathrm{Cr}$. Remembering the high $\mathrm{K}$ concentrations and the presence of some $\mathrm{Mg}$ in material adjacent to the sheath in the electrode (region 5, Figure 2) it seems possible that the sheath broke down someplace and allowed reactions to take place between the MgO in the thermocouple assembly and seed. Figure 9 gives the EDX spectra from the thermocouple wire (lower) and MgO (upper). No obvious reaction has taken place with the thermocouple wire.

Figure 10 shows the lower part of cathode \#6 including the grade from APS $\mathrm{LaCrO}_{3}$ to the copper spacer. The material at the bottom of the micrograph is the copper spacer. In the copper, near the bond to the METCO, some $K$ has condensed, forming a $\mathrm{K}$-rich $\mathrm{Cu}-\mathrm{K}$ phase. The grade to the $\mathrm{LaCrO}_{3}$ shows the $\mathrm{Ni}$, Mo and Al concentrations decreasing as the $\mathrm{LaCrO}_{3}$ boundary is approached. However, just before the grade turns into LaCrO a band, 1 , is observed which is rich in $\mathrm{K}, \mathrm{Cu}, \mathrm{Ni}$ and $\mathrm{Al}$. In 2, the expected La-Cr phase is present together with a small amount of $\mathrm{K}$. In this lower area, it seems apparent that $\mathrm{K}$ has condensed on or near some kind of boundary. There was a band of $\mathrm{K}$-rich material just inside the $\mathrm{Cu}$ spacer, and a band of K-rich phases just inside the grade--electrode boundary. Perhaps this is a result of some temperature effect. In this area, it was also noted that the METCO-copper bond seems a little better than the electrode-iETCO bond. 
In Figure 1b, the remains of the cap on cathode 3 show several different colored areas. Figure 11 is a $20 X$ SEM micrograph showing the partial cap remalning on the electrode. Roll-off on the electrode and filling in by the Insulating material is seen at 1 . By comparing Figures $1 b$ and 11 , areas of discoloration could be located in Figure 11. Extensive EDX examination failed to show unambiguously evidence for compositional changes associated with the discolored material. It is possible that different oxidation states of $\mathrm{Ce}$ or slightly increased concentrations of $\mathrm{Ce}$ can account for the darker colored regions in the cap.

The $\mathrm{MgAl}_{2} \mathrm{O}_{4}$ insulator showed $\mathrm{K}$ penetration and reaction (with MgO grains) to some extent over the length of the insulator down to the base. The insulator was, despite these reactions, still in good post-test condition.

In sumary, the investigation of the cathode material has shown:

(1) $K$ has penetrated into almost all areas of the cathode, frequently condensing on or near the interface between different phase regions.

(2) Most of the cap was gone on 非6, and partially eroded away on 非. These electrodes still drew current. The cap suffered least on cathode 非 4 .

(3) The thermocouple and sheath were at least partially responsible for the lifting of the cap on cathode $k_{6}$. Some swelling and movement of material was observed around the thermocouple.

(4) The cap and grade to cap materials are attached through reactions with intergranular phases.

(5) $K$ was detected in the Mgo material insulating the thermocouple from its sheath. It probably entered through some crack in the inconel sheath.

Figuras $12 \mathrm{a}$ and $12 \mathrm{~b}$ are optical micrographs of slices taken from the anodes. Figure 12 a shows slices taken so as to include the thermocouple probed anode, 非5. The slices in Figure $12 \mathrm{~b}$ were cut from material away from the thermocouple, and more towards the electrode center. These micrographs show the lifting of the cap on anode $k_{5}$, the one containing the thermocouple. The caps on the other anodes were essentially damage free, showing at the worst cracking of cap, but no loss at the cap. In one case, anode $\#_{1} 1$ broke free of the copper strip at the METCO-LaCrO 3 bond. This was the most severe effect of testing on 1 and 2 .

Figure 13 displays the cap of anode 5 at $15 x$, including the lifting of the cap from the electrode body and the cracking originating around the thermocouple sheath. It appears that the sheath way have been the source of the problem with the cap. However, the material imnediately above the sheath doesn't show the degree of lifting that is shown by the cap. It is possible that the cap cracked, then, the force of the plasma may have lifted the cap from the electrode. Thus, directly, by causing swelling or indirectly, by being a source of cracks, the sheath and therrocouple played a role in the loss of the cap in anode 15 . 
Analysis of the material seen in Figure 13 showed that the large crack running horizontally (indicated by the arrow) separated the graded material from the APS. $\mathrm{LaCrO}_{3}$, there is none of the $\mathrm{Zr}-\mathrm{Y}-\mathrm{Ce}$ phase below the crack. The remains of the cap at 1 are nearly single phase $\mathrm{Zr}-\mathrm{Y}-\mathrm{Ce}$ with very little $K$ present. Material in 2 is part of the graded material containing $\mathrm{Zr}, \mathrm{Y}, \mathrm{Ce}, \mathrm{La}, \mathrm{Cr}$ and $\mathrm{K}$. Higher concentrations of $\mathrm{K}$ are seen In 2 than 1. Material such as 3 is still part of the grade. In this particular area, the phases are a little poor in $Y$ and $\mathrm{Ce}$ but richer in Cr than either 1 or 2. Material 4 is the APS LaCrO here containing substantial concentrations of $K$. The anode has seemingly separated at the cap-grade and grade- $\mathrm{LaCrO}_{3}$ boundaries.

The microstructure, (close to the plasma surface) in the APS $\mathrm{LaCrO}_{3}$, is seen in Figure 14 at $1800 x$. The large grain, 1 is $\mathrm{LaCrO}_{3}$. It is surrounded by $\mathrm{K}-\mathrm{La}-\mathrm{Cr}$ phases, the dark layer-like material, 2 .

The microstructure 3 of Figure 13 is shown in Figure 15 at $1800 \mathrm{X}$. In this piece of graded electrode the larger grains are the $\mathrm{Zr}-\mathrm{Y}-\mathrm{Ce}$ phase, 1. La-Cr-Zr phases were detected at 2 and $\mathrm{Cr}$-poor La-Cr-Zr were found in the vein-like material at 3. Little $K$ was found in these phases.

The microstructure seen in the remains of the cap, 1 in Figure 13, is shown in Figure 16 at 1800x. This material is nearly single phase $\mathrm{Zr}-\mathrm{Y}-\mathrm{Ce}$ material. There was no $\mathrm{K}$ found in this material. The dark appearing areas in the micrograph are holes or pures in the structures. These areas were probably the La-Cr-Zr phases and were reacted away by the seeded plasma.

Figure 17 shows the base of the anode at 45x. There are smooth junctions of the copper to the METCO grade and of the METCO to the APS LaCrO . No $^{\circ}$ $\mathrm{K}$-rich bands were seen at the anode base. In fact, no $\mathrm{K}$ was detected in the base area of the anode at all. The dark islands in the METCO are Mo, Al-rich Mo-Ni-Al-La-Cr phases. The microstructure of the phase is different from that seen in the cathode base. This may be the result of the $k$ reactions in the cathode.

The inconel thermocouple sheath did not allow $\mathrm{K}$ penetration into the thermocouple assembly in anode 非. The MgO insulation between the sheath and the thernocouple wire was essentially single phase MgO. However, in electrode material surrounding the sheath, areas of Cr-rich phases are detected. Figure 18 shows a Cr-rich Al-ig-La-Cr phase, 1, in the electrode material which is adjacent to the inconel thermocouple sheath, 2 . It is difficult to determine if this phase resulted from reactions with the inconel sheath or not.

In summary, the investigation of the anode has shown:

(I) No K-Rich bands at interfaces, where different composition in graded material meet, exist in the anode base. The highest $K$ concentrations are where the cap to APS $\mathrm{LaCrO}_{3}$ grade ends. The $\mathrm{K}$ concentration are not as strong as those detected in the cathode. 
(2) Anode \#5 was the only anode in which the cap came free. It is posstble that the thermocouple sheath played a role in this deterioration.

(3) The cap seems to be attacked through reactions involving the intergranular material surrounding the Zr-Y-Ce phases. Generally, the corrosion mechanism appears to involve intergranular reactions first.

(4) The grade from Cu cooling strip to APS $\mathrm{LaCrO}_{3}$ was free from cracks or segration of any phases. At the plasma surface some cracking appeared at cap-grade and grade-APS $\mathrm{LaCrO}_{3}$ boundaries. 


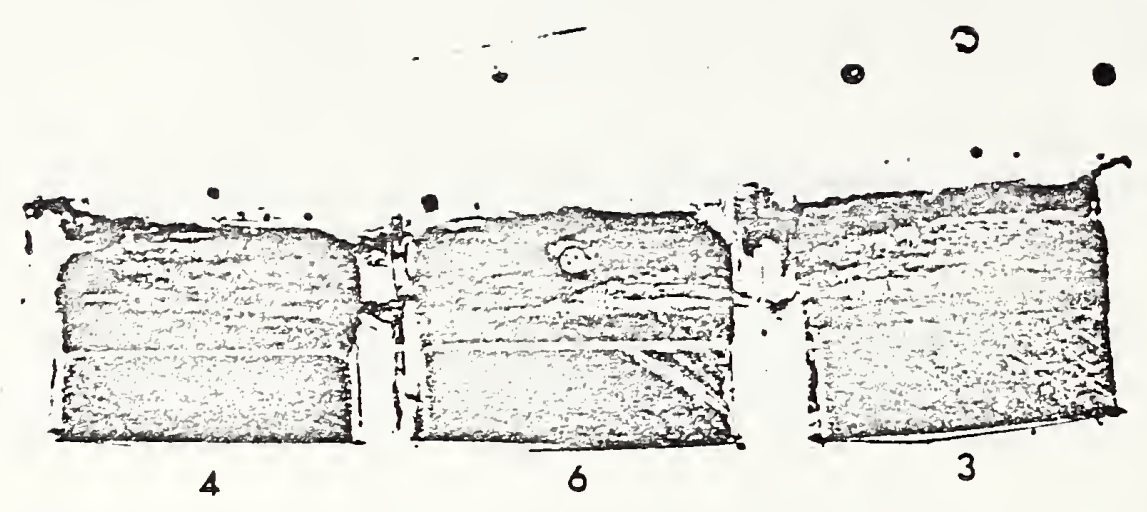

Figure 1a. Optical micrograph of cathode slices.

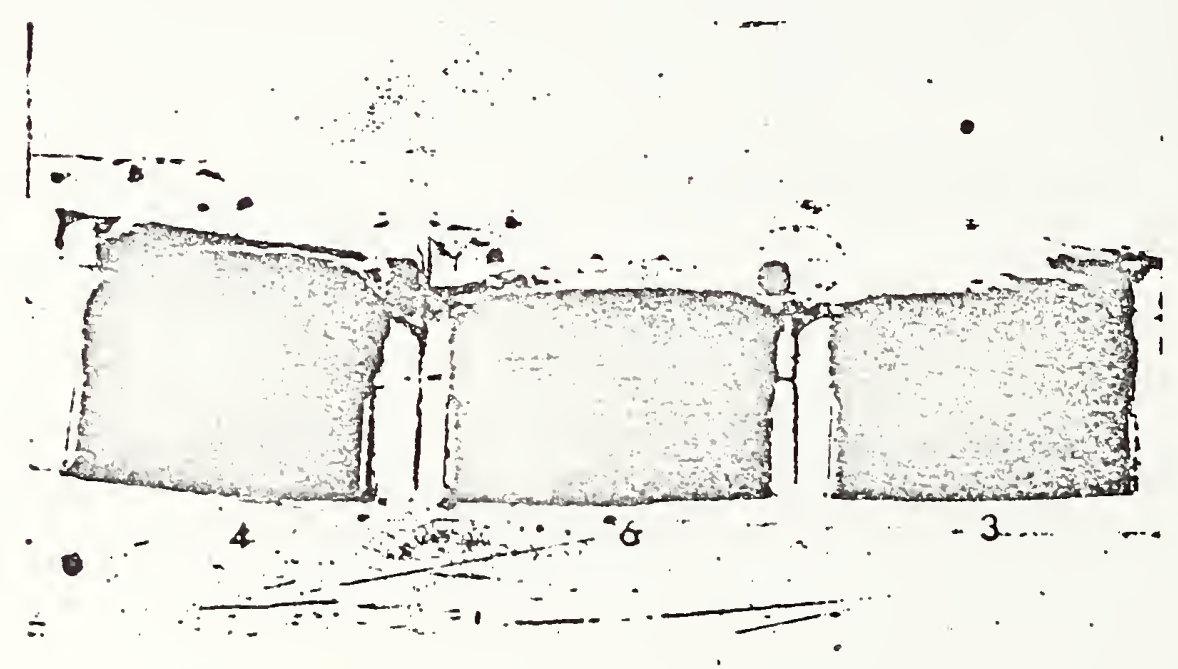

Figure 1b. Optical micrograph of cathode slices. 


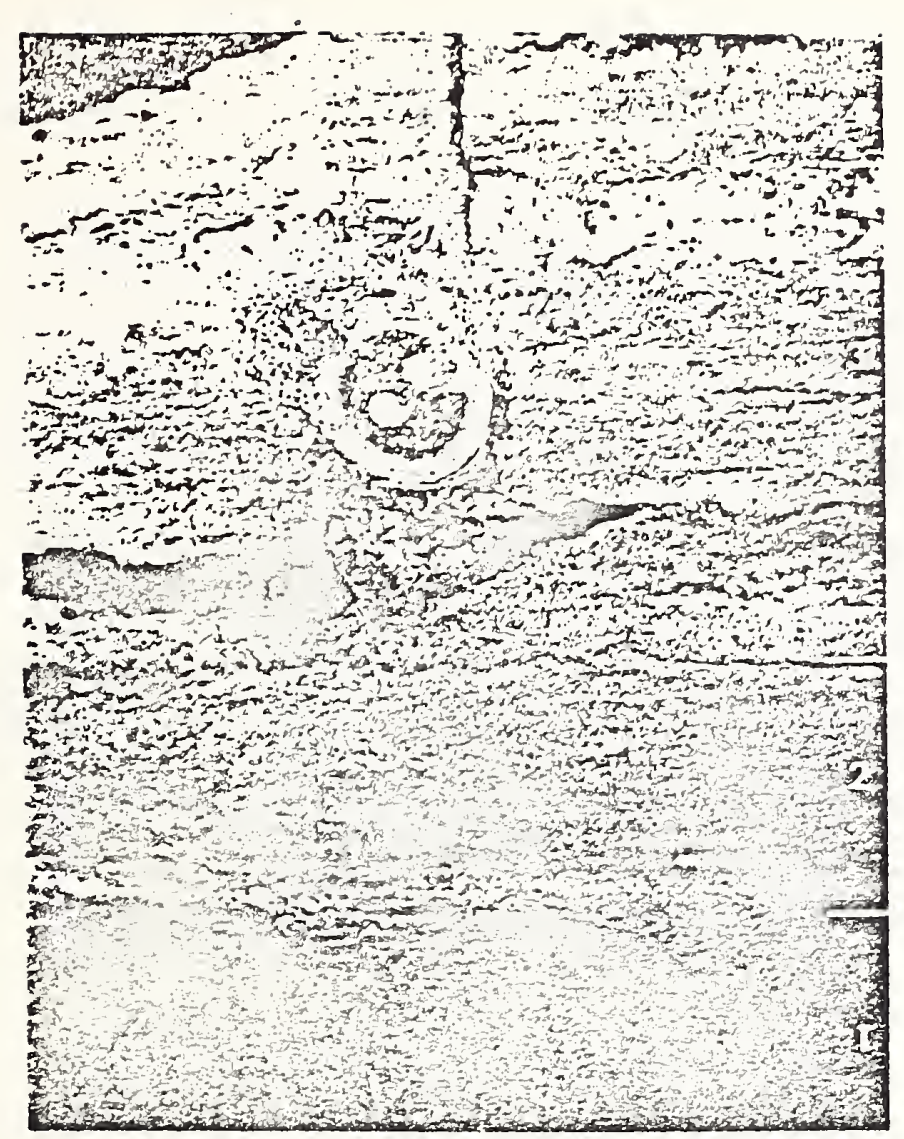

Figure 2. 19X SEM micrograph of cathode \#6.

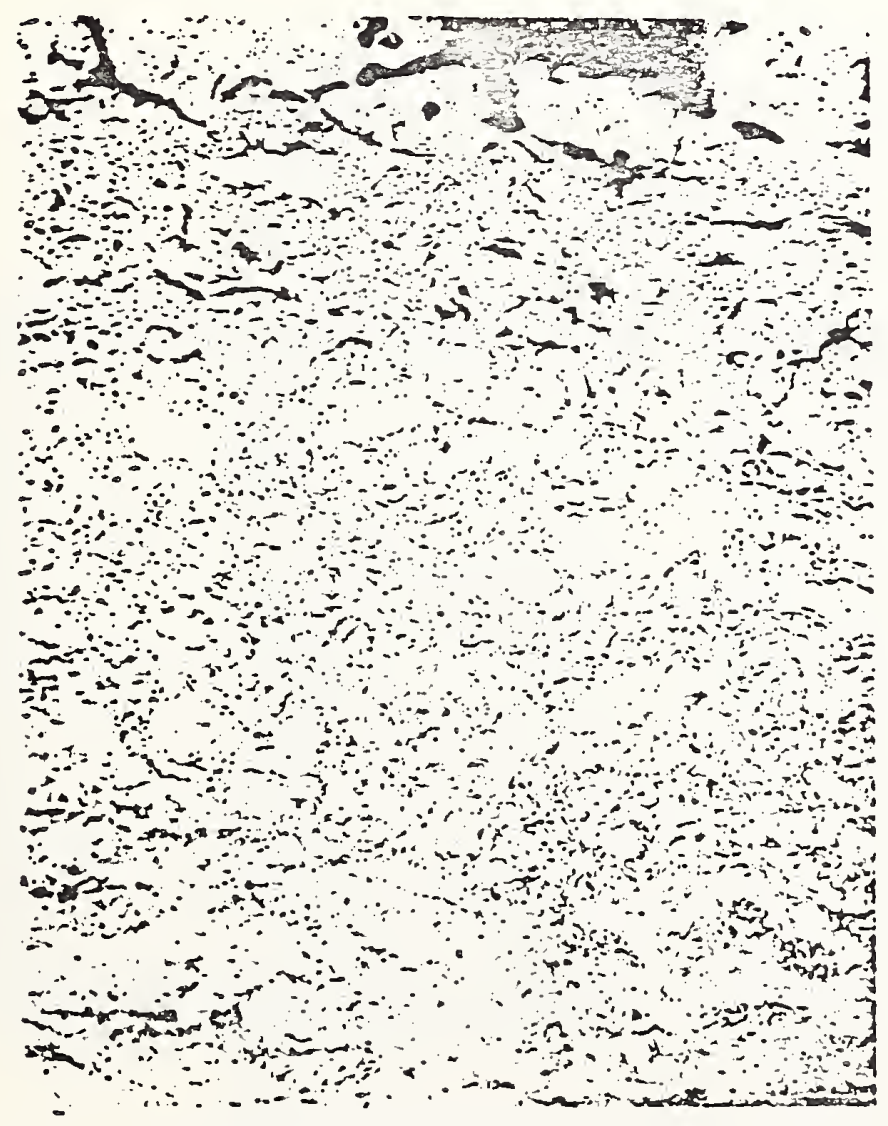

Figure 3. 180X SEY micrograph of the plasma surface of $\mathbb{H}^{6} 6$. 


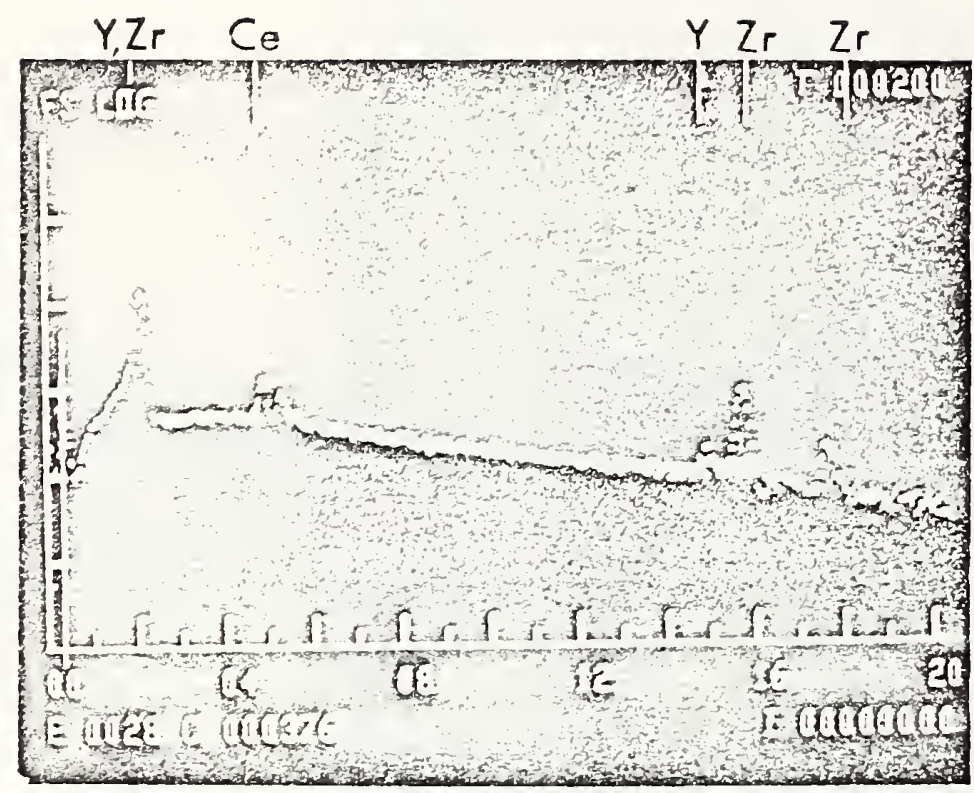

Figure 4. EDX spectra from the remains of the cap.

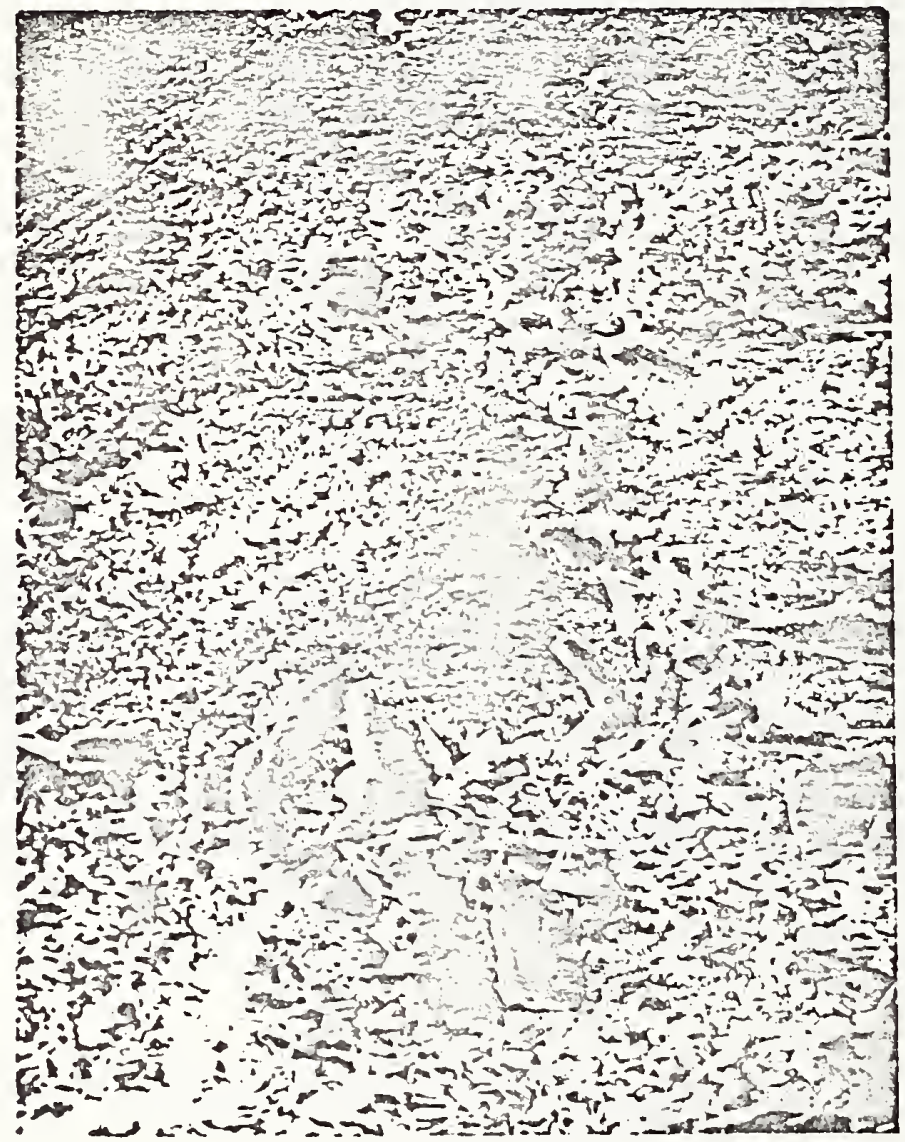

Figure 5. 180X SEI micrograph showing the boundary between the grade 2 and $\mathrm{APS} \mathrm{LaCrO}_{3}, 3$. 


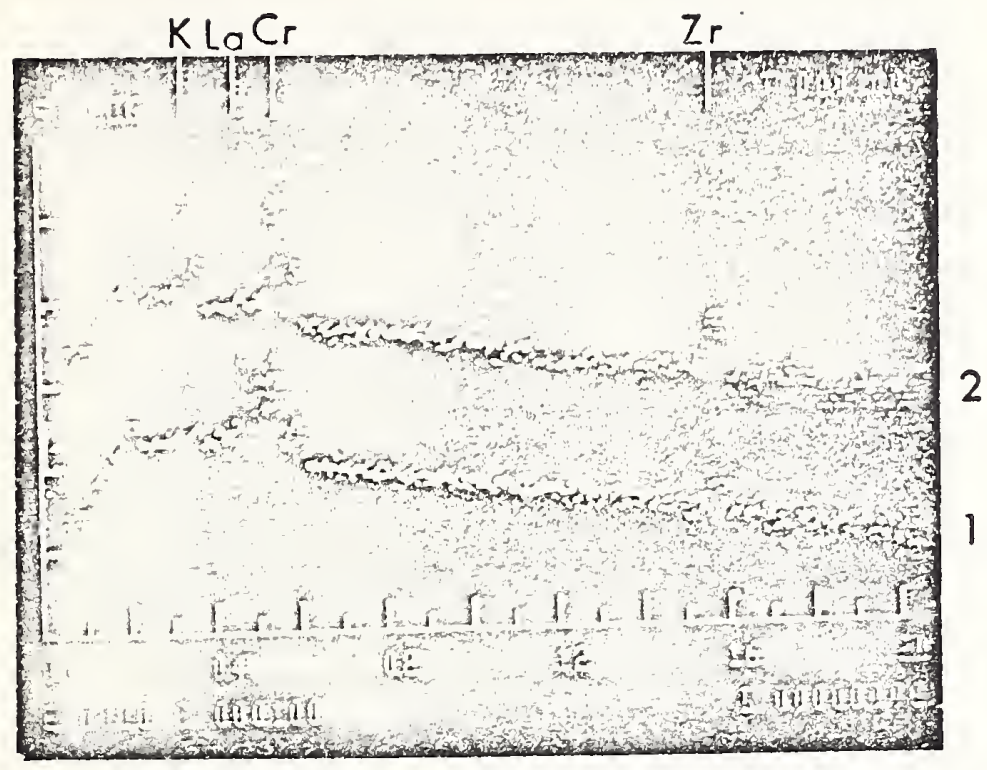

Figure 6. EDX spectra from areas 1 and 2 in Figure 5.

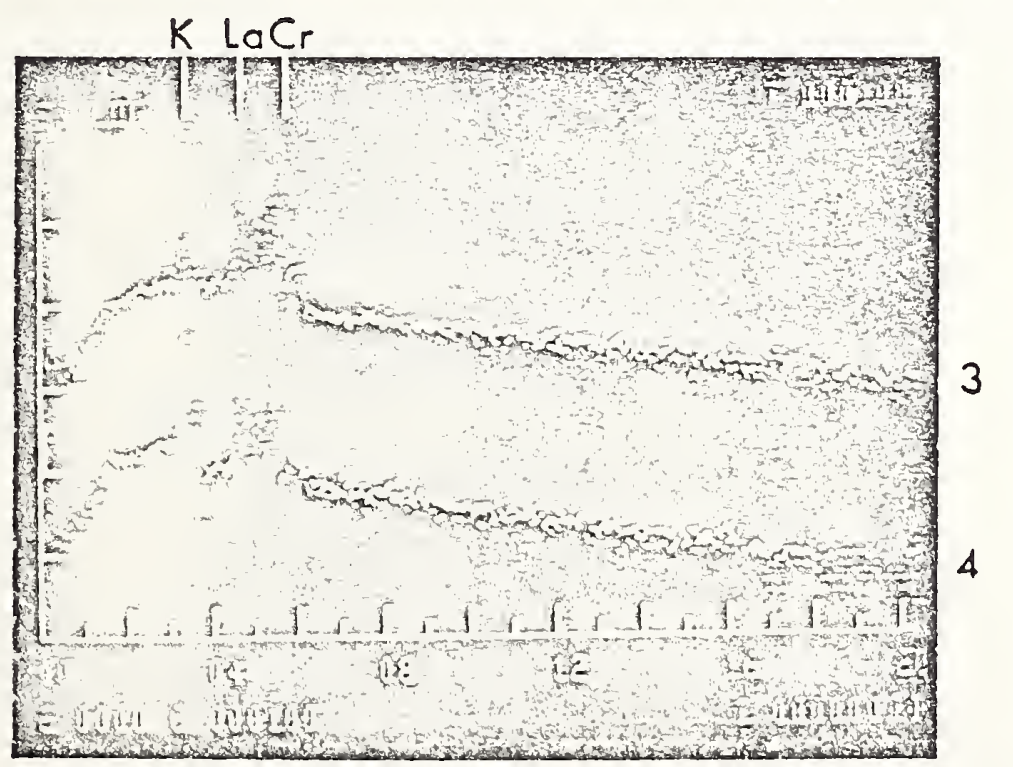

Figure 7. EDX spectra from areas 3 and 4 in Figure 5. 


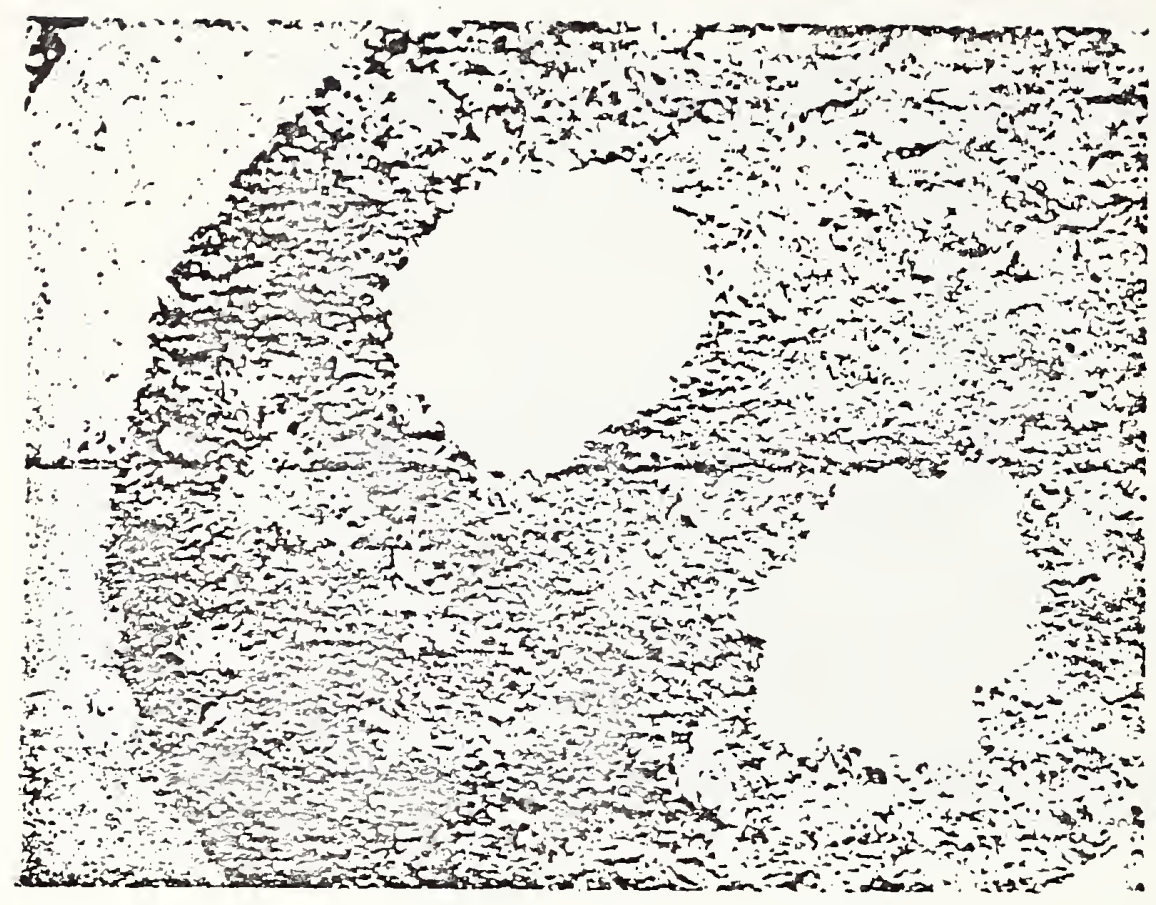

Figure 8. 180X SEM micrograph of thermocouple wires, protective sheath, and $\mathrm{MgO}$ insulating material.

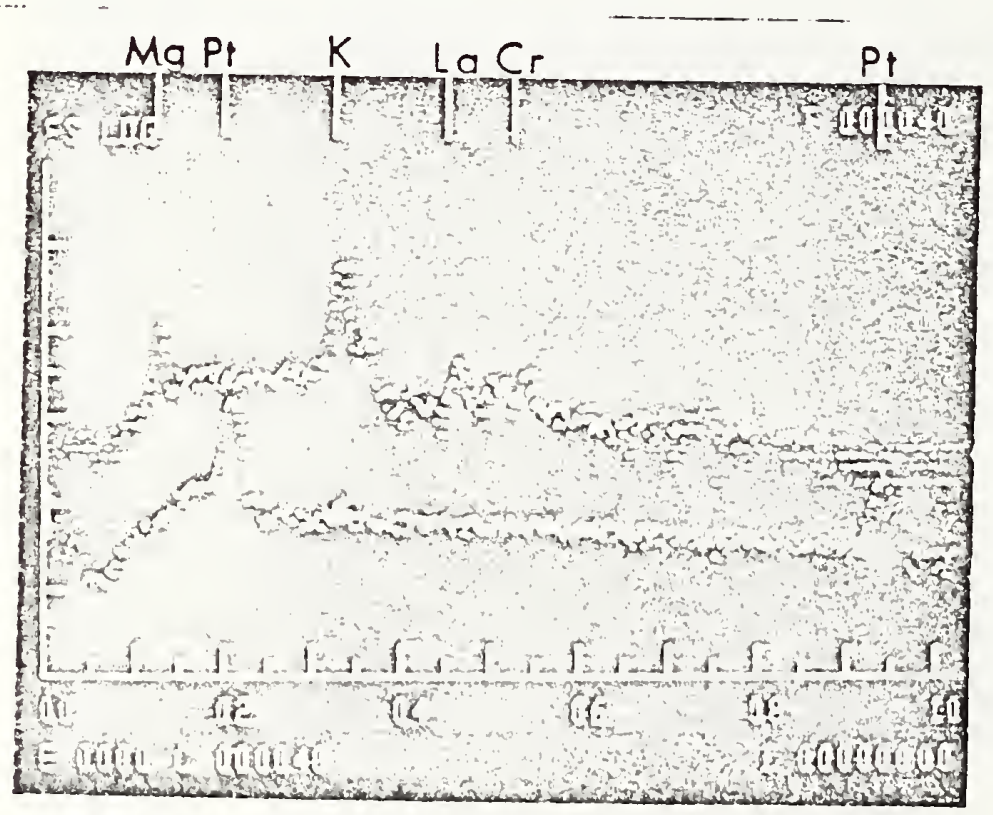

Figure 9. EDX spectra from the thermocouple wire (lower) and Mgo insulator (upper). 


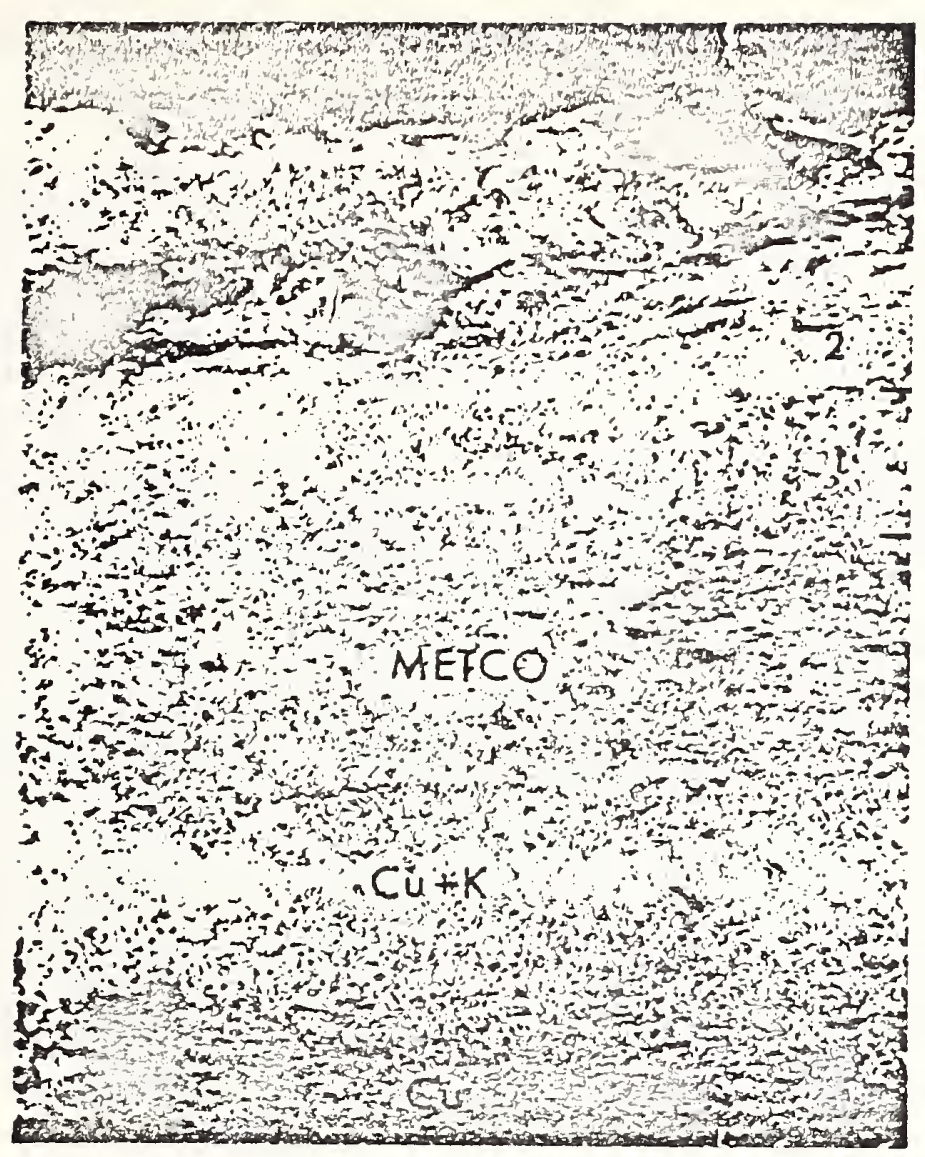

Figure 10. 45X SEM micrograph of lower part of cathode 非6.

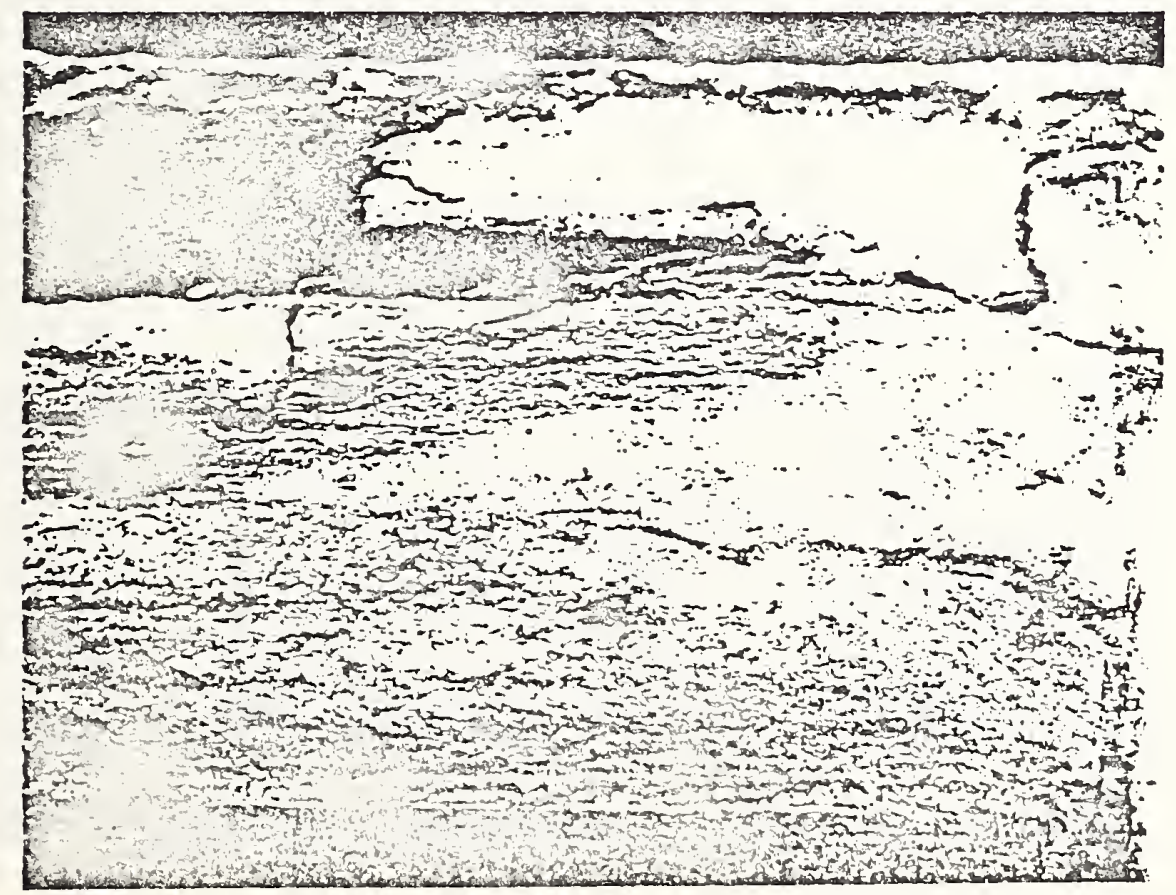

Figure 11. 20X SEM micrograph of cathode \#3 (from the section shown in Figure 1b). 


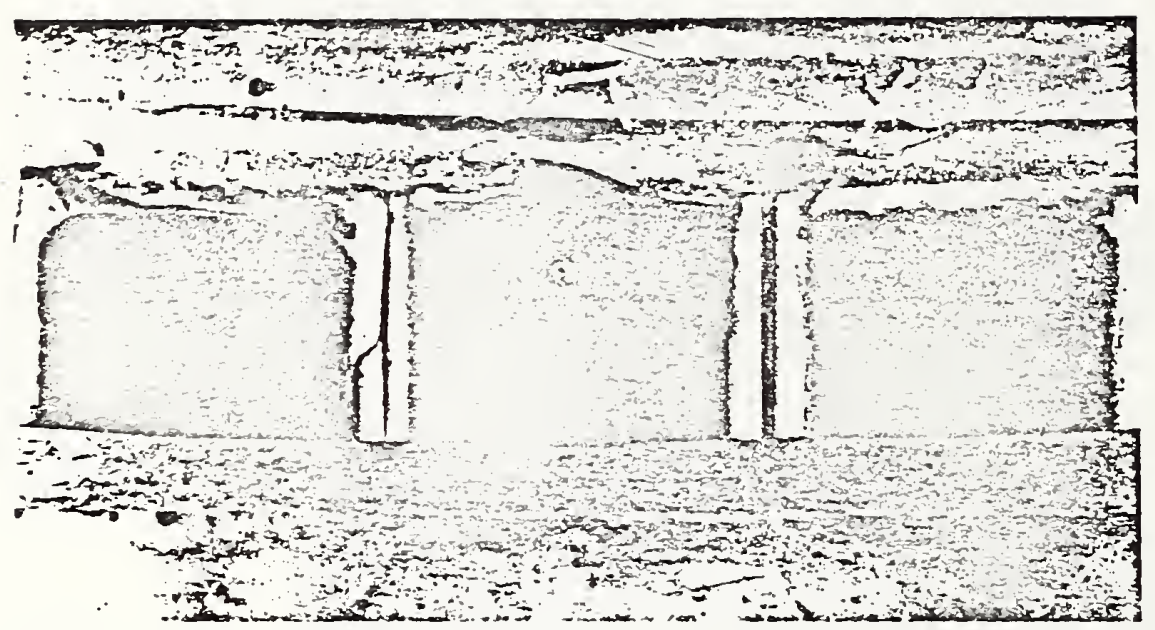

Figure 12a. Optical micrograph showing other slices taken from the anodes.

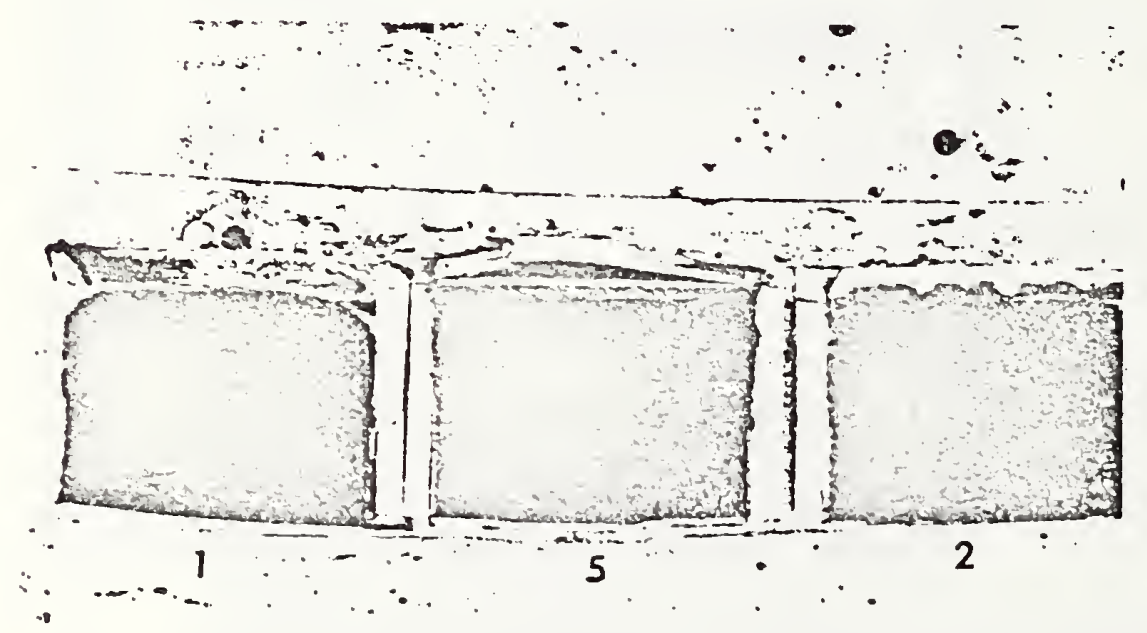

Fiqure 12b. Optical micrograph showing slices taken from the anodes. 


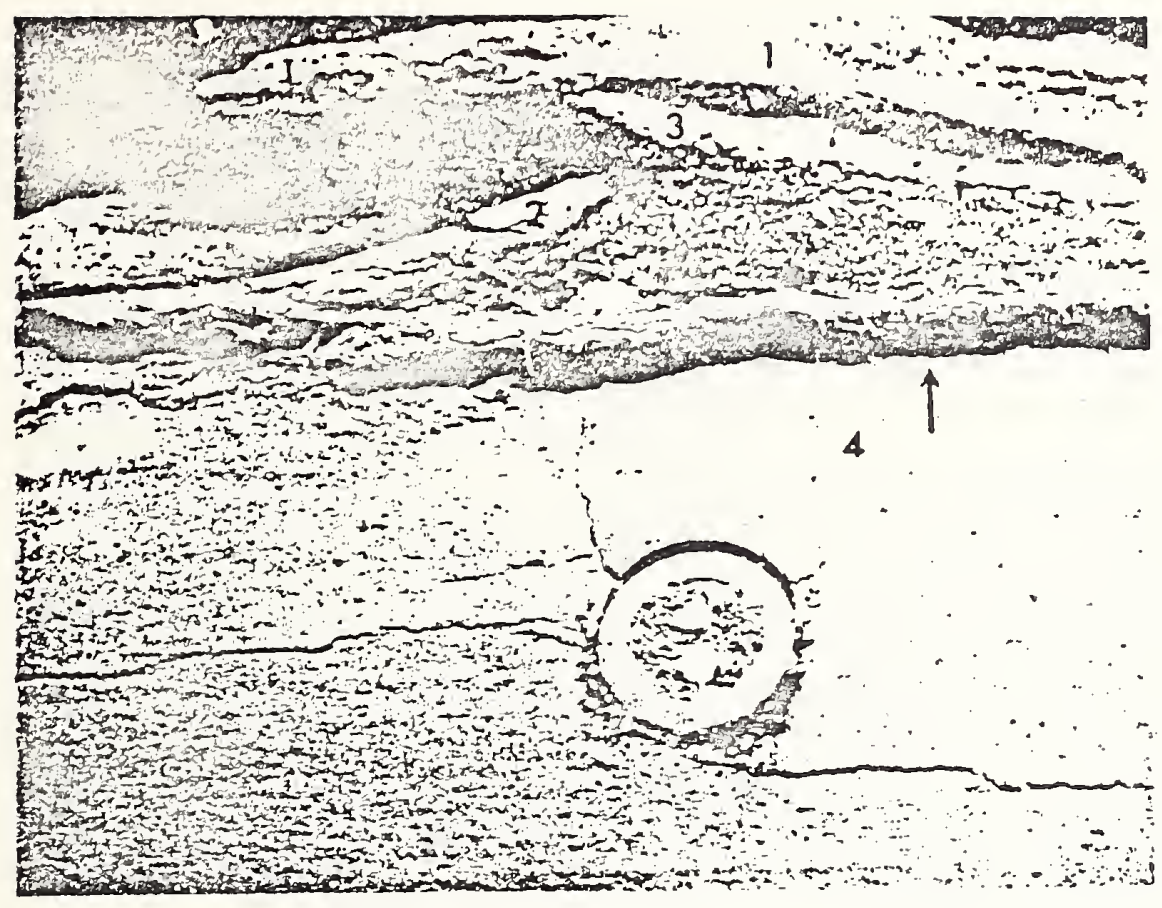

Figure 13.15X SEM micrograph of anode 非5.

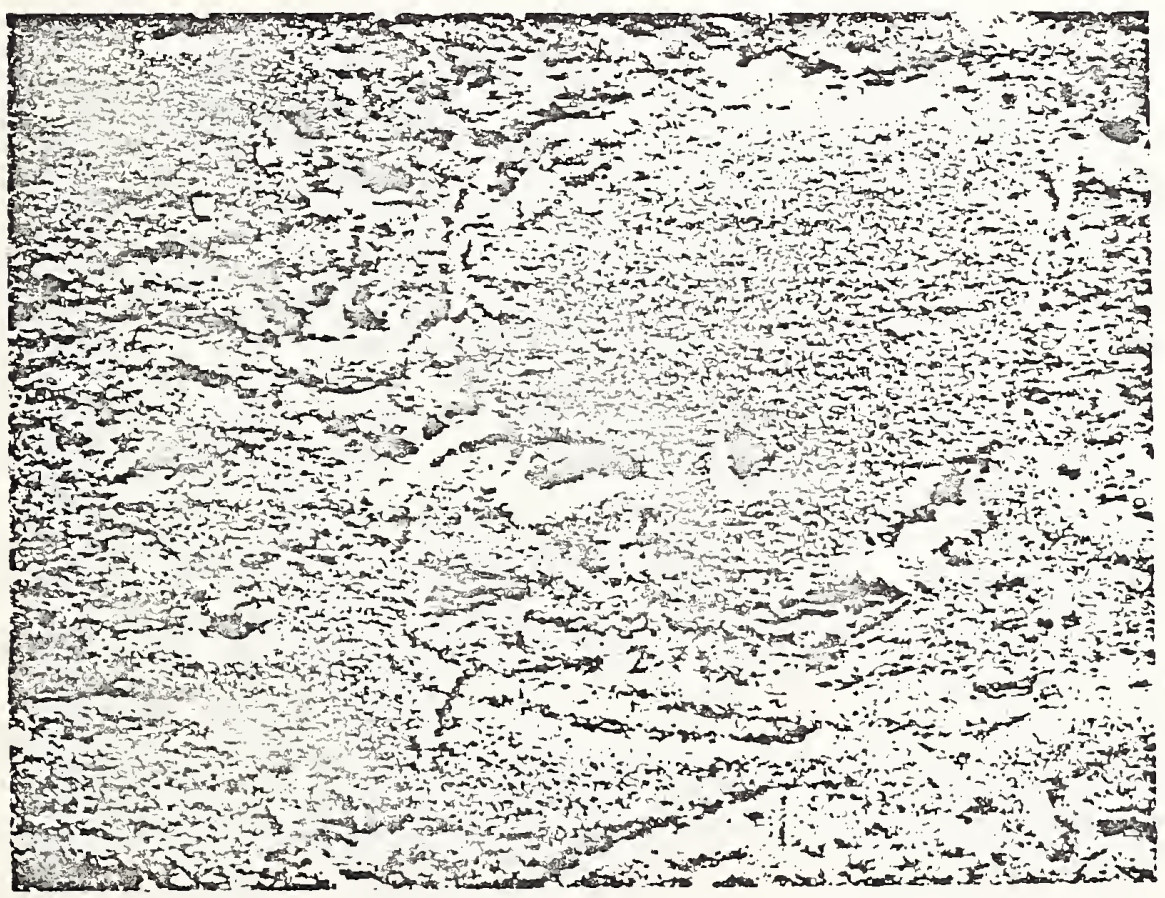

Figure 14. 1800X SEM micrograph of microstructure in APS $\mathrm{LaCrO}_{3}$ near the plasma surface. 


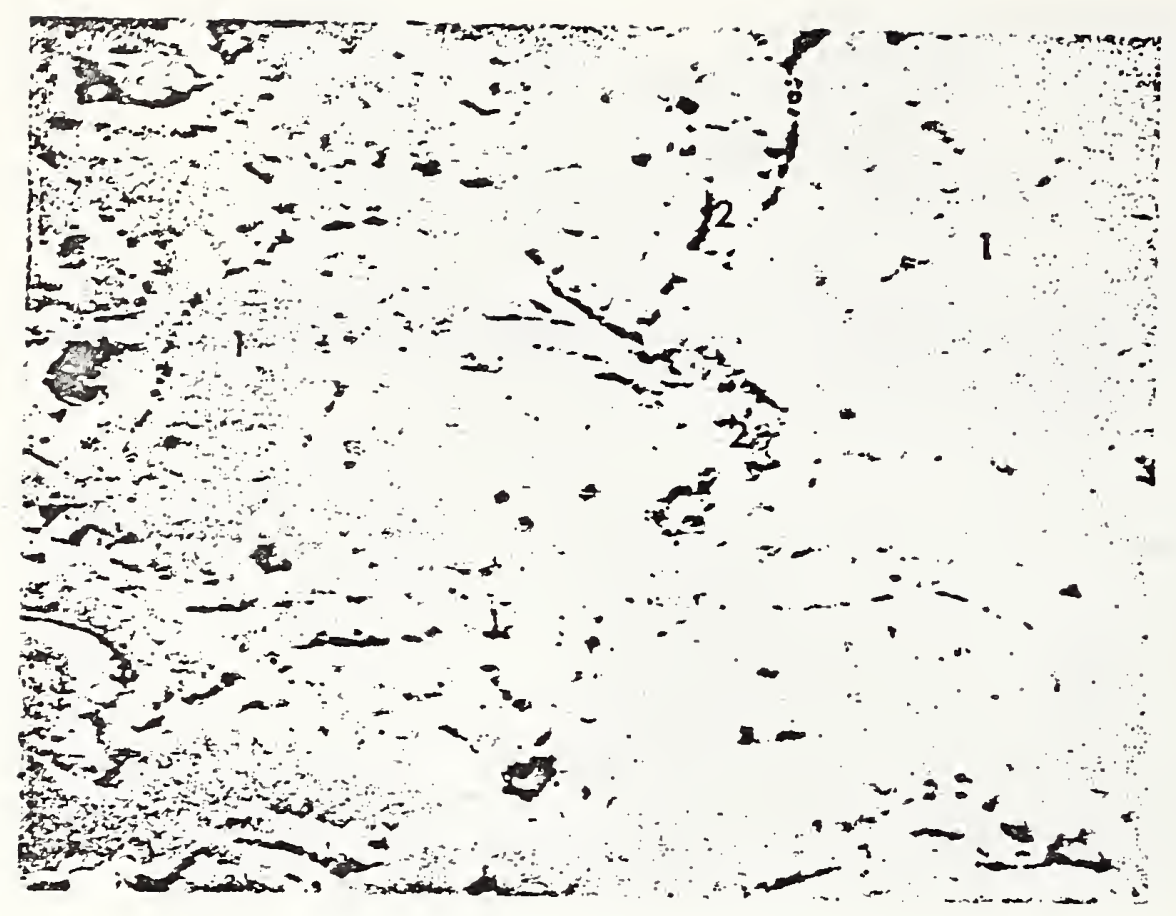

Figure 15. 1800X SEM micrograph of microstructure of material 3 in Figure.13.

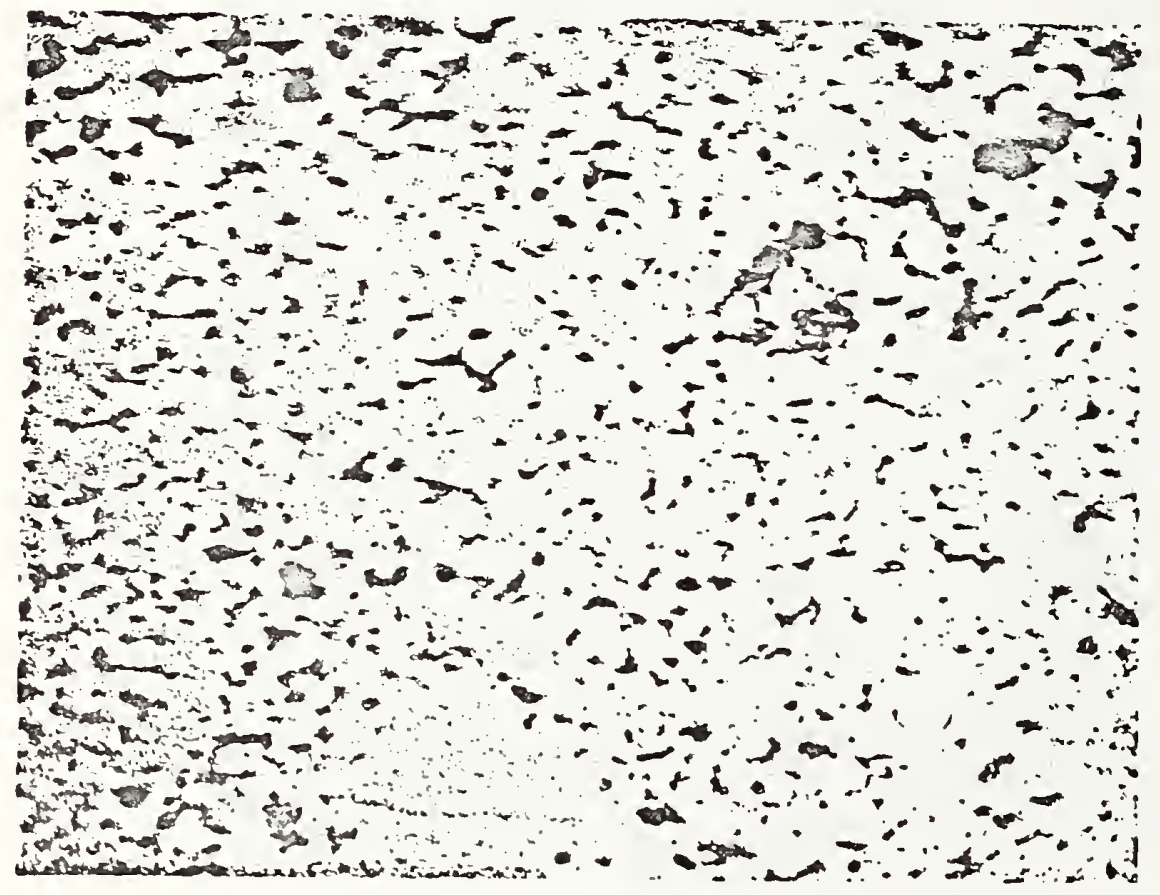




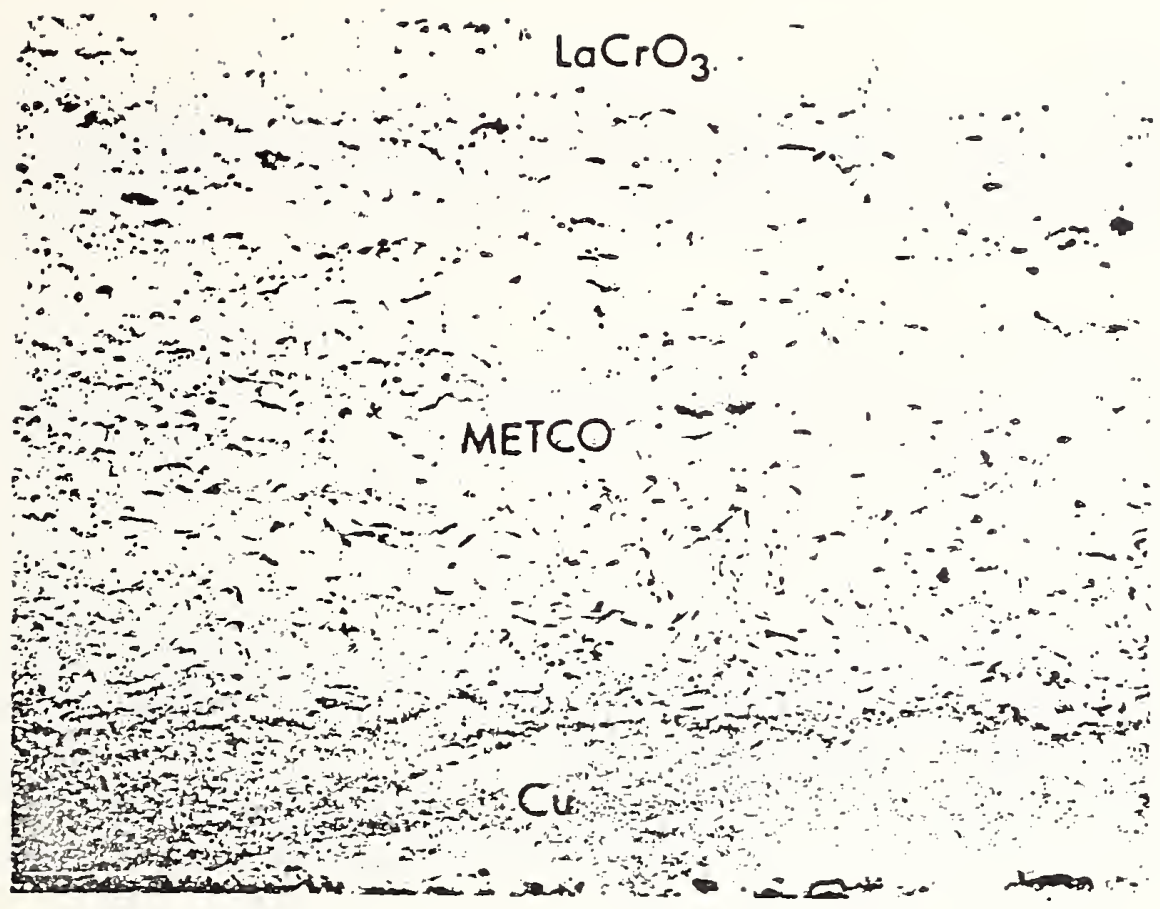

Figure 17. 45X SEM micrograph of the area at the base of the anode F. .

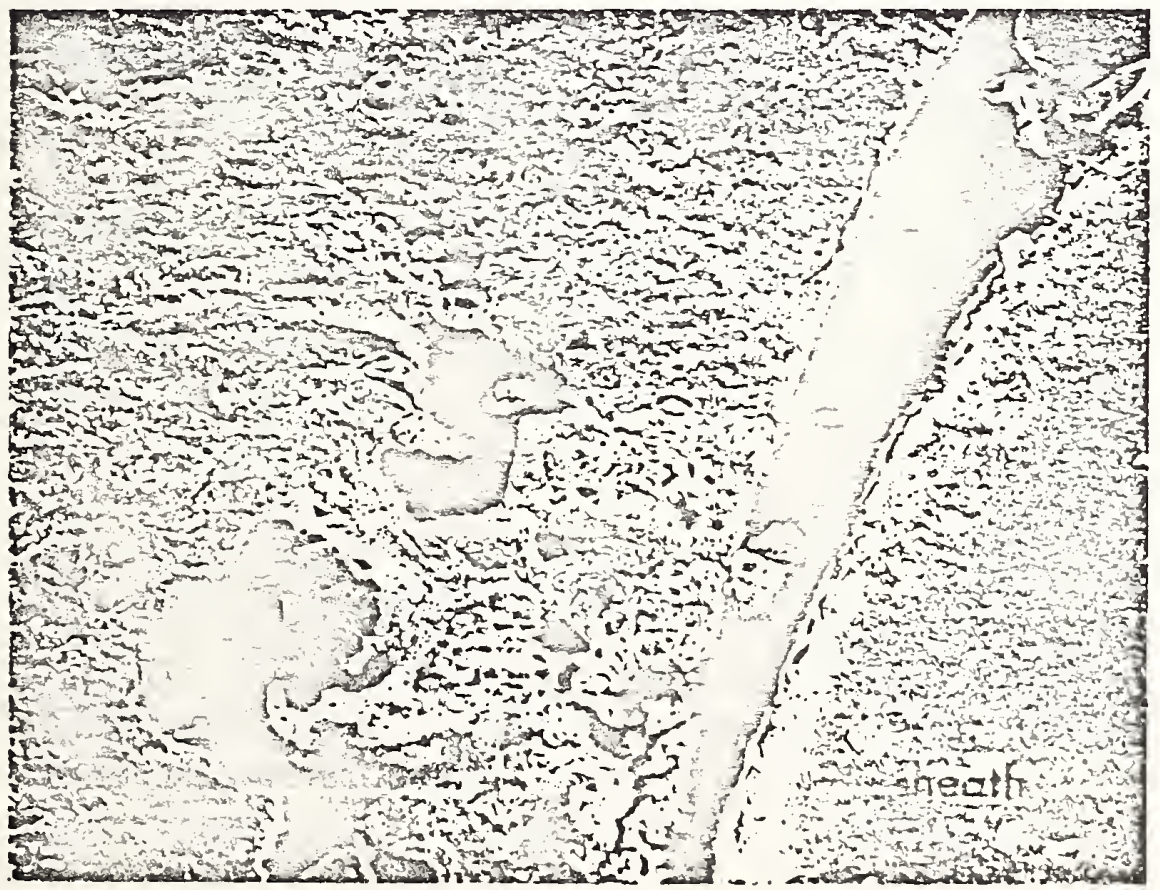

Figure 18. 450X SEM micrograph taken of the area surrounding the thermocouple sheath in anode $\# 5$. 
3.2 Examination of Soviet Electrode Materials (Titanium Doped Silicon Carbide and Lanthanum Chromite-Chromium Cermet) Tested in the Joint US-USSR Experiment in the UTSI Test Installation (E. N. Farabaugh, A. Perloff)

An extensive investigation of these materials was conducted and a brief sumary of the results is given below. The full report, as presented to the USSR team is available.

The electrodes were tested with the combustion products of both acid and basic coals containing seed $\left(\mathrm{K}_{2} \mathrm{SO}_{4}\right)$. The basic coal was made by adding 5.5 parts of $\mathrm{Ca}(\mathrm{OH})_{2}$ per 85 parts Kentucky acid coal. The first series of electrodes was tested without current. A second phase of the test was conducted under similar conditions to the first with the addition of an externally applied electrical field.

Specimens from electrodes tested in thermal, acid coal + seed, basic coal + seed with and without current, as well as untested coupons of each material were examined by EDX, SEM, and XRD techniques.

3.2.1 SiC $+\mathrm{Ti}$ (Untested Material)

From information supplied by the USSR team, the titanium doped SiC is composed of hexagonal and cubic forms of silicon carbide with excess silicon and titanium silicide. X-ray diffraction analysis of the untested material showed it was primarily various forms of SiC. Also, there were identifiable amounts of free $\mathrm{Si}$ and TiSi2. There was no indication of metallic Ti or titanium silicides with higher $\mathrm{Ti}$ content than $\mathrm{TiSi}_{2}$. Some small unidentifiable peaks exist in the diffraction pattern, but they would represent material present in very minor proportions.

The untested material can be characterized as being composed nearly completely of three phases -- TiSi 2 islands, a free Si matrix containing the islands and SiC grains. No oxidation, other than that of the surface, of either SiC or Si was detected. The untested material is quite uniform in density, microstructure and distribution of grains.

3.2.2 SiC + Ti electrodes (Tested Material)

Most of the microstructures, reaction products, and phase changes observed in the current-tested cathode were seen in one or another of the electrodes tested without current. One exception was that in the current tested cathode, some possible oxidation of a Si phase was apparent. Redistribution of Ti, melting of Ti-Si phase islands, observation of Ti-si phase 'clumps' outside of the electrode body all were 
seen in electrodes tested without current as well as the electrodes tested with an applied electric field. Temperatures in excess of the reported values, for electrodes with redistributed $\mathrm{Ti}$, may well have caused the Ti-Si phase island melting.

In all the electrodes the SiC phase appeared to be most resistant to attack, the reactions mainly taking place either via slag interaction or oxidation with the Si and Ti-Si intergranular phases. Breaking up of the electrode material probably started by weakening the microstructure through these $\mathrm{Si}$ and $\mathrm{Ti}-\mathrm{Si}$ phase reactions allowing erosion to take place at the plasma surface.

The question of oxidation of these electrode is difficult to answer. No striking evidence was developed but still there is some indication that both $\mathrm{Si}$ and SiC material were oxidized to some degree. It is possible that the oxidized material, probably being friable pulled out during polishing thus accounting for the absence of heavily oxidized Si or SiC phases.

The attack was most severe on current tested cathoces and anodes. It is possible that whatever reactions take place to degrade the electrode in currentless tests are simply speeded up by the application of the electric field.

\subsection{3 $\mathrm{LaCrO}_{3}+\mathrm{Cr}$ cermet (Untested Material)}

From information supplied by the test team this cermet is composed of grains of $\mathrm{LaCrO}_{3}$ surrounded by areas of $\mathrm{Cr}$ with an eutectic of $\mathrm{LaCrO}_{3}-$ $\mathrm{Cr}_{2} \mathrm{O}_{3}$ at the phase boundaries. XRD analysis of an untested piece of cermet showed that all the peaks in the pattern could be identified as belonging to the typical orthorhombic $\mathrm{LaCrO}_{3}$ phase or to the normal cubic Cr metal. The eutectic phase must be a minor part of the cermet.

The untested $\mathrm{LaCrO}_{3}$ cermet is characterized by:

(I) $\mathrm{LaCrO}_{3}$ grains showing nearly equal concentration of $\mathrm{La}+\mathrm{Cr}$ in their spectrum.

(2) Non-uniform density.

(3) No oxidized $\mathrm{Cr}$ phases detected even at $\mathrm{LaCrO}_{3}-\mathrm{Cr}$ boundary.

(4) Large variation of grain size in $\mathrm{LaCrO}_{3}$.

\subsection{4 $\mathrm{LaCrO}_{3}+\mathrm{Cr}$ electrodes (Tested Material)}

As was the case with the SiC electrodes it is apparent that nearly all of the features seen in the current tested material were seen in one or another of the electrodes tested without an electric field. Similar 
phases were developed in all the tested material and the general corrosion mechanism of intergranular reaction seem common to all materials. The anode had much more extensive fluid slag phase regions in it, but fluid phase regions in itself were not unique to that electrode.

The oxidation of the Cr metallic phase is well established, some oxidizedphase appearing in nearly every electrode. The role the oxidized-phase plays is less well established. Vaporization of the oxidized phase may well occur or oxidized phase slag reactions may predominate, to yield the microstructure characteristic of the tested specimen.

Generally it would appear that the effect of the current on these $\mathrm{LaCrO}_{3}$ electrodes seemed mainly to speed up reactions and phase changes which occur in non-powered condition only at a slower rate. 
3.3 Westinghouse Proof Test III for U-02, Phase III (T. Negas, I.P. Cook,

E.N. Farabaugh, W.R. Hosler)

A test of four candidate electrode systems was conducted at the Westinghouse Research and Development Center on January 4-5, 1978. Twelve electrode pairs were operated for 21.8 hours. Surface temperatures were between 1600 and $1785^{\circ} \mathrm{C}$ while current density was maintained at $1.0 \mathrm{~A} / \mathrm{cm}^{2}$. Results of this test were submitted by Westinghouse to DoE via an Express Report.

Anode and cathode cross sections from the tested module were delivered to NBS for examination. These were analyzed by powder x-ray diffraction and SEM/EDX methods. Although an extensive report was submitted to Westinghouse a sumary of conclusions is proviced below.

3.3.1 LaCrO ${ }_{3}-$ SrZrO $_{3}$ Electrodes, A-T Research Co. (T. Negas)

This set of electrodes was fabricated by sintering ( $\mathrm{T}^{\circ}, \mathrm{P}_{\mathrm{O}_{2}}=$ ?) a composition with $\mathrm{LaCrO}_{3} / \mathrm{SrZrO}_{3}=1.00$. A $100 \mathrm{micron}$ film of Pt was sputtered onto the ceramic and joined to copper via Ag-filled epoxy ( $\leq 0.25 \mathrm{~mm}$ ). Monolithic $\mathrm{MgAl}_{2} \mathrm{O}_{4}$ was used for the side insulation.

All three electrodes pairs (04 through 06) apparently maintained $1.0 \mathrm{~A} / \mathrm{cm}^{2}$ throughout the test. Post-test visual observations by test monitors include,

a) ".... most severely eroded-corroded are $204-206$.... (and) .... resulted in enhanced damage to 203 and 204," and

b) ".... most severely damaged cathodes were 104-106 ... more uniformly eroded."

Based on the electrode cross sections provided us, it appears that anodes operated much hotter than cathodes. Use of $\mathrm{MgAl}_{2} \mathrm{O}_{4}$ insulation between anoces 203 and 204 probably altered thermal design parameters to cause mutual up- and downstrean interaction and obvious melting. Cathodes appear to have operated within a lower temperature regime although $\mathrm{MgAl}_{2} \mathrm{O}_{4}$ also was used between 103 and 104. Pertinent cathode leacouts are in fair condition. secondary phases related to fabrication were noted for both anodes and cathodes suggesting poor homogeneity and densification of ceranics. Due most likely to relatively high initial porosity, anodes and cathodes suffered from corrosion by seed. Cathodes, especially, were corroded considerably. The chrome-oxide component of cathode ceramics was leached/vaporized selectively to yield phase assemblages composed of refractory $\mathrm{Ia}_{2} \mathrm{O}_{3}$ ( $\mathrm{Ia}(\mathrm{OH}){ }_{3}$, after cool-down), La $\mathrm{Zr}_{2} \mathrm{O}_{7}$, and $\mathrm{SrZrO}_{3}$-rich materials which are considerably more resistive electrically. Denser $\mathrm{IaCrO}_{3}$-based ceramics have performed much better in this and previous proof-tests for U-O2, Phase III. 
3.3.2 LaCro "Flex-Bed" Electrodes (General Electric Co.) (L. P. Cook)

Microchemical and microstructural examination concentrated primarily on electrode pair 108/208, to avoid contamination from the pair immediately upstream as much as possible and also because this electrode pair exhibited intermediate voltages (constant current) among those of the three G.E. pairs tested. Reportedly, voltages ranged from 22 to 84 for electrode pair $108 / 208$ during the test. The anode side exhibited heat fluxes 20 to 408 higher than the cathode side.

LaCrO 3 ceramic survived the test well, in terms of total preservation (708 or better) and lack of seed penetration. Principal mechanism of $\mathrm{LaCrO}_{3}$ degradation is thought to be an increase in porosity in the outer regions, with resultant loss of mechanical strength. This may be associated with vaporization of the ceramic. The attachments apparently did not survive well, as evicienced by corrosion of lead-out tabs, ceramic/metal bond areas, and in the case of the anode, areas of the ceramic near the attachment.

$\mathrm{MgAl}_{2} \mathrm{O}_{4}$ insulators have undergone degradation suggestive of interelectrode breakcôn, especially between $G E$ and other electrode assemblies on the cathode side. Evidence for melting at the electrode insulator interface is strong on the anode side, where it should be noted that heat fluxes were considerably higher than on the cathode side.

\subsubsection{MAFF-31/"Hercynite" Electrodes, APS Materials (T. Negas)}

As incicated in the Express Rexort for Proof-Test III to DoE (January 1978), these electrodes consist of $13 \mathrm{~mm}$ of MAFF- 31 spinel ( $\mathrm{MgAl}_{2} \mathrm{O}_{4}: \mathrm{Fe} \mathrm{O}_{4}$ solid solution) on $7 \mathrm{~mm}$ of "hercynite" bonded to copper via an ion plated Ni layer and a "hercynite"/METCO 447 composite $(3 \mathrm{~mm})$. The bulk composition of "hercynite" was not given but is presumed to be an Fe/Al-oxide spinel (the term hercynite should be reserved only for the spinel, $\mathrm{FeAl}_{2} \mathrm{O}_{4}$ ). All materials, including $\mathrm{MgAl}_{2} \mathrm{O}_{4}$ insulators, were plasma sprayed.

Electrode pairs 110 (cathode) $/ 210$ (anode) and $111 / 211$ majntained $1.0 \mathrm{~A} / \mathrm{cm}^{2}$ throughout the test while $112 / 212$ operated at $20.36 \mathrm{~A} / \mathrm{cm}^{2}$. Surface temperature calculated for anode 211 was $1590 \pm 75^{\circ} \mathrm{C}$ is the initial stages of the test but thermocouples were either inoperable or unreliable thereafter. Post-test visual observations by test monitors include,

a) "electrodes 210-212 are uniformly eroded but not excessively so", and

b) ".... next most severely damaged was electrode(s) 110-112. Part of the damage is due to bloating ... bloated region appears to contain the reddish colored hematite...." (as noted below, hematite is not an alteration product within our cathode sections). 
Based specifically on analytical data for the electrode cross-sections provided us by Westinghouse Corp. the following conclusions are apparent,

1) surface temperature probably did not exceed $1700^{\circ} \mathrm{C}$,

2) cathodes showed extensive penetration and corrosion by seed which ultimately may have been the primary conductor, and

3) anode spinels were subjected to phase transitions while corrosion by seed was less devastating.

These phenomena result from the enhanced porosity of plasma sprayed spinels. Denser materials have performed much better but are linited by other factors for clean-fired MHD.

3.3.4 Graded LaCrO $3 /{\underline{\mathrm{LaAlO}_{3}}}_{3}$ Solid Solutions, Westinghouse Corp. (E.N. Farabaugh)

of the three electrode pairs, the only pair which didn't suffer severe damage was 101-201. This could possibly be attributed to the fact that it was run at the lowest current density.

of the other two pairs, either the cathode or the anode of each pair was damaged. The 102-202 was in the next best shape after tesing. 102 suffered a little more damage than 202. In the pair 103-203, 203 was very severely reacted especially on the downstrean side (toward 204).

The pair 102-202 possessed a different microstructure from 103-203, lathlike islands of an Al-Cr rich Mg-Al-La-Cr phase present in 103-203 but not in 102-202. The islands (irregularly shaped) were also smaller in 202 and 203. It coesn't seem that this has had any effect on the performance of the electroces since it was difficult to attribute any specific degradation to these lath-like islands.

The anodes possessed a rather high concentration of $\mathrm{K}$ compared to other anodes which have been examined.

The reactions, in both cathodes and anodes, seem to be initiated in the Mg-Al-La-Cr phases islands. The $\mathrm{K}$ appears to react with the islands, depletes the $\mathrm{Mg}$ and probably causes the $\mathrm{Cr}$ to be vaporized more easily. As the reaction goes to its conclusion, the result, in the extreme, is that the islands are gone leaving a porous stricture. The material left is Cr depleted. In 102, 202, 203, there was evidence of a fluid phase being developed also which seems to begin as a joining of islands and results, in the plasma surface, in occupying much of the surface area.

A Cr-poor Zr-Ca-Al-La-Cr phase was developed at the plasma surface on all of the electrodes. The composition of this surface layer varied both in composition and thickness from electrode to electrode.

All the electrodes examined were parted from the copper cooling strip so little study could be made of this joint. 


\subsubsection{U-02, Phase III Pre-Test Ceramics (T. Negas)}

Prior to the U-02, Phase III test scheduled for May 1978, we received several representative electrode materials from westinghouse Corp. for characterization by SEM/EDX methods. These materials include,
$70 \mathrm{w} / 0 \mathrm{La}$
dispersedi $95^{\mathrm{Mg}} 0.05^{\mathrm{CrO}_{3}}$ with $30 \mathrm{w} / 0 \mathrm{ZrO}_{2}$ (Y-doped).
b) same as in (a) but graded to $1008 \mathrm{La}_{0.95^{\mathrm{Mg}}} 0.05^{\mathrm{CrO}_{3}}$;
c) $\mathrm{La}_{0.95^{\mathrm{Mg}}} 0.05^{\mathrm{CrO}} 3^{\text {; }}$
d) $\mathrm{LaMg}_{0.02} \mathrm{Cr}_{0.98^{\mathrm{O}}}$; and e) Graded LaCr $\mathrm{Al}^{\mathrm{A}} \mathrm{O}_{3} \mathrm{x}=0.32,0.24,0.15$, and $0.00 ;$ all stated to
contain the component Mgo as in (a).

All materials were examined and details are available upon request. Results, however, are sumarized below.

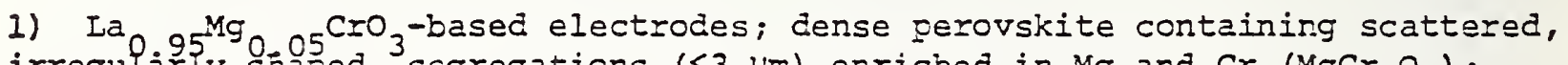
irregularly snaped, segregations $(<3 \mu \mathrm{m})$ enriched in $\mathrm{Mg}$ and $\mathrm{Cr}\left(\mathrm{MgCr}_{2} \mathrm{O}_{4}\right)$; assemblage $\mathrm{MgCr}_{2} \mathrm{O}_{4}$ plus $\mathrm{LaCrO}_{3}$.

2) La ${ }^{\mathrm{Mg}} \mathrm{Mg}^{\mathrm{CrO}_{3}}$ plus dispersed or graded $\mathrm{ZrO}_{2}$; anhedral, dense zirconia grains ${ }^{0}(20.75 \cdot 05$ wim) whin dense $\mathrm{LaCrO}$, with segregations noted in (1) above; $\mathrm{Al}, \mathrm{Si}, \mathrm{Fe}( \pm \mathrm{Ca})$-rich materials noted at $\mathrm{LaCrO}_{3} / \mathrm{ZrO}_{2}$ interfaces; $\mathrm{Al}, \mathrm{Si}, \mathrm{Y}$, ( \pm Ca) -rich segregations $(<0.01 \mathrm{~mm})$ distributed within $\mathrm{ZrO}_{2}$ grains.

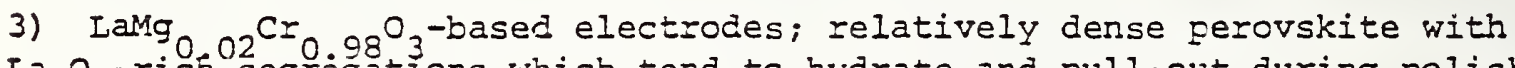
$\mathrm{La} \mathrm{O}_{3}$-rich segrẹgtions which tend to hydrate and pull-out during polishing; fracture surfaces better to analyze; no $\mathrm{MgCr}_{2} \mathrm{O}_{4}$ segregations.

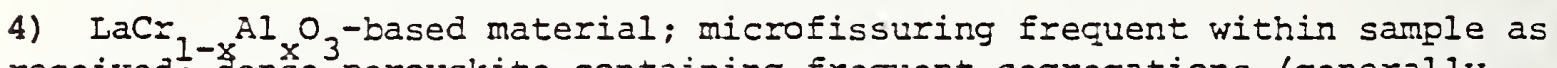
received; cense perovskite containing frequent segregations (generally $<3 \mathrm{\mu m}$ ) enriched in $\mathrm{Mg} ; \mathrm{Al}$, and $\mathrm{Cr}$ (spinel); lowermost (leacout) portion of ceramic resembles the LaMg $0.02 \mathrm{Cr} 0.98^{\mathrm{O}} 3$-based material (see above) rather than the $\mathrm{La}_{0.95^{\mathrm{Mg}}} 0.05^{\mathrm{CrO}_{3}}$ ceramic as originally incicated by the supplier. 
3.4 NBS/AVCO Slagging Test 2 (T. Negas, C. Olson, W. R. Hosler)

A prototype electrode for this test, constructed by APS Materials, was described in the previous Quarterly Report. A typical cross section (Figure I) was examined by SEM/EDX, primarily to verify attachment among dissimilar materials. Attachment of copper (C, Figure 19) to LaCrO (L) via a graded METCO $447 / \mathrm{LaCrO}_{3}$ bond appears excellent. Bonding between slag (S) and platinum (P) is poor, much of the slag being held by the side insulation ( $\mathrm{MgAl}_{2} \mathrm{O}_{4}, \mathrm{M}$ ). The $\mathrm{LaCrO}_{3}(\mathrm{I})$ to $\mathrm{Pt}$ bond remains fair but could be optimized by grading.

Plasma sprayed $\mathrm{LaCrO}_{3}$ faintly shows a lamellar structure and occasional intersecting fissures parallel with and perpendicular to this structure. This particular cross section was exposed at room temperature to air for several days prior to examination. When inserted into the SEM chamber difficulty was experienced in purping down the system. This suggested that a hygroscopic material was present. The sample was removed, "bakedout", and repositioned within the SEM. After normal pump-down, the LaCro, was found to be relatively inhomogeneous on a microscale. Figure 20 (9000k) is typical of the material. The brighter material in Figure 20 is richer in lanthana than the carker LaCrO $_{3}$ proper. This suggests a $\mathrm{La}_{2} \mathrm{O}_{3}$ Dlus $\mathrm{LaCrO}_{3}$ phase assemblage which accounts for the pump-down problen noted above. Bycration of lanthana with consequent swelling may create storage problems prior to testing. 


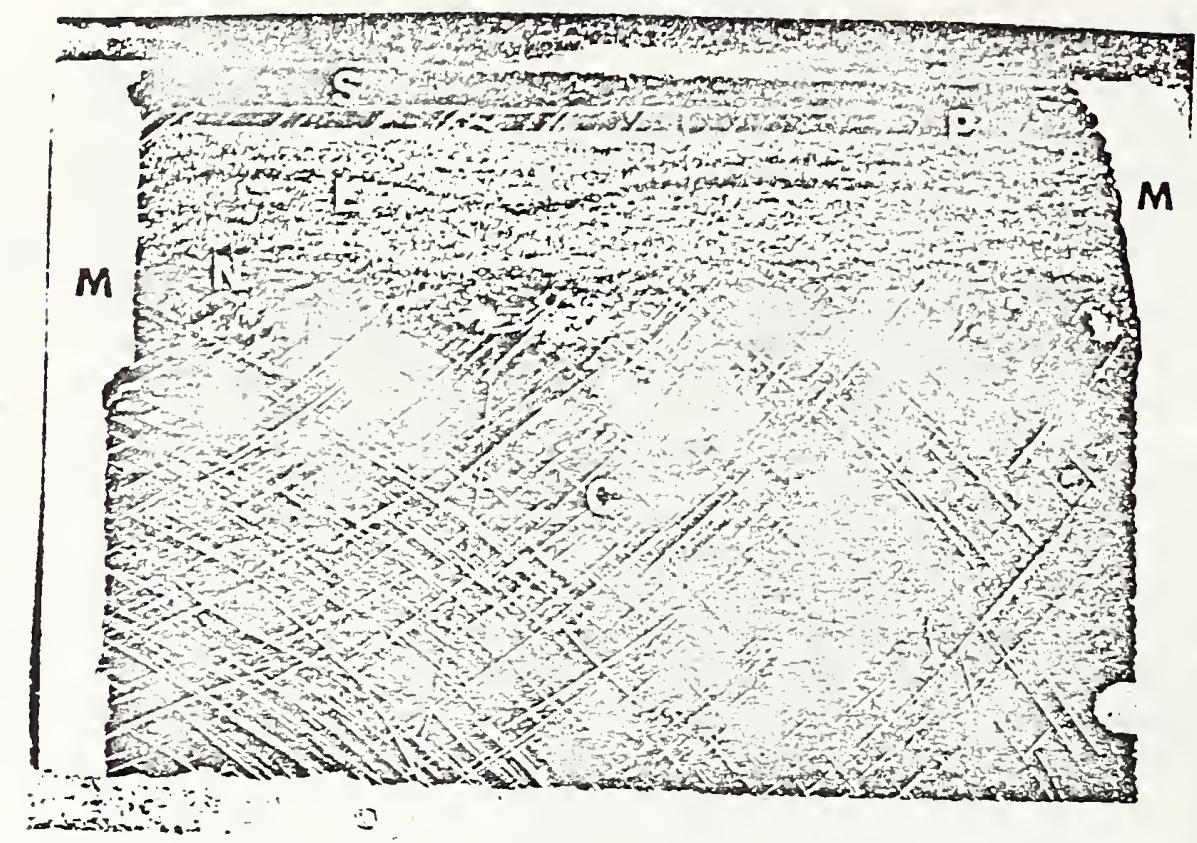

Figure 19. Cross section of electrode ( $5 \mathrm{X}) . \quad S=$ slag; $P=$ Pt metal; $M=\mathrm{MgAl}_{2} \mathrm{O}_{4} ; \mathrm{I}=\mathrm{LaCrO}_{3} ; \mathrm{N}=\mathrm{METCO} 447 / \mathrm{LaCrO}_{3}$ bond; $\mathrm{C}=$ copper.

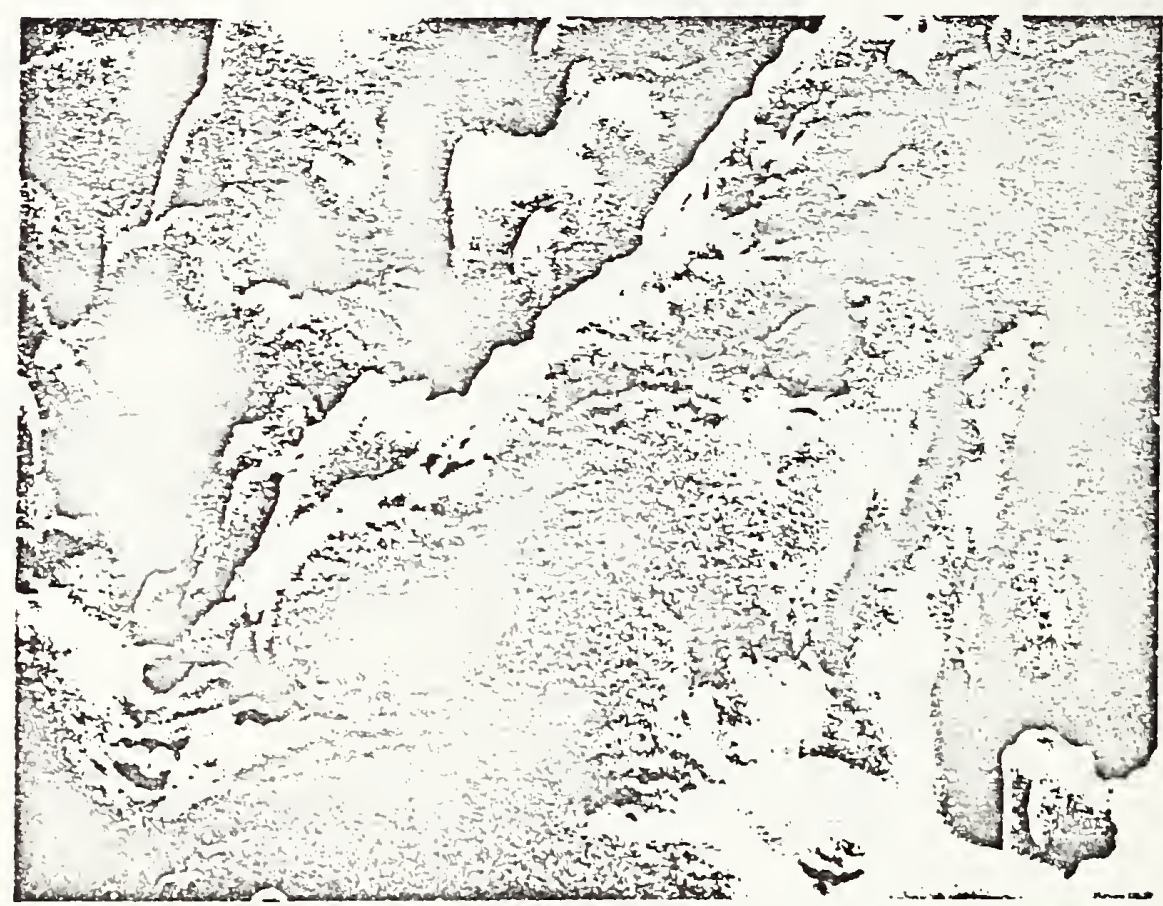

Figure 20. SEM micrograph (9000X) of $\mathrm{LaC}_{3}$ (see text). 
3.5 USSR Magnesia (T. Negas and $W$. R. Hosler)

Figs. 2lA and $21 \mathrm{~B}$ illustrate a specimen of the MgO-based ceramic utilized as a construction material for insulating walls by Soviet MHD researchers. This material was received from DoE.

The following properties can be sumarized,

a) bulk density, $3.16 \mathrm{~g} / \mathrm{cc}$; apparent density, 3.586,

b) open porosity, $u_{128}$

c) electrical conductivity,

1) $1000^{\circ} \mathrm{C},<3 \times 10^{-6}(\mathrm{ohm} \mathrm{cm})^{-1}$

2) $1200^{\circ} \mathrm{C},<2 \times 10^{-5}$ " "

3) $1400^{\circ} \mathrm{C},<5 \times 10^{-4}$

d) powder $x$-ray diffraction of the bulk (major phases), Mgo plus merwinite $\left(\mathrm{Ca}_{3} \mathrm{MgSi}_{2} \mathrm{O}_{8}\right)$ and/or $\mathrm{B}-(\mathrm{Ca}, \mathrm{Mg})_{2} \mathrm{SiO}_{4}$ solid solution,

e) dominant major and minor constituents (EDX analysis), Mg, Ca, Si, and $\mathrm{Fe} ; \mathrm{Ti}$ and $\mathrm{Mn}$ in traces.

Powder $x$-ray diffraction data reveal the presence of a significant quantity of $\mathrm{Ca}, \mathrm{Mg}-\mathrm{silicate}(\mathrm{s})$ within this particular ceramic specimen. The phase(s) apparently does not develop from natural impurities but rather is functional for processing and for operation. Figure 22A ( $40 \mathrm{X})$ illustrates the major general features of the material observed from a lightly polished surface. Large (up to ul mil), anhedral, and relatively dense particles of magresia (many of which are transparent to translucent) are contained within a finer-grained, more porous matrix of magnesia. Figure $22 \mathrm{~B}$ is a tipical EDX spectrum taken from the large magnesia particles. Calciun and iron frequently are detectable and are not partitioned. This suggests that the magnesia contains these minor components in solid solution. Refractoriness of the magnesia, however, is not compromised.

The large particles in Figure $23 \mathrm{~A}$ frequently are agglomerates "cemented" by $\mathrm{Ca}, \mathrm{Mg}-\mathrm{silicate}(\mathrm{s})$. Note, for example, the bright regions (1) in Figures 23 . $(1450 \mathrm{X}), 233(7600 \mathrm{X})$ and $23 \mathrm{C}(375 \mathrm{X})$. Figure 23D (1500X) shows similar, bright rounded inclusions within and adjacent to the larger particles. The spectra in Figs. 23E \& $23 \mathrm{~F}$ are typical for the "cement" phase, and inclusions. Calcium and $\mathrm{Si}$ always dominate but the Mg-content varies. This association of elements agrees with the powder $x$-ray diffraction data noted above although the presence also of a glassy phase is not precluded.

The finer-grained matrix of the ceramic is well illustrated by a freshly fractured surface. Figure $24 \mathrm{~A}(1500 \mathrm{x})$ is typical in revealing darker rounded particles of magnesia effectively "cemented" by the brighter Ca, Mg-silicate. Note, for example, the corresponding map in $24 \mathrm{~B}$ for $\mathrm{Si}$ plus Ca distribution. 
Chemical and physical evidence suggest that this particular ceramic is composed of fused-grain magnesia "grog" carefully classified according to particle size. The material probably was then rebonded by reactive thermal sintering utilizing a finer-grained magresia fraction together with a calcium silicate reactive agent. Development of a fluid phase and compolind formation with MgO enhanced bonding of the particles and densification. This ceramic body has been cleverly engineered for ease of preparation and for operation under thermal stress. Bulk size and shape (hexagonal prisms) together with controlled optimum porosity serve to diminish themomechanical stresses. During operation, certainly above $1500^{\circ} \mathrm{C}$, a very small amount of a liquid phase probably develops associated with the $\mathrm{Ca}, \mathrm{Mg}-\mathrm{silicate}$ phase. In trace amounts liquid phase formation would not be destructive but rather would serve to further "relax" the ceramic body to accommodate thermal stress.

Obviously this ceramic has been utilized successfully by Soviet researchers in 0-02 type generators. For "windowframe", high heat flux channel designs this ceramic would not be necessary. However, its use could be considered for other elements of the MHD system. 


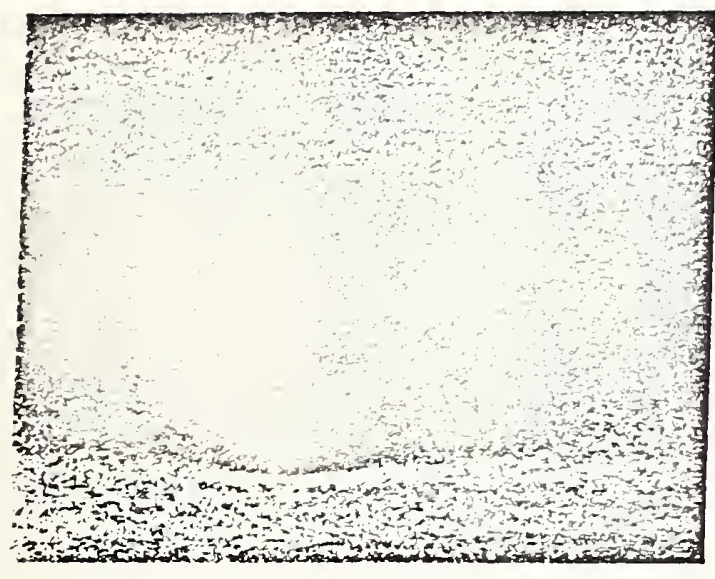

A

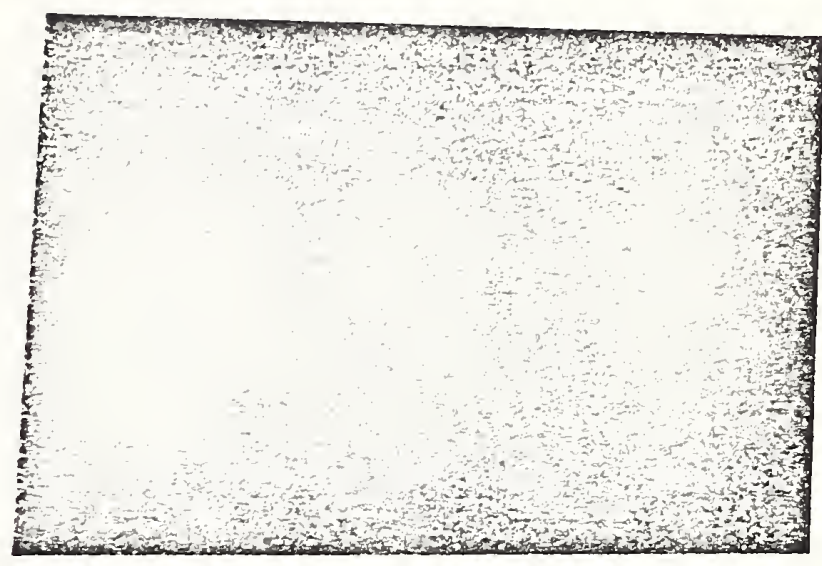

B

Figure 21. Magnesia-based ceramic for MFD generator insulating walls, USSR. 

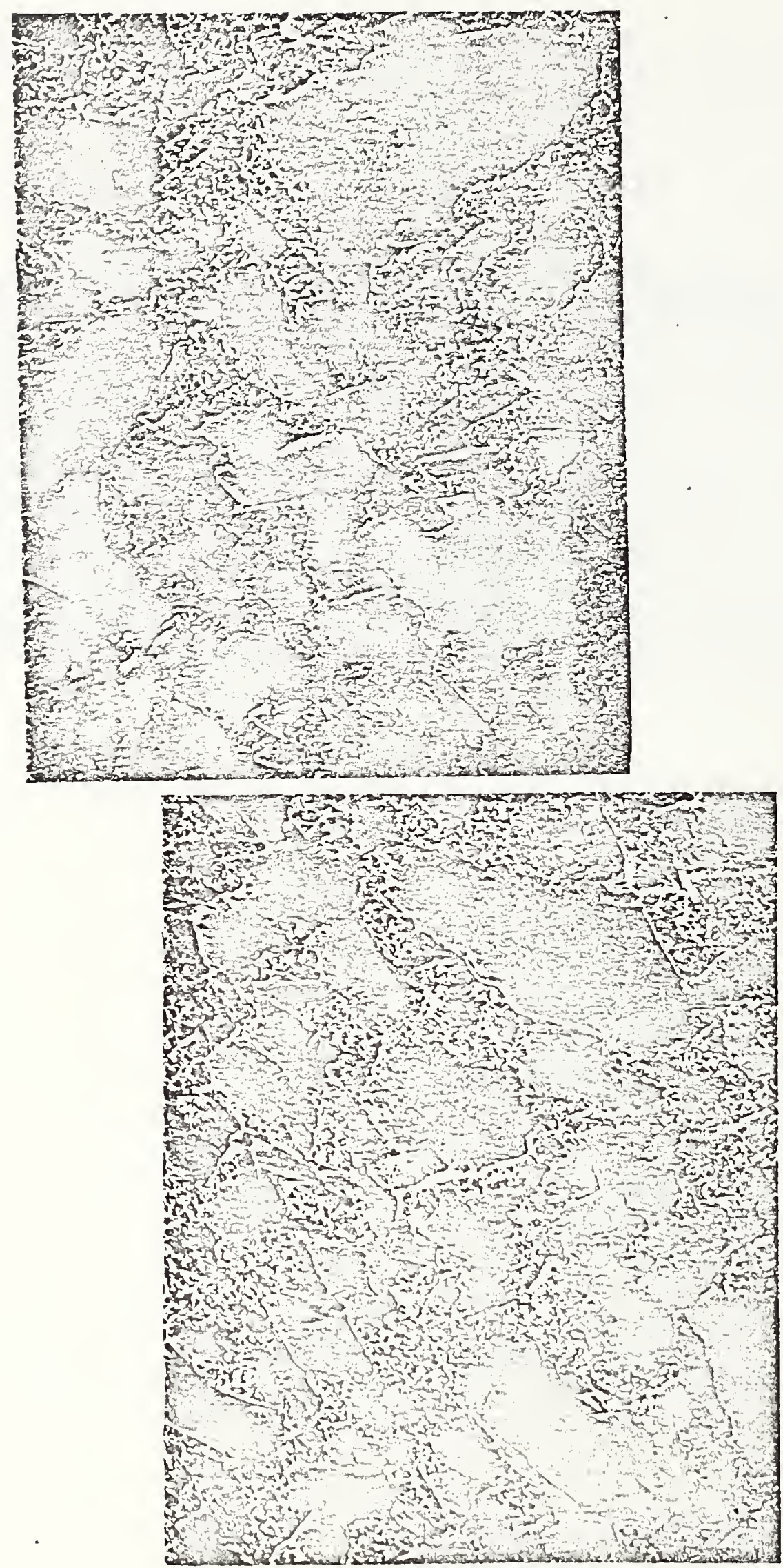

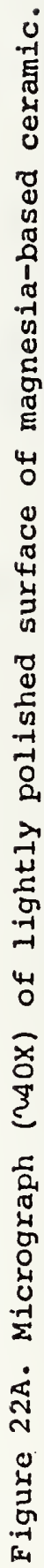



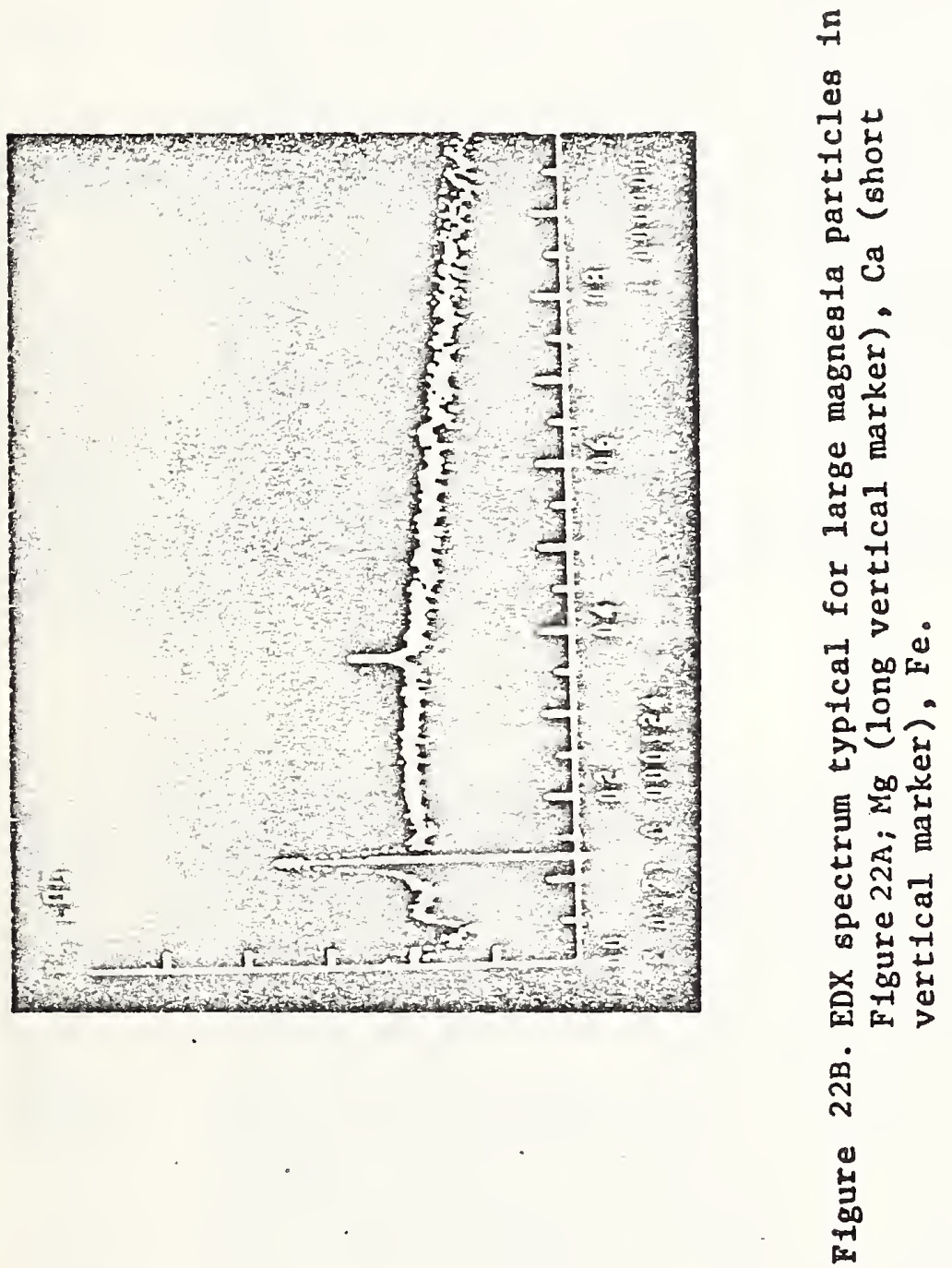


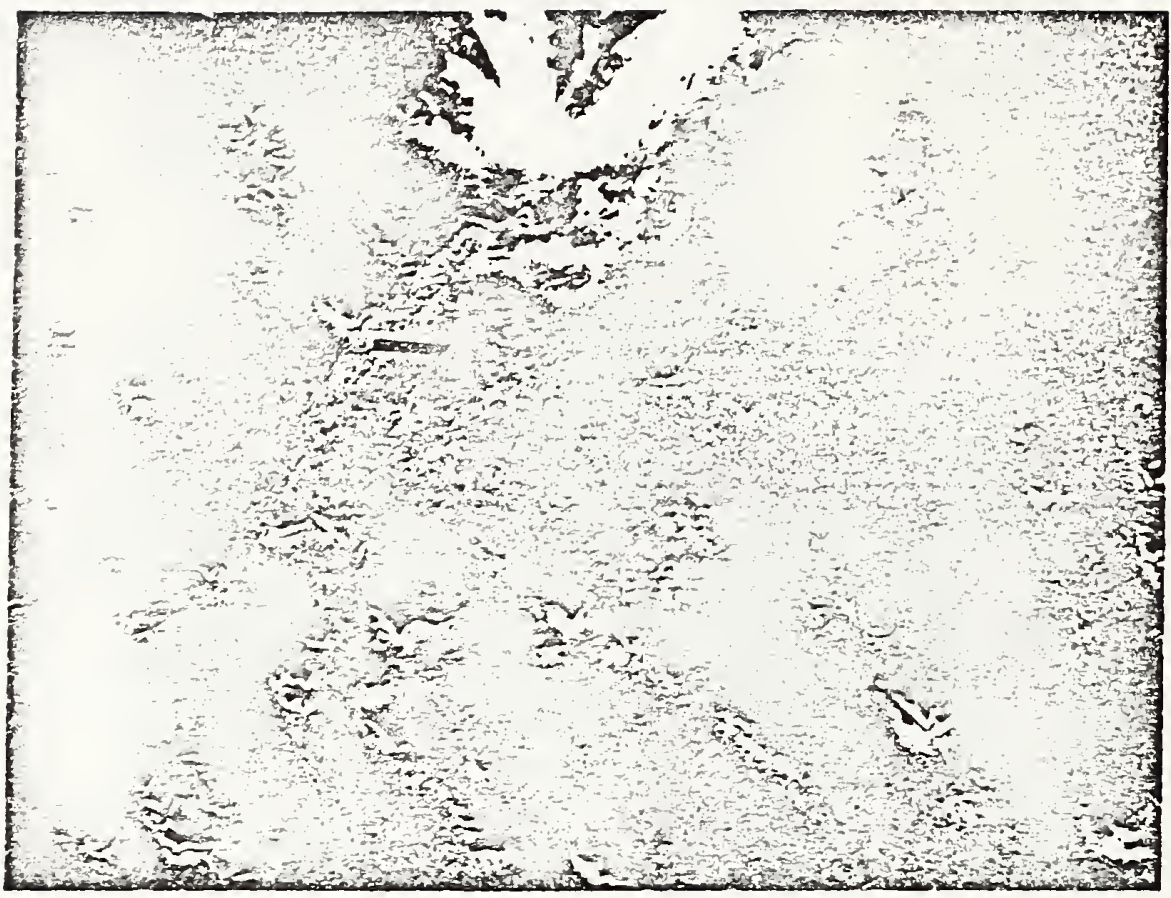

Figure $23 \mathrm{~A}$

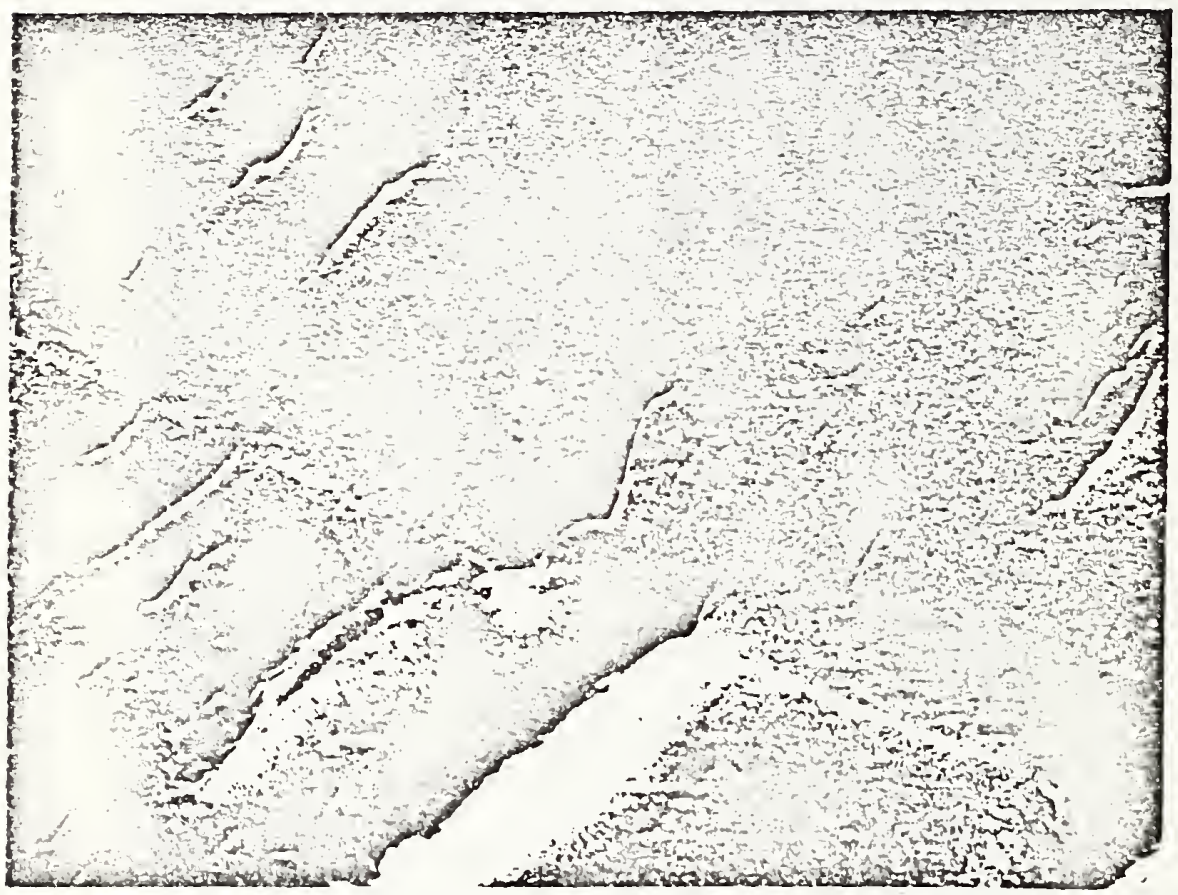

Figure

$23 B$ 




Figure

$23 \mathrm{C}$

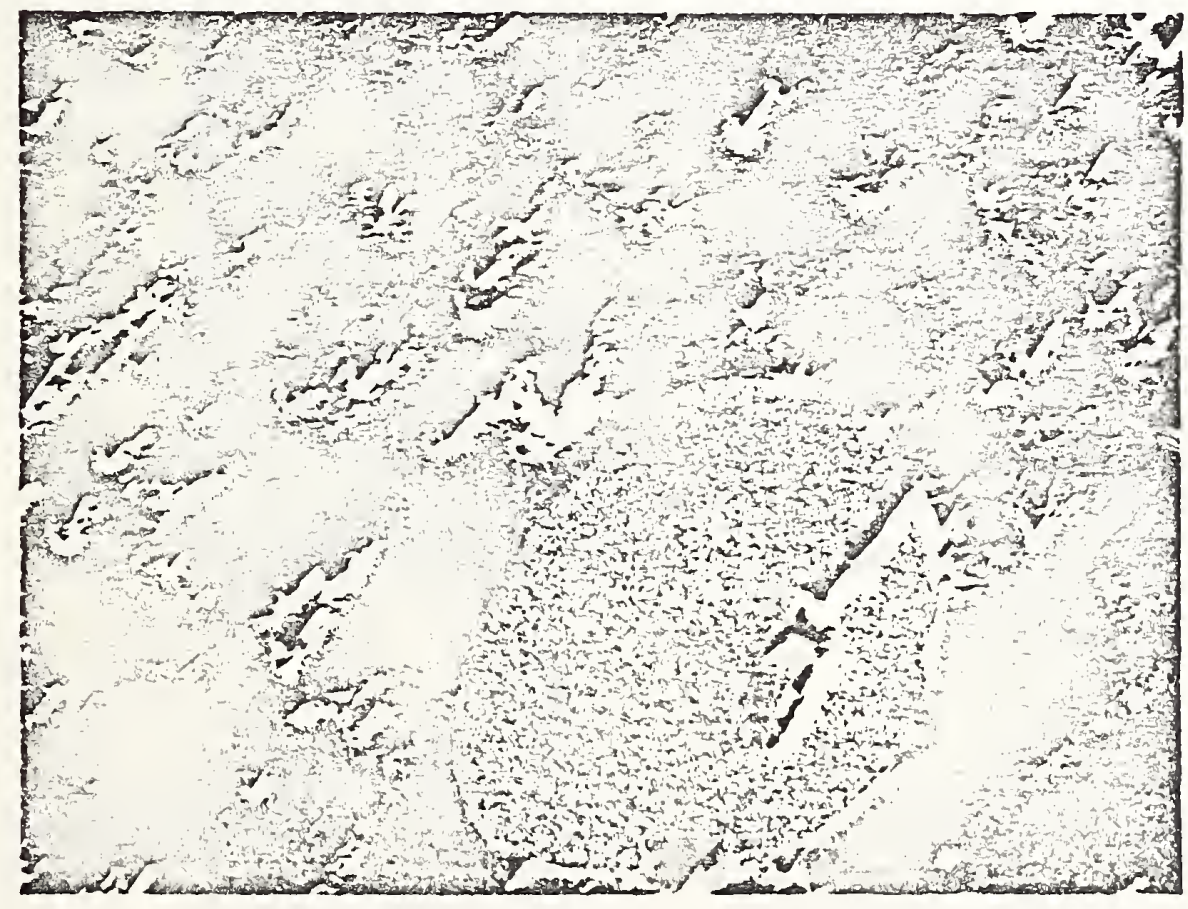

Figure

23D 


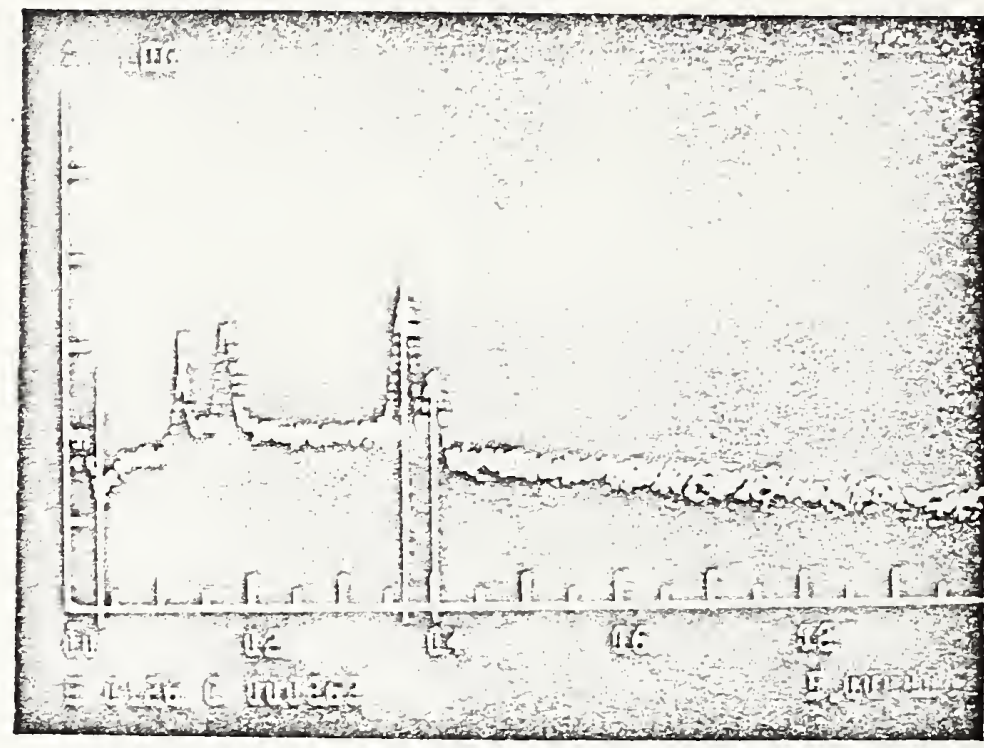

$23 E$

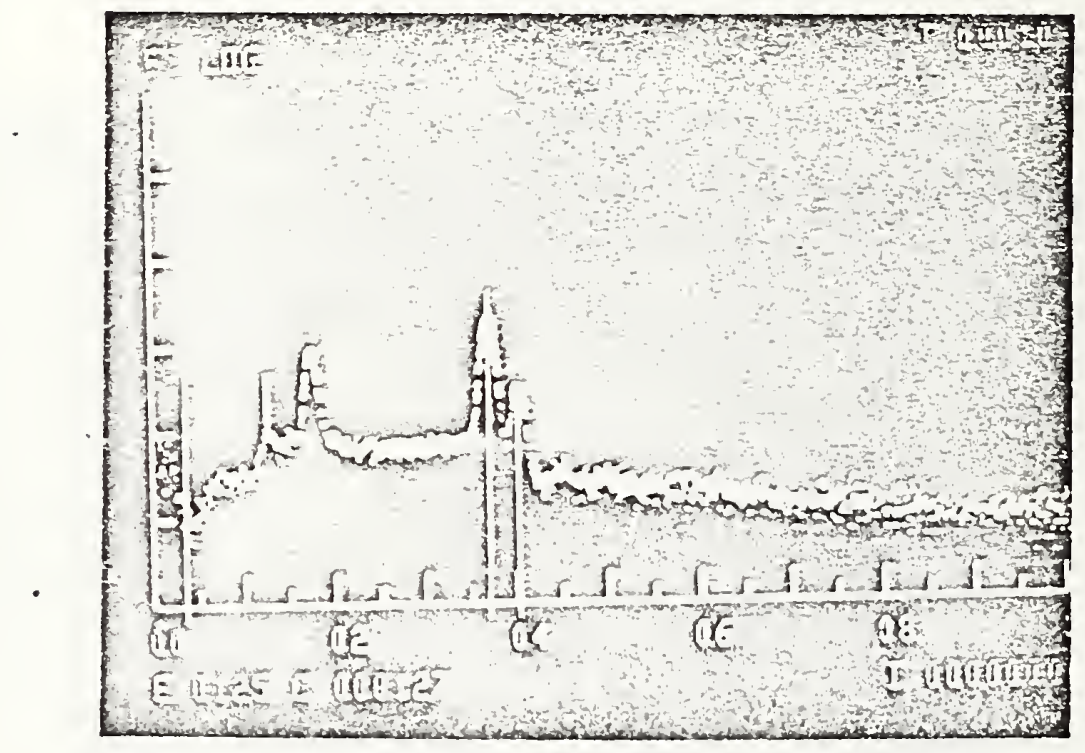

$23 F$

Figure 23. Micrographs A (1450X), B (7600X), C (375X), and D (1500X) showing bonding of magnesta particles by and inclustons of a Ca, Mg-silicate phase (1). Figures $E$ and $F$, are EDX spectra for phase (1); Mg (short vertfcal marker), Si, and $\mathrm{Ca}$ (long vertical markers). 

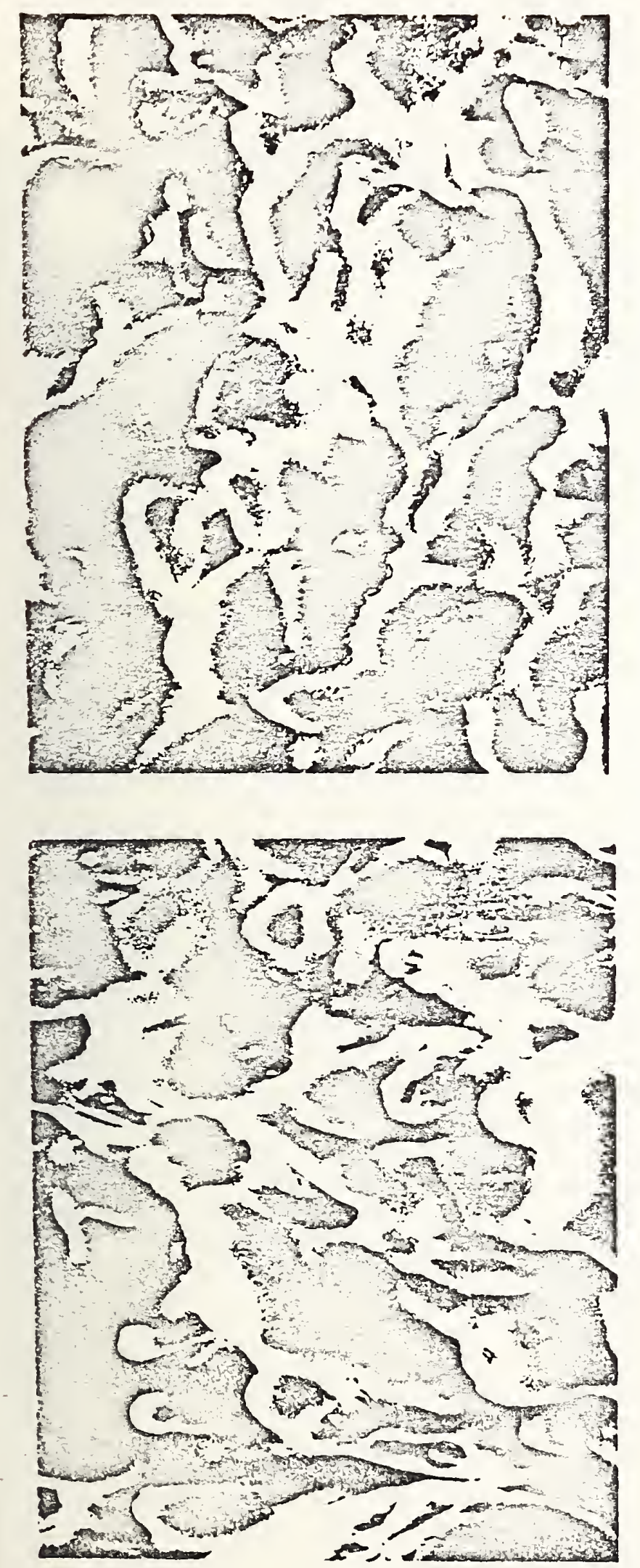

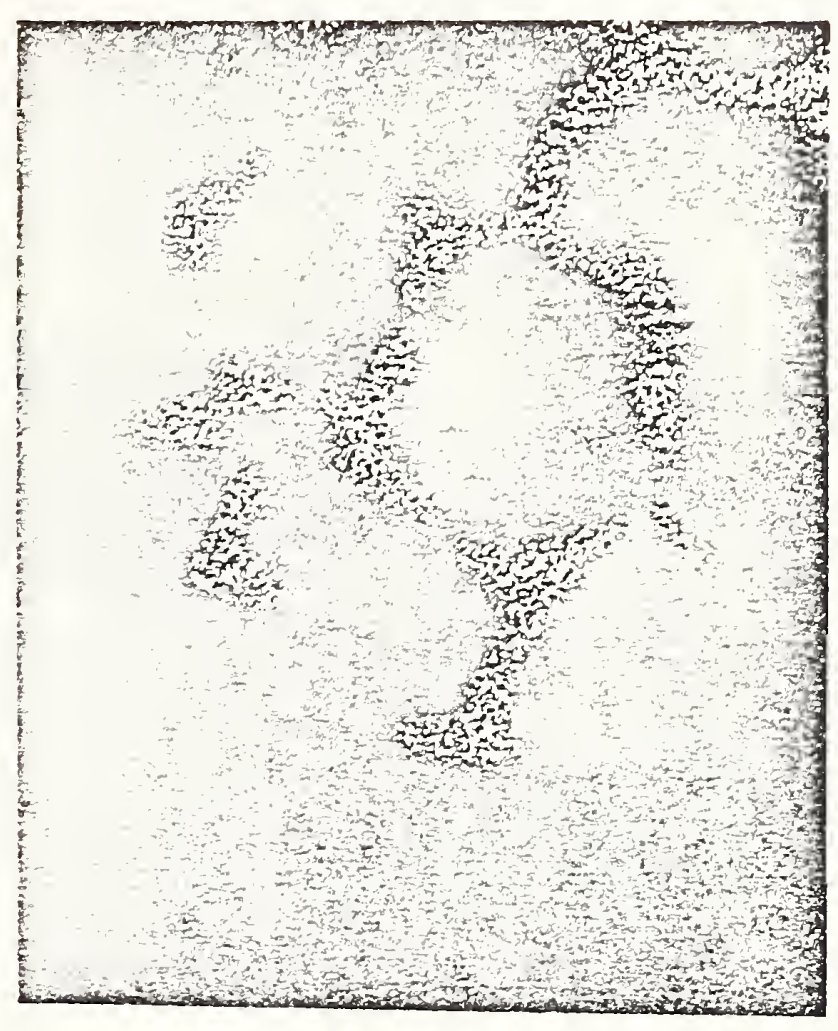

\্

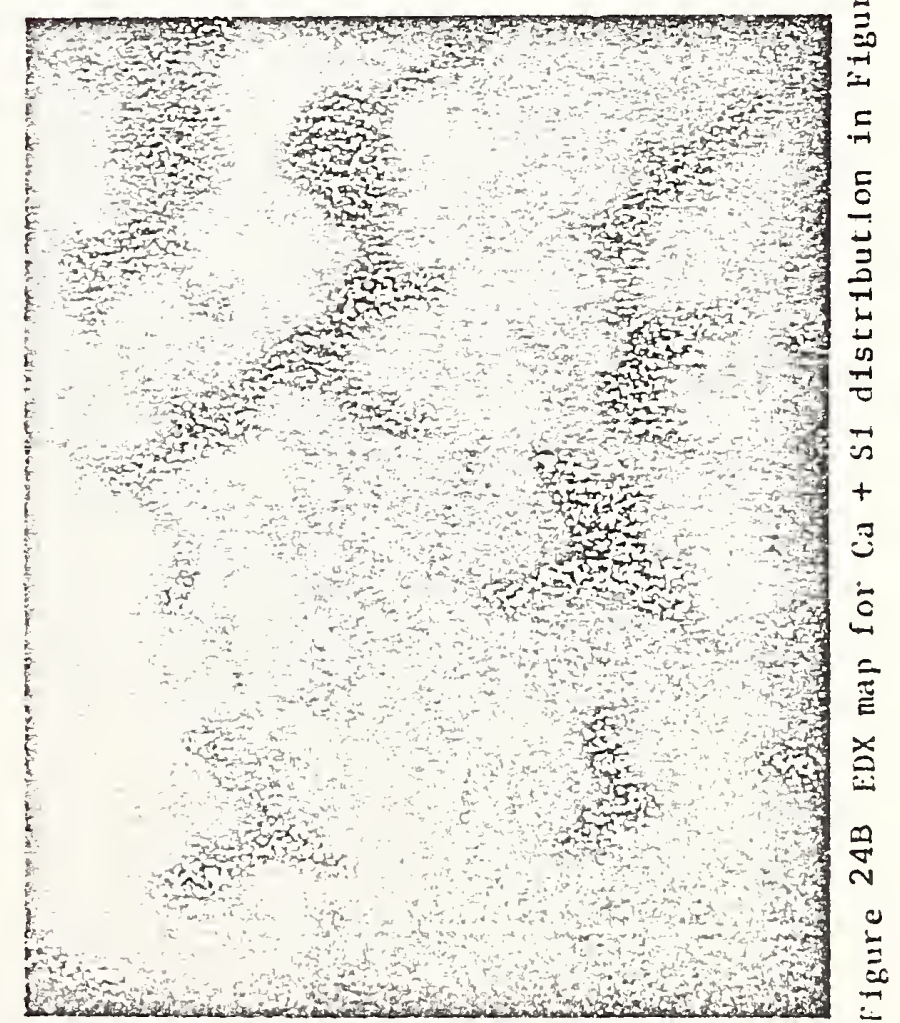




\subsection{UTSI Slag (T. Negas)}

The following specimens recently were received from UTSI,

a) several milligrams of a residue taken from the surface of a copper anode,

b) a "chunk" of anode slag, and

c) a well-polished cross-section of slag extracted from above a copper anode.

Insulation used and upstream/downstream orientation associated with item c) were not specified. These materials were examined and a report was submitted to UTSI. A sumary of this report is provided below.

Item (a) was identified as $\mathrm{Cu}_{2} \mathrm{O}$ by powder $\mathrm{x}$-ray diffraction. Item (b) was ground and also analyzed by $x$-ray diffraction to determine major crystalline phases present. Low-KAlSio and a "spinel" having a cell parameter similar to $\mathrm{Fe}_{3} \mathrm{O}_{4}$ dominate the material (excluding amorphous glass). The "spinel" phase could be a series of spinel solid solutions closely related in bulk composition and having similar cell parameters (e.g. iron oxide-rich members within the $\mathrm{CuFe} \mathrm{O}_{4}-\mathrm{Fe}_{3} \mathrm{O}_{4}$ series perhaps including $\mathrm{MgFe}_{2} \mathrm{O}_{4}, \mathrm{MgAl}_{2} \mathrm{O}_{4}$, and/Or $\mathrm{FeAl}_{2} \mathrm{O}_{4}$ components). SEM/EDX analyses support this interpretation.

Item (c) was examined using SEM and EDX methods. The anode slag layer illustrated in Figure 25 is subdivided for purposes of characterization by the superimposed dashed lines. Evidently the protrusion apparent in the figure defines the position of the insulator gap between copper frames. The "slag" has "stuck" and partly interacted with the cooled insulator ( $\mathrm{Al}_{2} \mathrm{O}_{3}$ ?) to locally thicken. A thinner slag layer cevelops above cold copper at either side of the insulator gap. Within the lowermost part of the protrusion (zone A, Figure 25) and within zone B, Figure 25 , the "slag" remains relatively homogeneous except when acjacent to $\mathrm{Cu}$ and/or insulation (see below). Crystallization and/or partitioning of elements are mostly absent within zone $A$ and the lower part of zone B, apparently reflecting the combined effects of lower temperature, higher viscosity, and short equilibration tine. Slag within the upper (plasma side) part of zone $B$ was probably entirely molten and quenched to a glass during cooldown. This homogeneity combined with a relatively flat surface permits, at least, a qualitative assessment of the distribution of copper dissolved in slag. Typical spectra, therefore, are shown in Figure 25. As expected, Cu-content diminishes from base to surface. At and near the slag surface, copper is barely detectable. 
Slag zones C and D (Figure 25) are heterogeneous and their interface is marked by well-developed porosity. Zone $D$ is characterized by extensive internal porosity and fissuring suggestive of evolution of gas and/or localized turbulence and crystallization. Zone $C$ appears less well-defined within the thinner slag segment and is included as part of zone $D$.

Anode slag zones are further characterized by rather consistent microchemical and microstructural features which are documented in the final report.

Apart from the relatively large concentration of Cu within this anode slag, few conclusions can be derived without examining additional anode and cathode samples. Copper metal apparently is oxidized and simultaneously dissolved within the slag layer. Sulfur and, possibly, phosphorus may participate in corrosion processes. Available iron from the slag acts as a "scavenger" to precipitate much of the dissolved copper as an oxide, probably a spinel. Some of our observations could be related to electrochemical phenomena but these interpretations are reserved until additional samples are examined. 


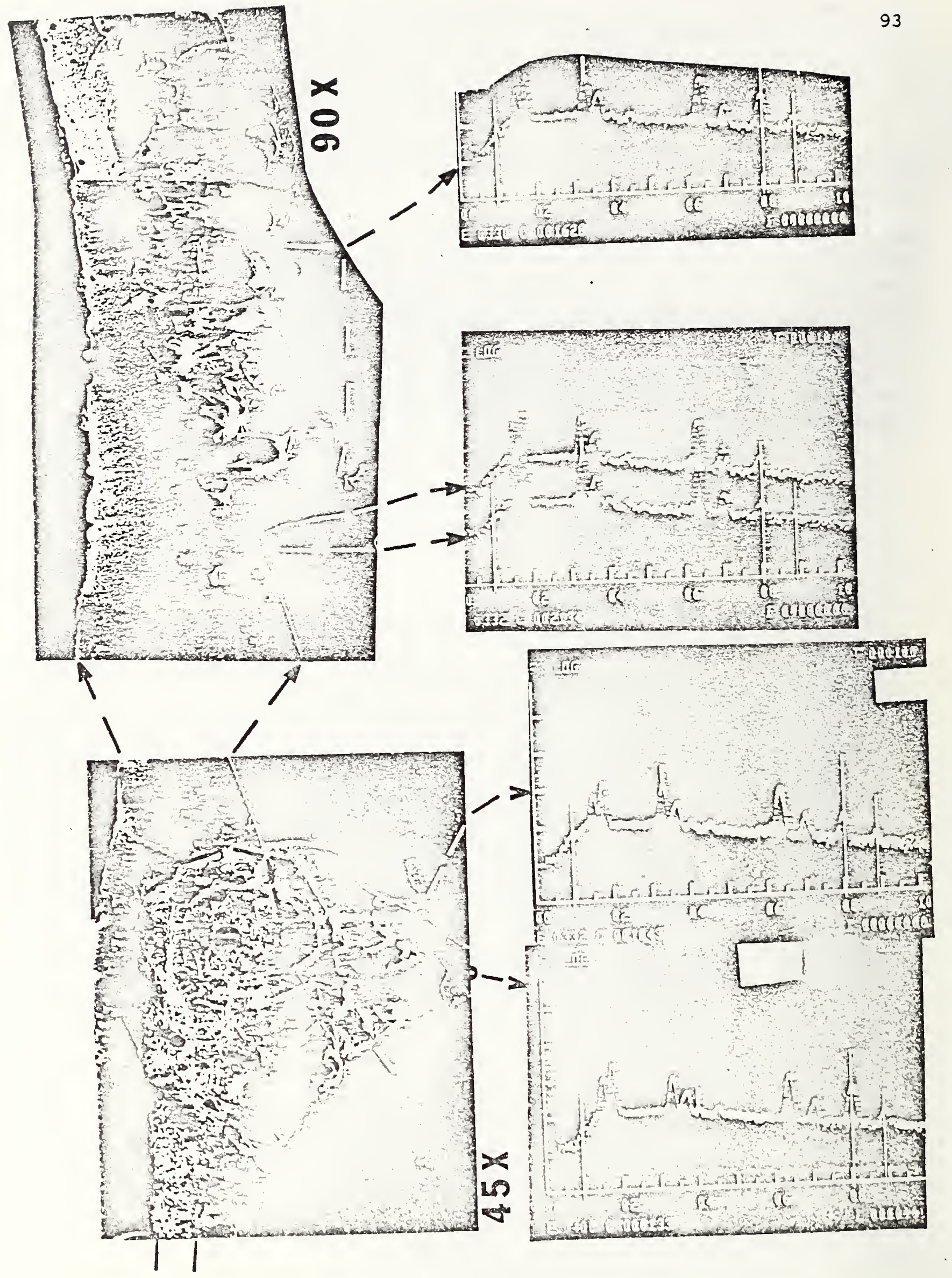

• 
4. Materials Development and Analysis

\section{Preparation of YCrO 3 -Based Ceramics (T. Negas)}

Utilizing sinterable powders developed by L. Domingues of Trans-Tech, several exploratory thermal sintering runs were performed to establish conditions which could be used to produce high density ceramics based on $\mathrm{YCrO}_{3}$. The first experiment was conducted at $1700-1725^{\circ} \mathrm{C}, \mathrm{P}_{\mathrm{O}_{2}}=10^{-10} \mathrm{~atm}$ (established by mixing $\mathrm{CO}_{2} / \mathrm{CO}$ ) for four hours of soaking. Cored, ceramic blocks less than 953 of theoretical density were obtained. From $1750^{\circ} \mathrm{C}$, $\mathrm{P}_{2}=10^{-12}$ atm and a soaking period of eight hours, crack-free ceramic rods, 96-97\% of theoretical density, were produced. Finally, a shortduration experiment at $21750^{\circ} \mathrm{C}$ (induction heating) in forming gas yielded $>96 \%$ dense specimens. Internal microfissuring, however, was generated by the rapid cooldown used. Nevertheless, a forming gas environment combined with controlled heating and cooldown rates and themal sintering in the $1700-1750^{\circ} \mathrm{C}$ range should prove suitable to prepare test specimens. 
1. Laboratory Hot Corrosion Screening Program

The apparatus constructed for this program has produced the required $1330^{\circ} \mathrm{C}$ hot zone temperature. In addition the temperature of the test specimen in the hot zone can be maintained down to the desired $550^{\circ} \mathrm{C}$ by air cooling. The temperature gradients and variations in the $2.5 \mathrm{~cm}$ working hot zone and in the corresponding specimen region are approximately $\pm 40^{\circ} \mathrm{C}$ at $1330^{\circ} \mathrm{C}$ in the hot zone and $\pm 30^{\circ} \mathrm{C}$ at $550^{\circ} \mathrm{C}$ for the air cooled specimen in that hot zone.

For tests conducted to date a reagent grade crystalline $\mathrm{K}_{2} \mathrm{SO}_{4}$ has been added to the hot gas stream at the burner. This results in a formation downstream in the hot zone of two types of deposits on the $1.25 \mathrm{~cm}$ diameter tubing test specimens. The first type is a heavy adherent columnar deposit on the surface facing the hot gas stream; the second type is a fine powdery deposit and is found on the remaining surface. Both deposits were analyzed by $x$-ray diffraction and found to be $\mathrm{K}_{2} \mathrm{SO}_{4}$. It was noted and not unexpected that as the deposits built up on the tubing the amount of cooling air required to maintain the specimen at the desired temperature diminished. The deposits acted as a thermal insulator. It takes but a short time, less than thirty minutes, at a $\mathrm{K}_{2} \mathrm{SO}_{4}$ flow rate of about 10 grams per minute to form deposits that appear not to increase in thickness beyond that time. A specimen of 304 stainless steel tubing, $1.25 \mathrm{~cm}$ in diameter with a wall thickness of $0.089 \mathrm{~cm}$ was exposed in the test apparatus for an abreviated flow time and then analyzed. The test conditions were:

$\begin{array}{ll}\text { a. Hot zone temperature } & 1330^{\circ} \mathrm{C} \\ \text { b. Specimen temperature } & 550^{\circ} \mathrm{C} \\ \text { c. Total test time } & 4 \text { hours } \\ \text { d. } \mathrm{K}_{2} \mathrm{SO}_{4} \text { flow rate } & 10 \mathrm{gm} / \mathrm{min} \\ \text { e. } \mathrm{K}_{2} \mathrm{SO}_{4} \text { flow time } & 30 \mathrm{~min} .\end{array}$

Metallographic specimens were prepared from sections taken out of the test piece at the mid point position in the hot zone and at approximately $0.6 \mathrm{~cm}$ away from that position. The specimens were prepared using non-aqueous media for both cutting and polishing to minimize reaction with the $\mathrm{K}_{2} \mathrm{SO}_{4}$ deposits.

SEM/EDX analysis revealed non uniform attack in both specimens. In specimen 1, the mid point specimen, no apparent attack occurred under the heavy $\mathrm{K}_{2} \mathrm{SO}_{4}$ deposit. Figure 1 is typical SEil micrograph of the $\mathrm{K}_{2} \mathrm{SO}_{4}$ - stainless steel interface in this region. The light gray material on the left is 304 stainless steel; the material on the right is $\mathrm{K}_{2} \mathrm{SO}_{4}$. The interface region was analyzed by EDX and found to contain no abnormalities. In the same specimen, but under the powdery coating, discontinuous attack at the interface was observed. Figure 2 shows one such region. EDX analysis indicates that the light gray material on the left is the 304 stainless steel. The dark gray region immediately adjacent to it is a $\mathrm{Cr}$ rich region. The bright region next to that is $\mathrm{Fe}$ rich and the dark grayporous region to its right is the powdery $\mathrm{K}_{2} \mathrm{SO}_{4}$ deposit. Figures $3,4,5$ and 6 are the EDX spectra associated with these regions. The lower trace of figure 3 is the 
spectrum obtained for the 304 stainless steel and shows $\mathrm{Cr}, \mathrm{Fe}$ and $\mathrm{Ni}$. The upper trace is from the dark gray region immediately adjacent to the stainless steel. It indicates a $\mathrm{Cr}$ rich or Fe depleted region. The upper trace of figure 4 is of that same.region while the lower trace is of the bright region between it and the dark gray porous $\mathrm{K}_{2} \mathrm{SO}_{4}$ region. This trace shows an $\mathrm{Fe}$ rich region containing some $\mathrm{Cr}$ but no Ni. Figures 5 and 6 are traces of the $\mathrm{Cr}$ rich and Fe rich regions which were analyzed for oxygen. The oxygen peak shows at the far left of the left of the marker on both traces. This would indicate the following sequence of materials: 304 stainless steel, chromium rich oxide, iron rich oxide and $\mathrm{K}_{2} \mathrm{SO}_{4}$.

In specimen 2 , taken about $0.6 \mathrm{~cm}$ away from the mid point, no detectable attack occurred under the powdery $\mathrm{K}_{2} \mathrm{SO}_{4}$ deposit. There was, however, nonuniform attack under the heavy $\mathrm{K}_{2} \mathrm{SO}_{4}$ deposit. Figures 7 and 8 are SEM micrographs that illustrate this. Figure 7 shows a 304 stainless steel $\mathrm{K}_{2} \mathrm{SO}_{4}$ interface with no region of abnormality. Figure 8 shows a region of attack. Figure 9 is the sane region as figure 8 but at a higher magnification. This figure can be compared to figure 5 (approximately the same magnification) noting that the depth of attack is twice that is shown in figure 5 . Also note the greater degree of definition in the attack region in figure 9. As in figure 5 the EDX analysis shows the light gray material on the left to be 304 stainless steel and the dark gray fissured material on the right to be $\mathrm{K}_{2} \mathrm{SO}_{4}$. To the left of the $\mathrm{K}_{2} \mathrm{SO}_{4}$, the region between the two slender dark bands is an $\mathrm{Fe}$ rich $\mathrm{Ni}$ free region. To the left of this is the $\mathrm{Cr}$ rich region. However, in this case there is a narrow sulfur rich band between the 304 stainless steel and the $\mathrm{Cr}$ rich region. Figure 10 is the EDX spectra of the region between the $\mathrm{S}$ and the $\mathrm{K}_{2} \mathrm{SO}_{4}$ region. The lower trace is of the $\mathrm{Fe}$ rich region next to the $\mathrm{K}_{2} \mathrm{SO}_{4}$; the upper trace is of the $\mathrm{Fe}$ depleted region between the $F e$ rich region and the S- stainless steel region. The corrosion band is about 25 microns thick in this case as opposed to the 10 micron thick band under the powdery deposits. The material sequence is the same as the in $10 \mathrm{micron}$ band except for the sulfur band between the 304 stainless steel and the $C_{r}$ rich oxide region.

There are two interesting findings from the analysis detailed above. The first is the localized nature of the corrosion attack and the second is the appearance of sulfur in the region of most severe attack. An unstated, though implied goal of this program is the detection of corrosion in its initial stages. It appears that the procedures and techniques described in this section are capable of detecting incipient corrosion induced by a salt laden hot gas stream. Other candidate materials for down stream components, as detailed in the previous quarterly report will be treated and analyzed in this way to verify and to determine the reasonableness of short duration exposures. 


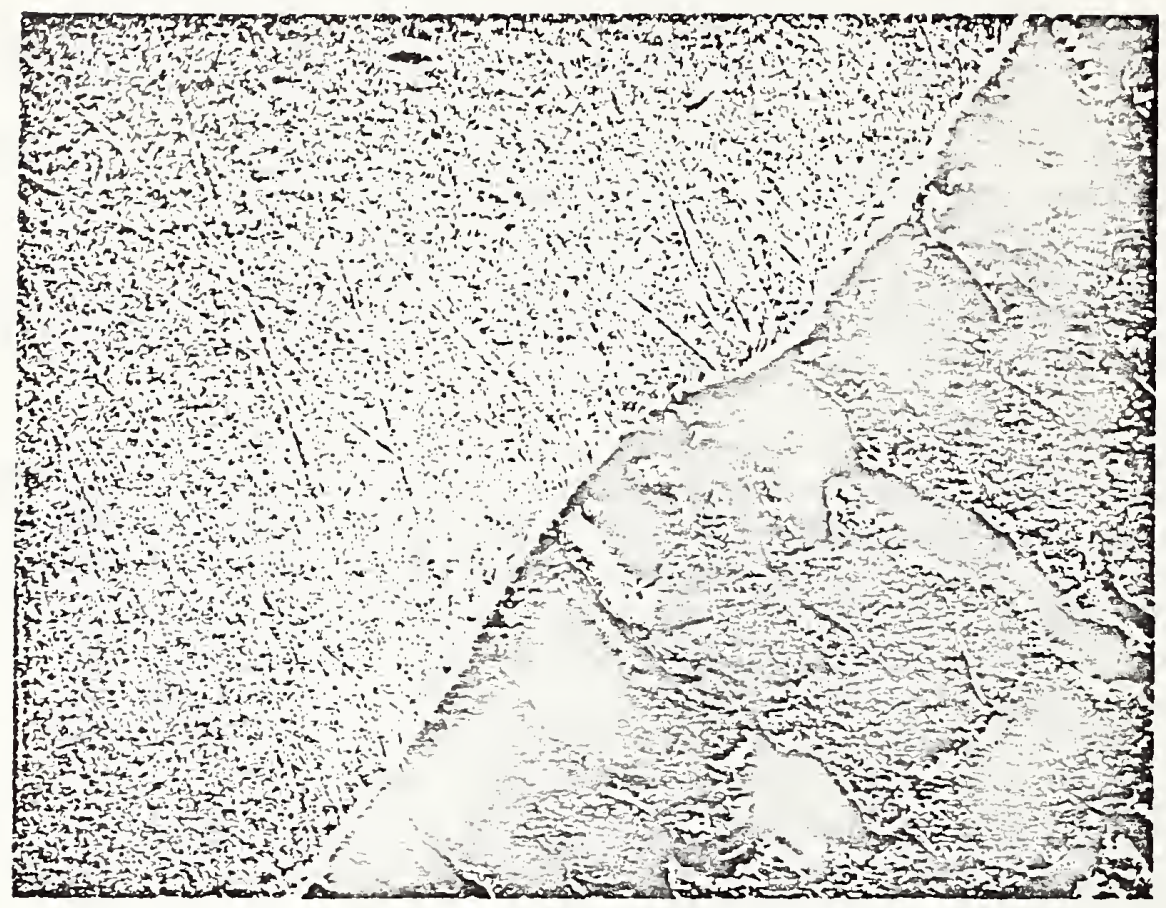

Figure 1. SEM micrograph (900X) of interface region between 304 stainless steel (left) and columnar $\mathrm{K}_{2} \mathrm{SO}_{4}$ (right).

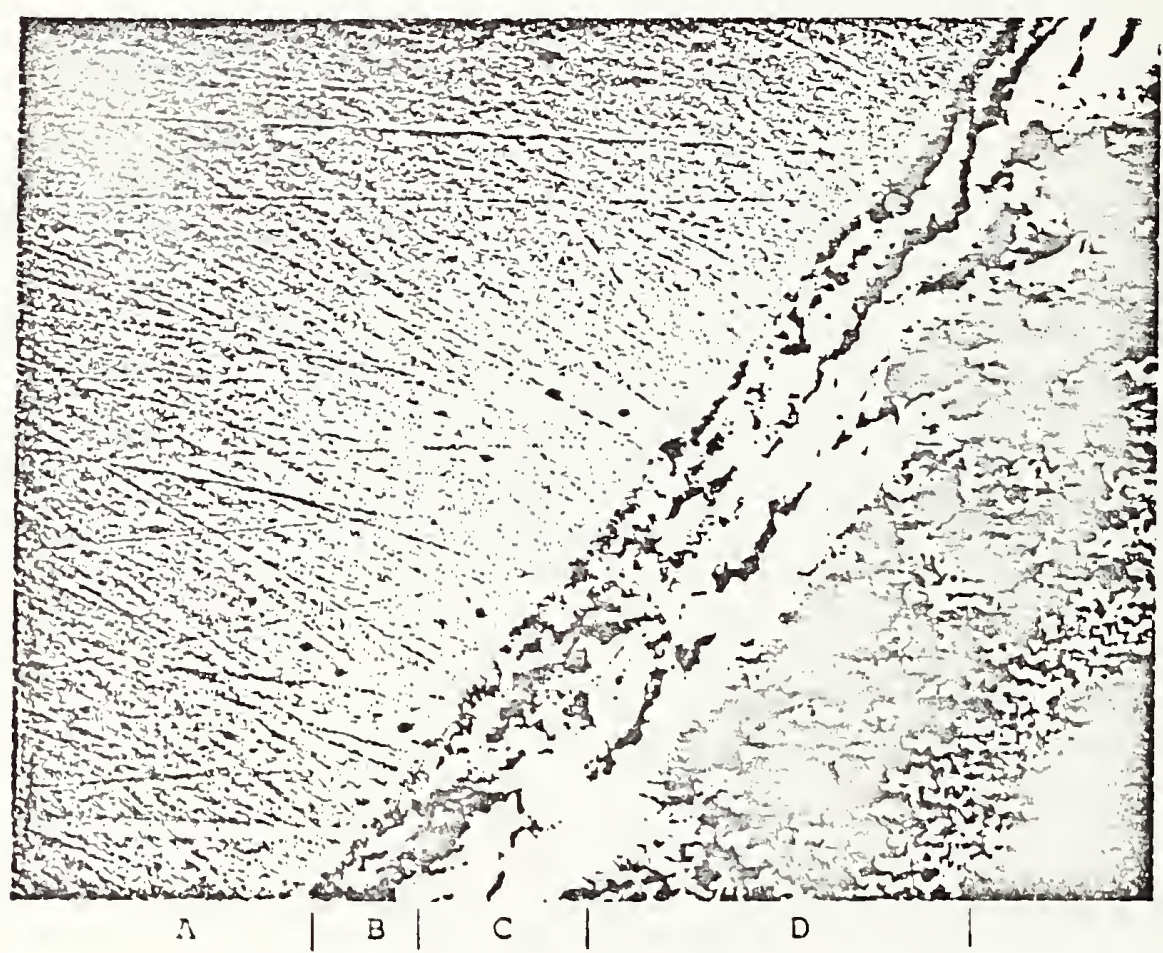

Figure 2. SEV micrograph (1800X) of interface region between 304 stainless steel (A) and powdery $\mathrm{K}_{2} \mathrm{SO}_{4}$ (D) showing corrosion band of $\mathrm{Cr}$ rich oxide layer (B) and iron rich oxide layer (C). 


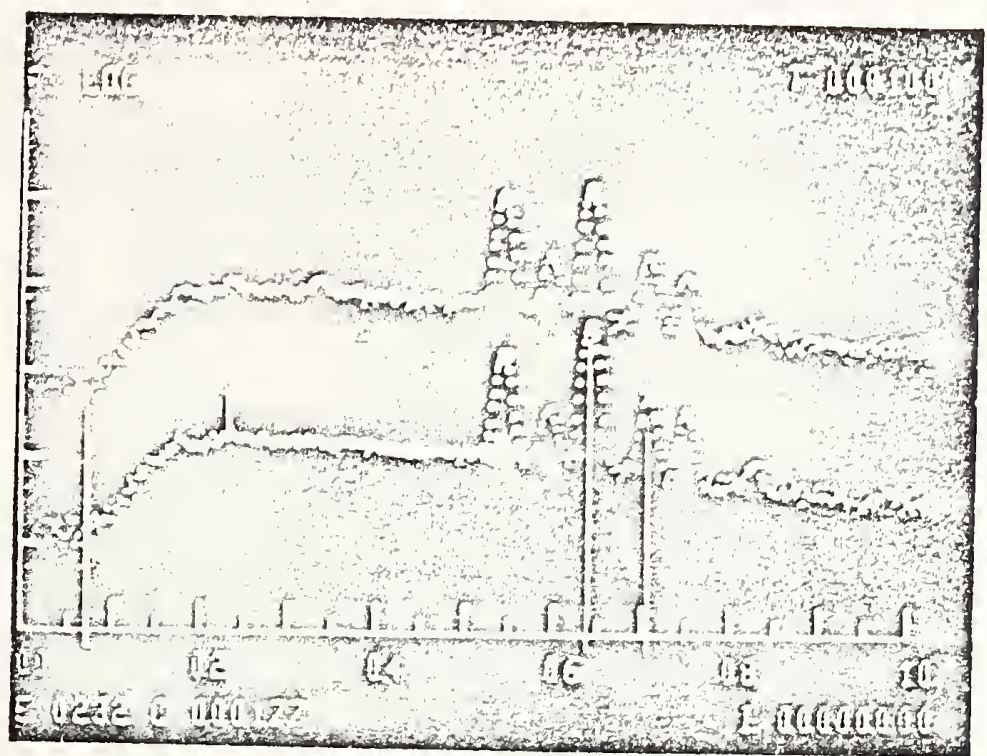

Figure 3. EDX spectra of corrosion region of figure 2. Lower spectrum is of 304 stainless steel, the upper trace is of zone (B). Markers on the right are set on the Fe peaks, the two peaks to the right of $\mathrm{Fe}$ on the lower spectrum are $\mathrm{Ni}$, the two to the left are $\mathrm{Cr}$.

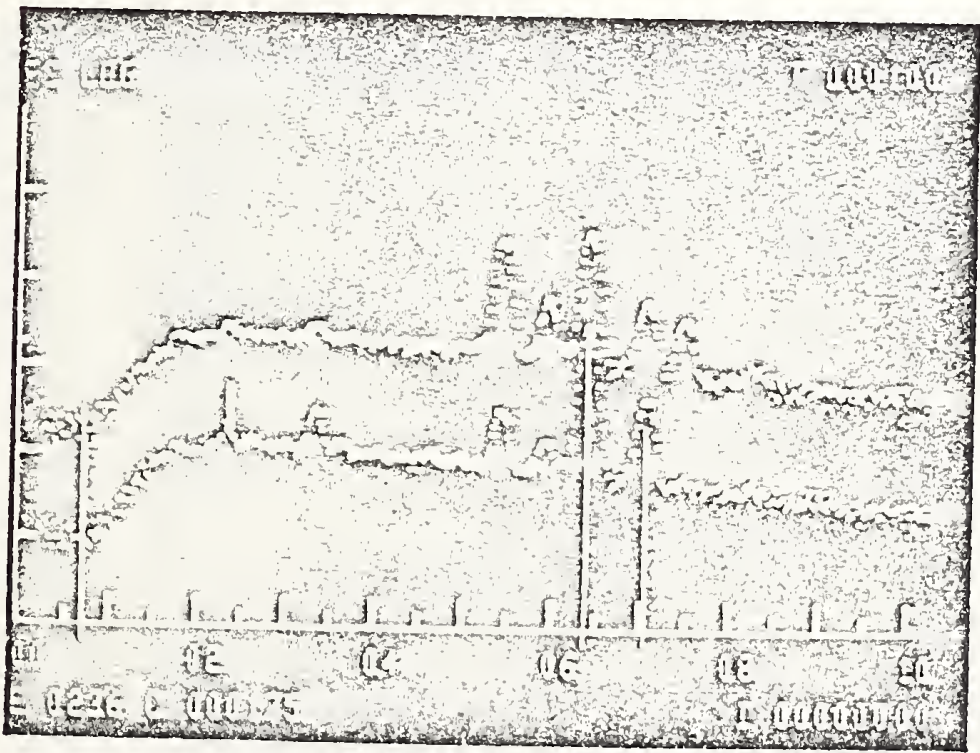

Figure 4. EDX spectra of the corrosion region of figure 2. Upper spectrum is of zone (B), shown to the $\mathrm{Cr}$ rich: The lower is of zone (C) shown to be $\mathrm{Ni}$ depleted and Fe rich. 


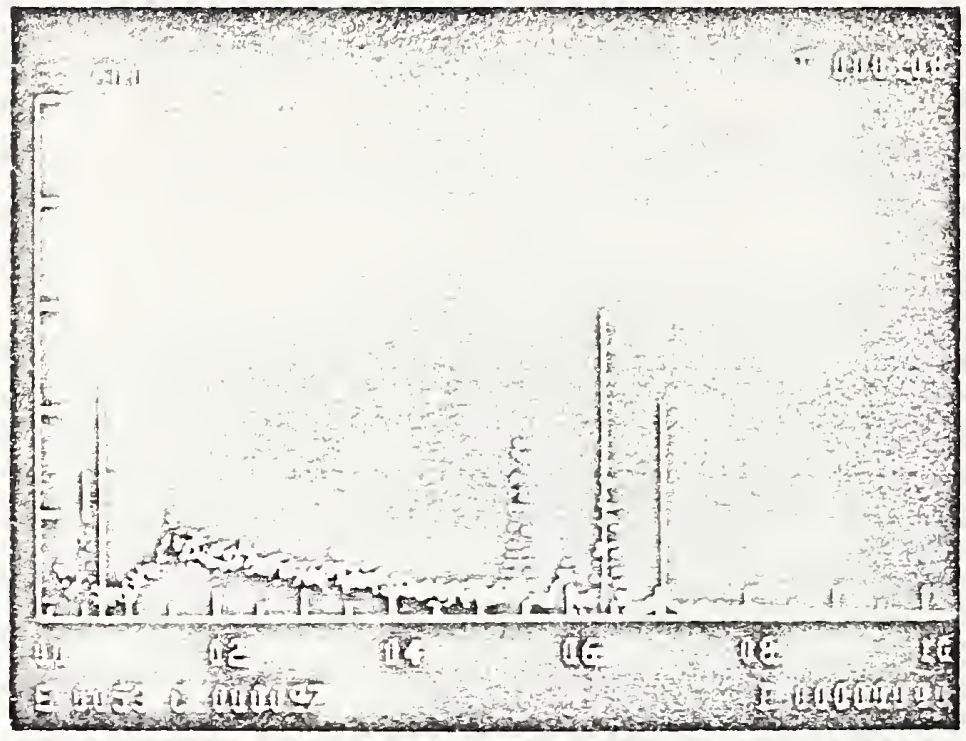

Figure 5. EDX spectra of zone (B) showing 0 peak at left of left hand marker.

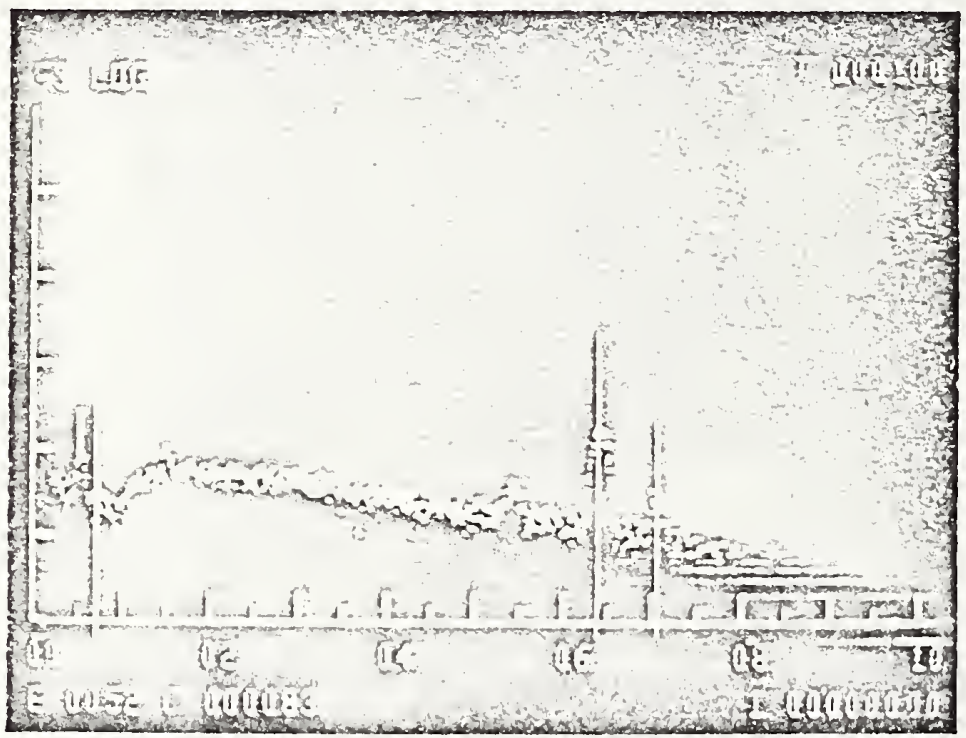

Figure 6. EDX spectra of zone (C) showing 0 peak at left of left hand marker. 


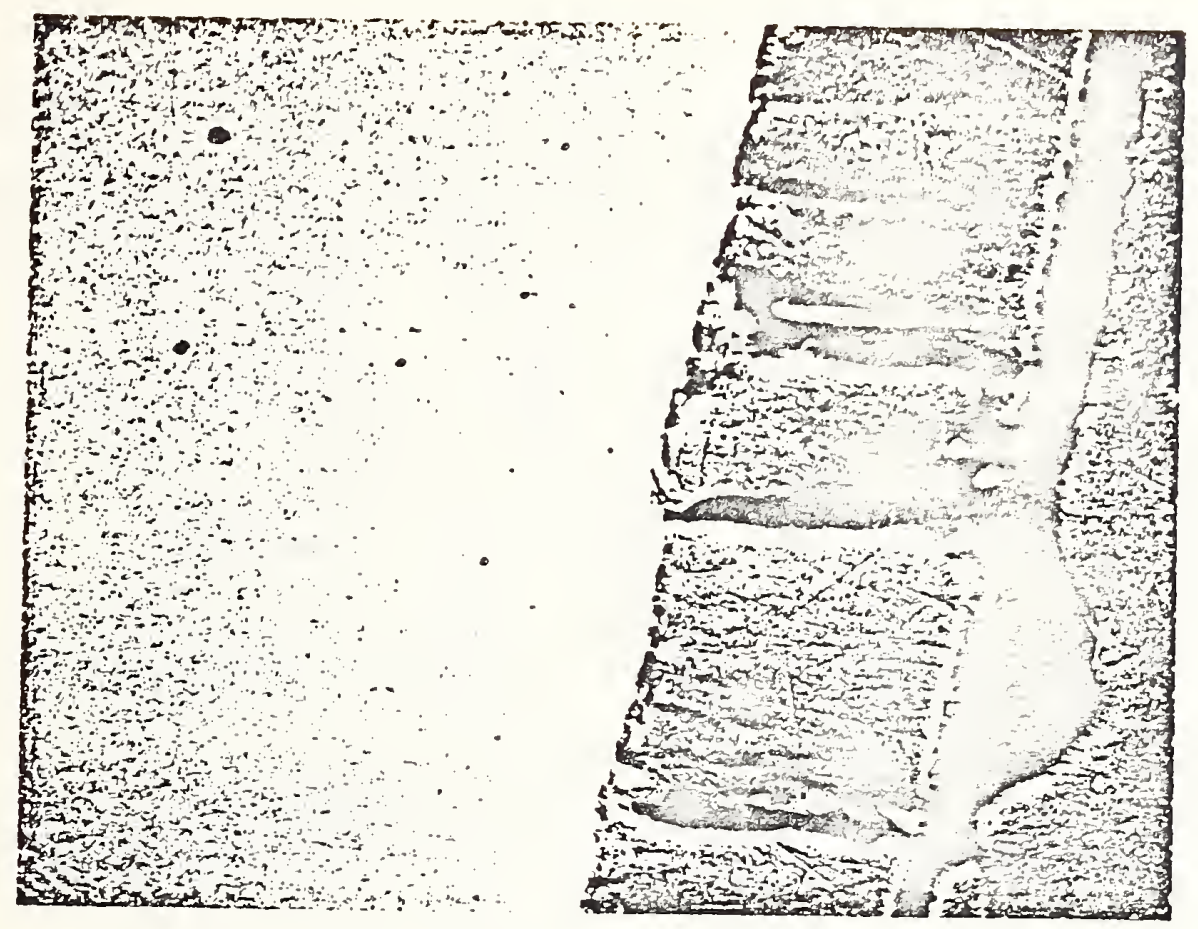

Figure 7. SEM micrograph (900X) of interface region between 304 stainless steel and columnar $\mathrm{K}_{2} \mathrm{SO}_{4}$ (right) (specimen 2).

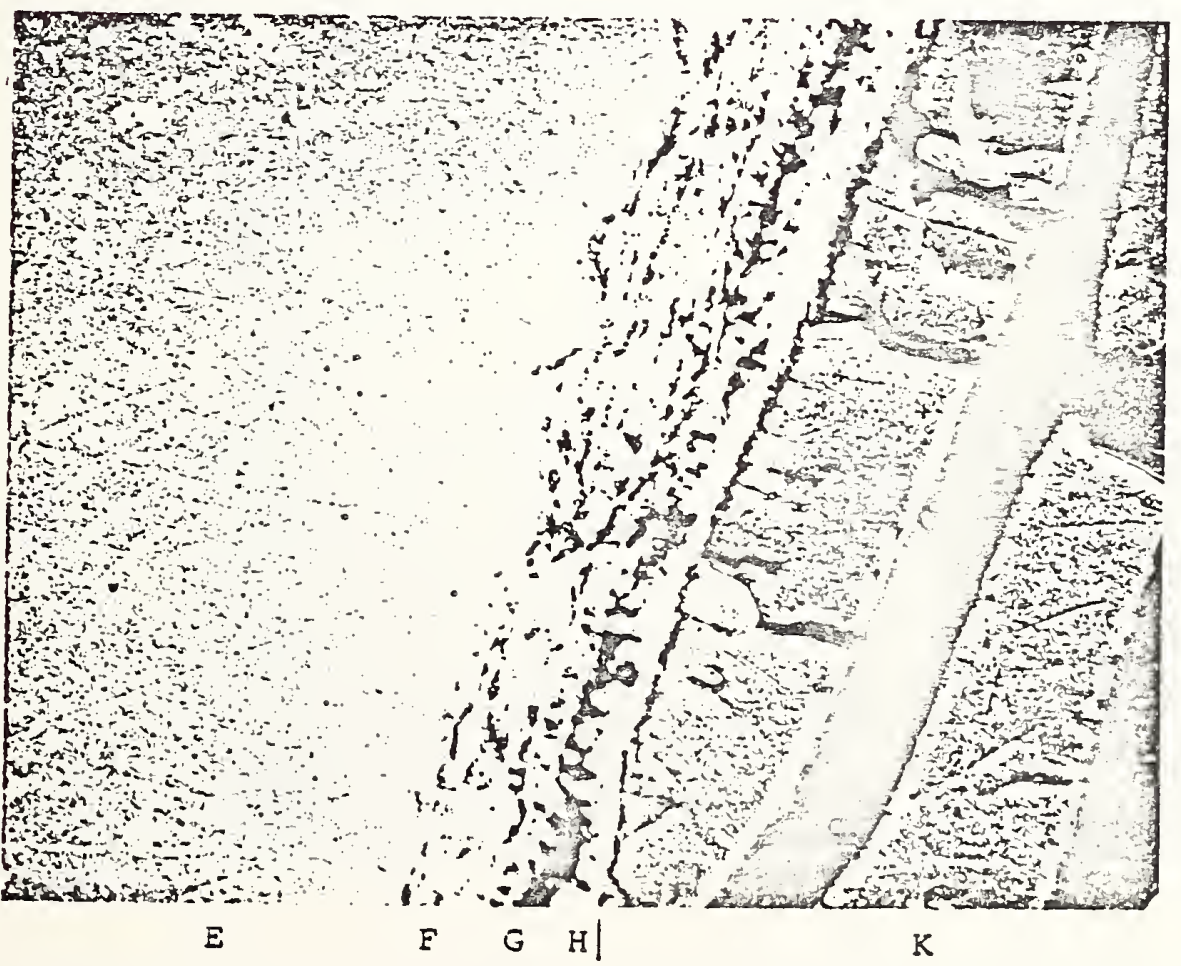

Figure 8. SEM micrograph $850 \mathrm{X}$ of interface region between 304 stainless steel (E) and columnar $\mathrm{K}_{2} \mathrm{SO}_{4}$ (K) showing corrosion band of Cr rich oxide layer (G), iron rich oxide layer (H), and sulfur band $(F)$. (Specimen 2) 


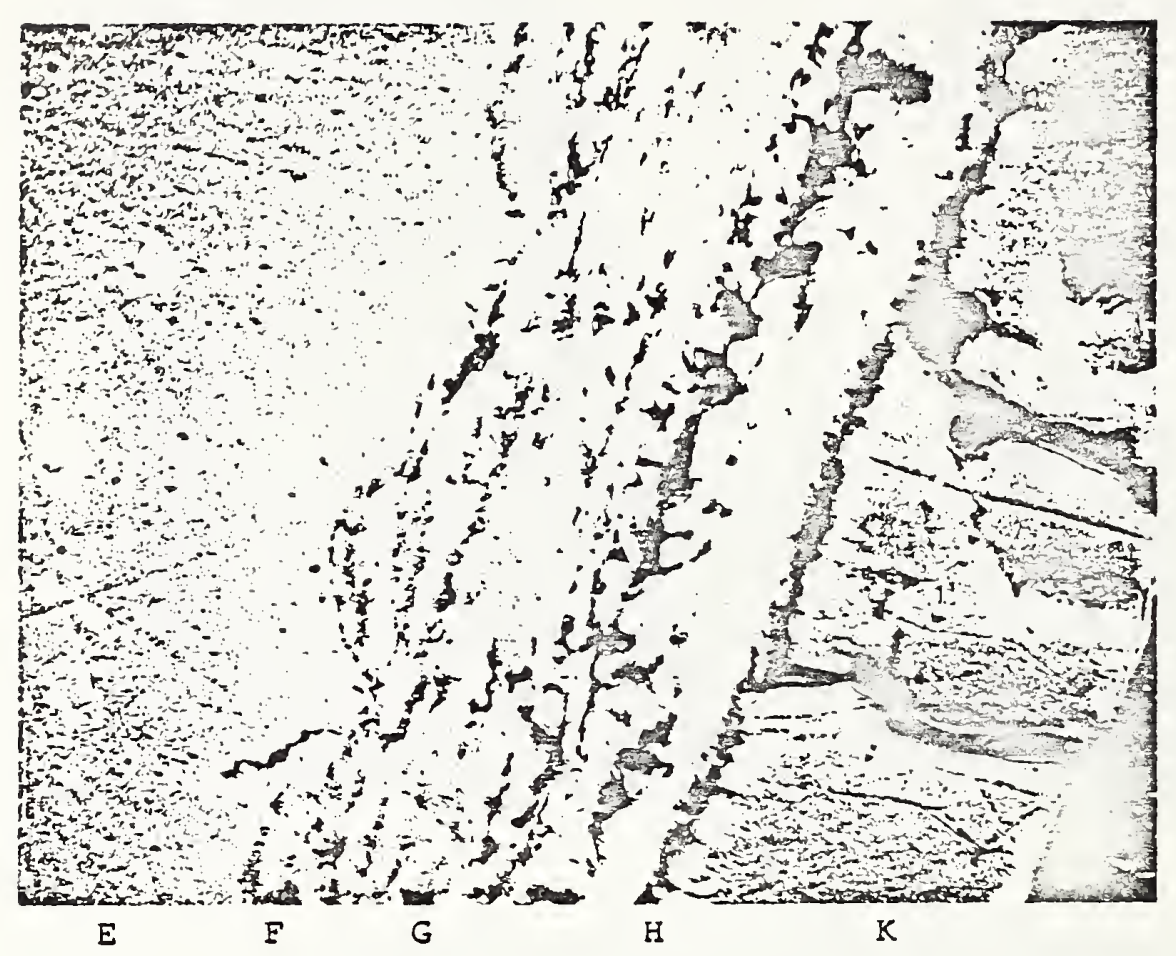

Figure 9. SEM micrograph (1700X) of upper region shown in figure 8 . Notation of figure 8 applies. Compare to figure 2 .

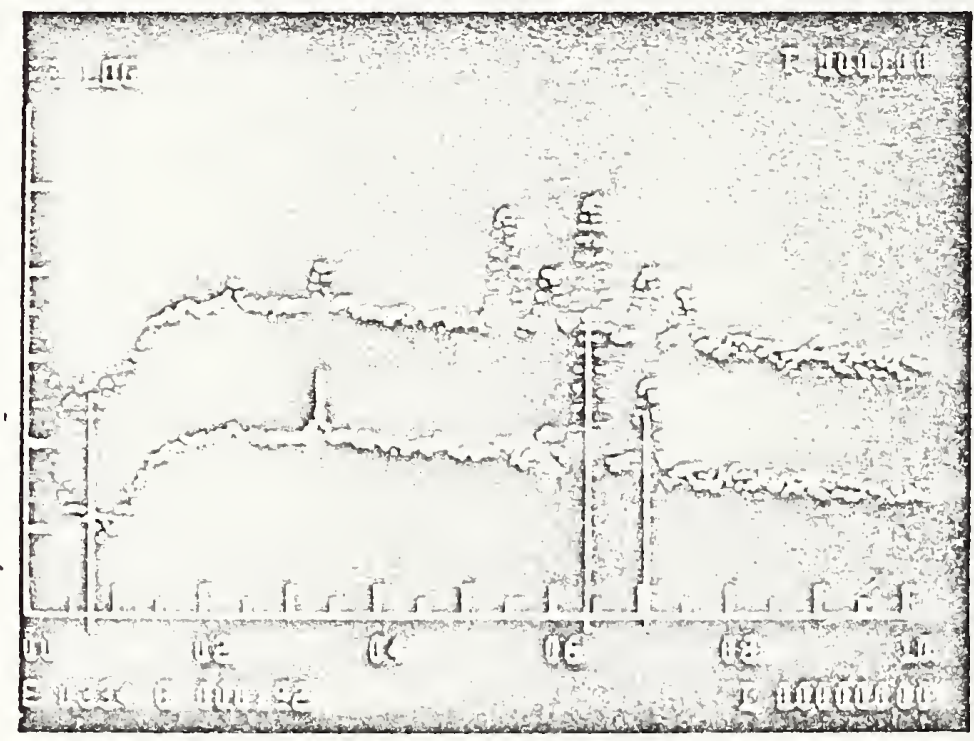

Figure 10. EDX spectra of corrosion region of figure 8 . Upper spectrum is of zone (G) shown to be $\mathrm{Cr}$ rich. The lower spectrum is of zone (H) shown to be Fe rich. 
2. New Alloy Products for Critical Applications (J. R. Cuthill)

In the previous quarterly report (for the period ending March 31, 1978) alloys were cited that appeared to have the possibility of offering advantages in certain critical component applications.

Additional data on the properties and prices of some of these alloys obtained from the respective producers are given in this report.

Substitute for 310 stainless steel to resist sulfur attack

Type 310 stainless steel has been successfully used for components of high corrosive units such as the seed recovery unit subject to $\mathrm{H}_{2} \mathrm{~S}$ attack. However, Incoloy 800 may be better from the point of view of resisting $\mathrm{H}_{2}$ attack; at least it was reported to show approximately half the weight loss of type 304 in $\mathrm{H}_{2} \mathrm{~S}$. (See quarterly report for period ending June 30,1977$)$. However, Incoloy 800 costs about twice the price of type 310 stainless steel. However, another alloy with the following designation and composition;

SANDIVIK 253 MA ${ }^{(1)}$

$\begin{array}{llllllll}\underline{\mathrm{Cr}} & \underline{N i} & \underline{N} & \underline{\mathrm{Si}} & \underline{\mathrm{Mn}} & \underline{P} & \underline{\mathrm{C}} & \underline{\mathrm{RE}} \\ 21 & 11 & 0.17 & 1.7 & 0.30 & 0.04 & 0.10 & 0.04\end{array}$

is reported to exhibit mechanical properties that are generally better than 310 S.S., and the oxidation resistance about the same as 310 sS but the price is considerably less. The price is reported to be comparable with type 316 SS. Current prices on some stainless steel are as follows:

\section{Stainless Steel}

304 SS

316

310
Base Price* (bar stock)

$\$ 0.86 / 16$.

1.16

1.64

*From American Metals Market, N. Y., N. Y.

Data on the creep-rupture strength of Sandvik 253 MA in comparison with type $310 \mathrm{SS}$ and Incoloy alloy $800 \mathrm{H}$ is shown in Figure 11. The oxidation resistance in air appears to be a little better than 310 ss up to $1100{ }^{\circ} \mathrm{C}$ (see figure 12). The catastrophic breakdown of its protective film at $1150^{\circ} \mathrm{C}$ is apparently due to the high percentage of silicon in the protective oxide, in comparison with 310 S.S. Data on the resistance of Sandvik 253 MA to sulfurdizing atmospheres is currently being obtained by the producer and is not yet available, but because of its lower nickel content, 11 vs 208 in 310 S.S., one would expect the Sandvik $253 \mathrm{MA}$ to be less vulnerable to sulfur attack than the $310 \mathrm{~S} . \mathrm{S}$. 
Another alloy that is reported to have even better mechanical properties, (compare the creep rupture values in Figure 13 with those in Figure 11), is the following:

\section{SANDVIK Sanicro $32 \mathrm{x}^{(1)}$}

$\underline{C r} \quad \underline{N i} \underline{N} \quad \underline{T} \quad \underline{A} \quad \underline{S i} \quad \underline{C} \underline{F e}$
21
$\begin{array}{lll}31 & 3.0 & 0.4\end{array}$
$0.4 \cdot 0.6$
0.09 bal.

Even with this high nickel content it is reported to have good resistance to the following high temperature sulfurous atmospheres:

1. Oxidizing atmosphere containing $\mathrm{SO}_{2}$ up to approx. $900^{\circ} \mathrm{C}$ 2. Reducing atmosphere containing $\mathrm{H}_{2} \mathrm{~S}$ up to approx. $650^{\circ} \mathrm{C}$
$\left(1200^{\circ} \mathrm{F}\right)$

The price of Sanicro $32 \mathrm{x}$ is reported to be just double the price of 304 SS or about $40 \%$ higher than $310 \mathrm{SS}$.

Piping to carry abrasive material

In the previous quarterly report mention was made of composite tubing products consisting of various hard facing compositions centrifugally cast onto the inside of SAE 4140 low alloy steel tubing by Xaloy, Inc. (2) These linings apparently have superior wear and abrasion resistance but they are expensive. Some price and property data were obtained this quarter. The mechanical properties of one of the composite materials,

HiChrome, HC250

$\underline{\text { Cr Si }} \underline{\underline{M}} \quad \underline{M o} \quad \underline{\mathrm{C}} \underline{\underline{\mathrm{E}}}$

$\begin{array}{lllllll}27 & 1.0 & 1.0 & 0.5 & 0.3 & 2.7 & \text { bal. }\end{array}$

are given in Table 1.

It is claimed that this material as a lining on 4140 steel exhibits twice the life, on the average, of the Stellite No. 6 hard facing alloy which Xaloy applies to the feed screw rotating inside of it when one is used. 
The price for a length of 8" I.D. $x$ 9" O.D 4140 steel tubing 8'4" long lined with 1/16" layer of "HiChrome 250", and the surface honed smooth and round, is $\$ 5,027$. The prices for 4140 lined with their other hard facing coatings range from $\$ 4,300$ to $\$ 7,900$ for the same size pipe. The price decreases proportionally with size, so the same length of 4" I.D. pipe lined with the HiChrome 250 would be about $\$ 2,500$.

\section{References}

1. Sandvik, Inc., Scranton Works, P.0. Box 1220, Scranton, PA 18501.

2. Xaloy, Inc., 3 Terminal Road, New Brunswick, N.J.

\begin{tabular}{|c|c|}
\hline \multicolumn{2}{|c|}{$\begin{array}{l}\text { Typical Mechanical Properties in Heat } \\
\text { Treated Condition }\end{array}$} \\
\hline \multicolumn{2}{|c|}{$\begin{array}{ll}\text { Hardness-Rockwell C } & \text { Range } 58-64 \\
\text { Ultimate Tensile Strength, psi } & 70.000-95.000 \\
\text { Yield Strength, psi } & \text { Near UTS } \\
\text { Elongation-\% } & 0-1.0 \\
\text { Elastic Modulus, psi } \check{100} & 32-35 \\
\text { Average Compression } & \\
\text { Properties: } & \end{array}$} \\
\hline $\begin{array}{l}\text { Yield } .05 \% \text { offset } \\
\text { Uitimate } \\
\text { Elastic Deformation } \\
\text { Plastic Deformation }\end{array}$ & $\begin{array}{l}145.000 \mathrm{psi} \\
400.000 \mathrm{psi} \\
1.2 \% \\
2.5 \%\end{array}$ \\
\hline
\end{tabular}

Physical Properties

Density: 7.35 gms./cu.cm. (RT) $0.268 \mathrm{los}$ /cu.in. (RT)

Melting Point: $1280^{\circ} \mathrm{C}\left(2336^{\circ} \mathrm{F}\right)$

Thermal Expansion Coefficient:

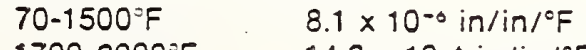
- $1700-2000^{\circ} \mathrm{F} \quad 14.3 \times 10^{-0} \mathrm{in} / \mathrm{in} /{ }^{\circ} \mathrm{F}$

Table 1. Properties of HiChrome HC250 (2) 


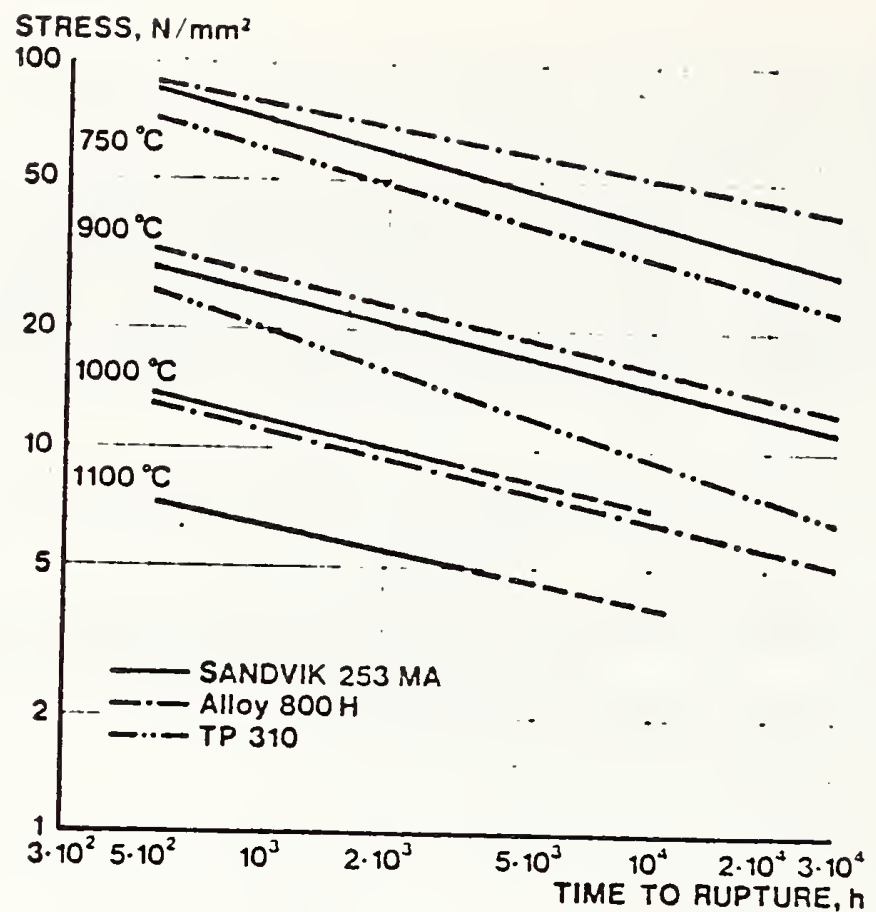

Fig. 11.Creep-rupture strength for solution-annealed SANDVIK $253 \mathrm{MA}$, Alloy $800 \mathrm{H}$ and TP 310 at $750-1100^{\circ} \mathrm{C}$.

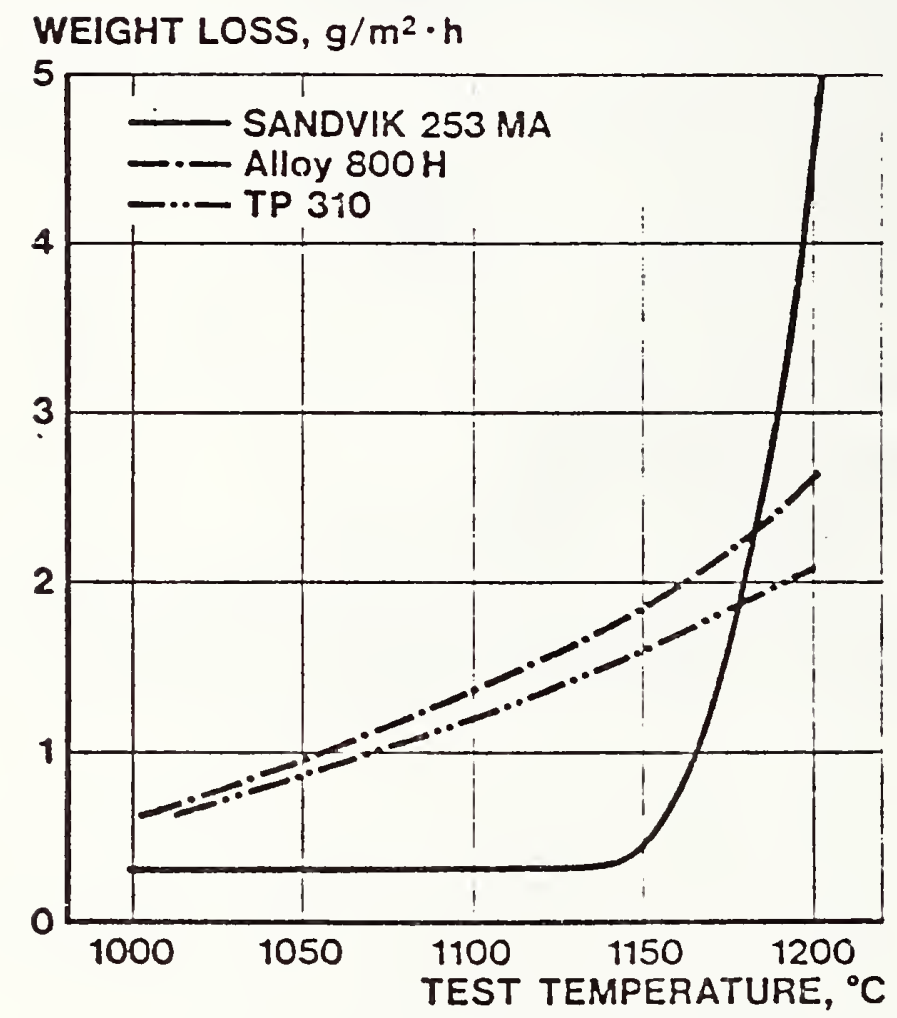

Fig. 12. Oxidation in air of SANDVIK 253MA, Alloy $800 \mathrm{H}$ and TP 310 resulting from cyclic exposure for $5 \times 24 \mathrm{~h}$ in the temperature range $1000-1200^{\circ} \mathrm{C}$ 
Stress, $\mathrm{N} / \mathrm{mm}^{2}$ (ksi)

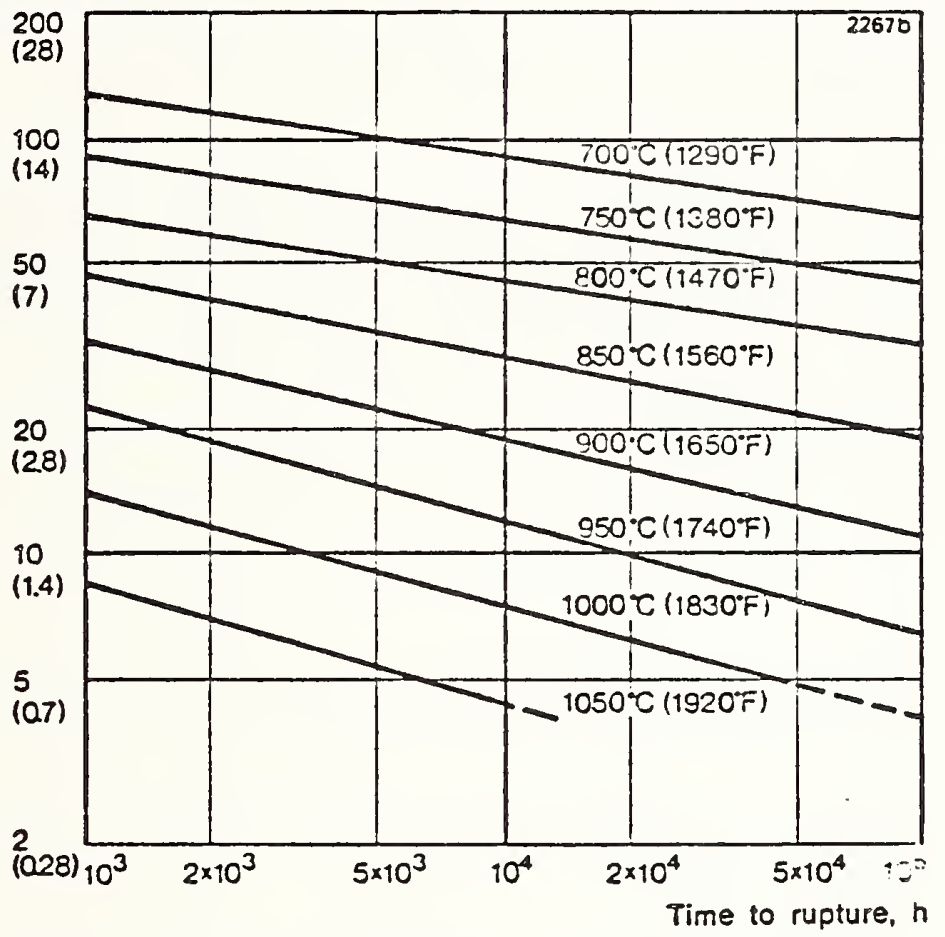

Fig. 13. Creep-rupture strength of SANDVIK Sanicro $32 \mathrm{x}(1)$ 
TASK M. DATA CENTER FOR MHD MATERIALS PROPERTIES (H. M. Ondik, A. Perloff, and J. R: Cuthili)

Progress: A decision has been made as to the computer Data Base Management System (DBMS) to be used. The system of choice has the necessary system flexibility, an appropriate data storage structure including an inverted file system, an ad hoc query language necessary for ready searching, and suitably large storage capacity for the projected contents of the data bank. The DBMS is available from several GSA-approved commercial vendors.

Investigation and comparison of the services provided by these vendors is in progress. Arrangements have been made for short-term (the remainder of the fiscal year) use of the chosen DBMS through the services of two different vendors. Benchmark testing will be performed by building a small portion of the Data Base, storing the data on the computer, manipulating it, and searching it. These operations will test the system controls provided by the two vendors, and also compare the costs incurred during use of the two vendors' systems. The appropriate documents are being prepared for the justifications to obtain the various approvals required for contracting with a vendor.

Members of the staff have taken a one week course on the chosen DBMS, learning how data should be structured to make the best use of the capabilities of the system. Since each DBMS has its own special features, and complicated restrictions, it is necessary to have detailed instruction in its use. The chosen system, because of its large capability and flexibility, especially requires this special study and instruction so that it may be used efficiently. Inefficient use can drastically affect the computer expenditures.

The design features of the data bank are being planned. The arrangement of the data must take into account the varied types of information to be stored and the estimated order and frequency of requests for information. The optimum structure of the file for ready search capability must provide for the use of the fastest, therefore least expensive, search patterns compatible with flexibility, having as many items being searchable as possible for reasonable use. Major search elements will, of course, include the material names or designations and the properties. Searches must be possible on various combinations of these elements. The conditions under which the properties were studied must be retrievable along with the property data and should probably also be a searchable item as well. Many other items which must be appropriately entered for retrieval with the property data such as brief summaries of the test procedures, references, etc., must be considered carefully as possible candidates for keying as search categories. Since search items are carried in storage as inverted files and, therefore, add to computer storage costs, the question of optimum use of the DBMS and its storage and query capabilities is an important one to answer carefully.

The two computer terminals and the two acoustic couplers which have been ordered have been delivered, but the telephone lires necessary for communication with a central computer have not yet been installed. Even though the terminals are not connected to a large computer, there are useful operations which may be performed, providing experience with the equipment and aiding in the data design. 
More equipment for the computer-terminal facility is now on order. A hard-copy unit, compatible with the "intelligent" terminal having a cathoderay display tube, will enable the operator to obtain a high-quality copy of material from the cathode-ray tube. Copies of graphs produced by the terminal and displayed on the tube will be available very simply with this copier.

The cataloging and review of contractors' reports is continuing.

Plans: The usual operations of the Center, review and cataloging of contractors' reports, and listing of materials data contained in them will continue. Communication and interaction with the MHD community will increase to provide the Center staff with users' needs. Design of the Data Base will move ahead. 
$$
\text { ( }
$$ 